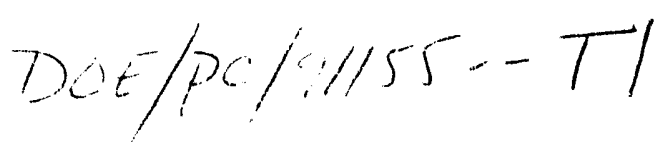

DOE/PC/91155--T1

DE93 004952

Coal-Fired High Performance

Power Generating System

DE-AC22-92PC91155

Quarterly Progress Report

July 1, 1992

Prepared for

\title{
Pittsburgh Energy Technology Center
}

Pittsburgh, Pennsylvania

United Technologies Research Center

411 Silver Lane, East Hartford, Connecticut 06108

\section{DISCLAIMER}

This report was prepared as an account of work sponsored by an agency of the United States Government. Neither the United States Government nor any agency thereof, nor any of their employees, makes any warranty, express or implied, or assumes any legal liability or responsibility for the accuracy, completeness, or usefulness of any information, apparatus, product, or process disclosed, or represents that its use would not infringe privately owned rights. Reference herein to any specific commercial product, process, or service by trade name, trademark, ence herein to any specific commercial product, process, or service by trade nocessarily constitute or imply its endorsement, recommendation, or favoring by the United States Government or any agency thereof. The views and opinio authors expressed herein do not necessarily state or reflect those of the United State, jovernment or any agency thereof. 
Executive Summary

This report covers work carried out under Task 2., Concept Definition and Analysis on contract DE-AC2.2-92PC91155 "Engineering Development of a Coal Fired High Performance Power Generation System" between DOE Pittsburgh Energy Technology Center and United Technologies Research Center.

The goals of the program are to develop a coal-fired high performance power generation system (HIPPS) by the year 2000 that is capable of

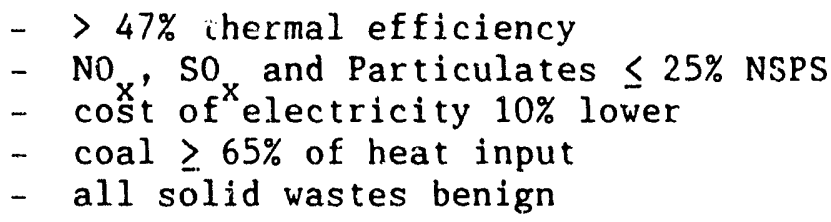

In order to achieve these goals our team has outlined a research plan based on an optimized analysis of a $250 \mathrm{MW}$ combined cycle system applicable to both frame type and aeroderivative gas turbines. Under the constraints of the cycle analysis we have designed a high temperature advanced furnace (HITAF) which integrates several combustor and air heater designs with appropriate ash management procedures. Most of this report discusses the details of work on these components, and the R\&D Plan for future work.

The discussion of the combustor designs illustrates how detailed modeling can be an effective tool to estimate NO production, minimum burnout lengths, combustion temperatures and evên particulate impact on the combustor walls. When our model is applied to the long flame concept it indicates that fuel bound nitrogen will limit the range of coals that can use this approach. For high nitrogen coals a rapid mixing, rich-lean, deep staging combustor will be necessary.

The air heater design has evolved into two segments:

(1) a convective heat exchanger downstream of the combustion process, fabricated from silicon carbide and only in contact with dry ash at a maximum surface temperature of $1600 \mathrm{~F}$, and

(2) a radiant panel heat exchanger, located in the combustor walls, protected by refractory lining which may be coaied with either dry or slagging ash and boosts the air temperature to $1800 \mathrm{~F}$.

The relative amount of heat transferred either radiatively or convectively will depend on the combustor type and the ash properties. 
The ash management technique will of necessity be coal specific. Our analysis reduces the possibilities to two major categories:

(1) a dry ash design, amenable to sootblowing and applicable to some eastern bituminous coals with high silica ash and accordingly high $\mathrm{T}_{250}$, and

(2) a wet or slagging ash design, with strict axial temperature control, applicable to some western coals, with more basic ash and lower $\mathrm{T}_{250}$.

The R\&D Plan projected for Task 3 is primarily a reconciliation of all the constraints of the different components and options. Analysis, modeling and some experimental testing are all employed to iterate on optimized coal specific designs. 
TABLE OF CONTENTS

$\underline{\text { Page }}$

Task 2. Concept Definition and Analysis ..................

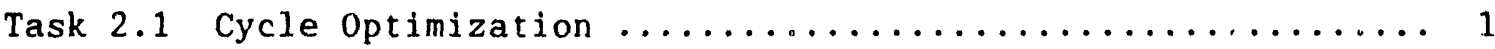

Task 2.2 Concept Screening ........................ 3

Task 2.2.1 Power Generating Systems .................. 5

Task 2.2.2 HITAF Combustor/Air Heater and Systems/Subsystems .... 7

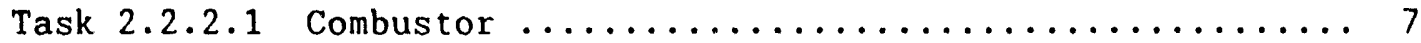

Task 2.2.2.2 Air Heater Concept Screening ............... 17

Task 2.2.2.3 Duct Heater Concept Screening ............... 33

Task 2.2.2.4 Coal Delivery ....................... 34

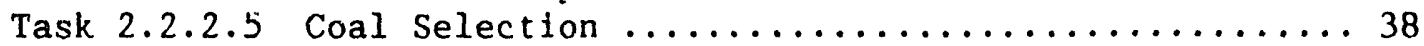

Task 2.2.2.6 Coal Cleaning Evaluation ................. 40

Task 2.2.2.7 Ash Management ...................... 41

Task 2.2.2.8 So and Fly Ash Control .................68

Task 2.2.2.9 Coñtrols ......................... 70

Task 2.3 Preliminary Economic Analysis $\ldots \ldots \ldots \ldots \ldots \ldots \ldots \ldots$

Task 2.4 Preliminary R\&D Program for Task $3 \ldots \ldots \ldots \ldots \ldots \ldots$

Task 3.1.1 Chemical Reactor Modeling ................. 75

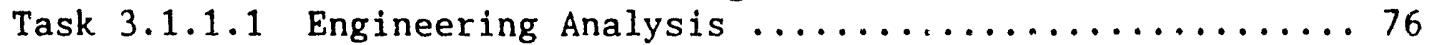

Task 3.1 .1 .2 Parametric Studies ........................ 77

Task 3.1 .2 Air Heater Design ............................ 78

Task 3.1 .3 Air Heater Materials ....................... 80

Task 3.1 .4 Air Heater Structural Analysis ................ 81

Task 3.1 .5 Definition/Evaluation of Slag Impacts $\ldots \ldots \ldots \ldots \ldots . . .63$

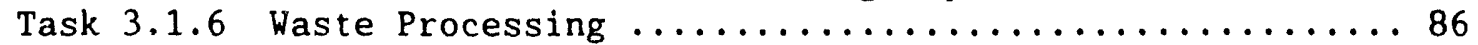

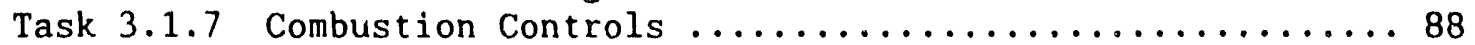

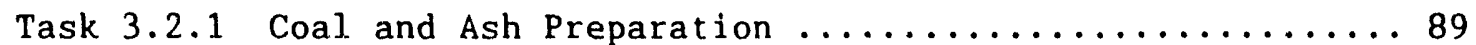

Task 3.2.2 Mineral/Inorganic Transformations .............. 90

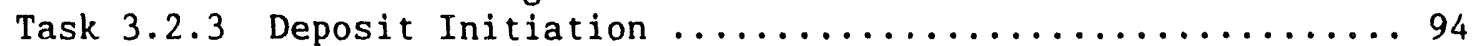

Task 3.2.3.1 Alkali Vapor Corrosion of Ceramic Air

Heater Coupons ................................ 94

Task 3.2.3.2 Corrosion of Ceramic Surfaces by Ash Deposits .... 97

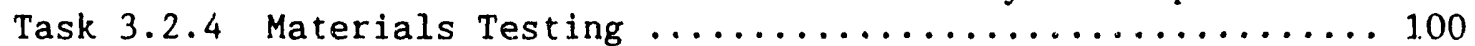

Task 3.2 .5 Additives for Deposit Mitigation .............. 1.03

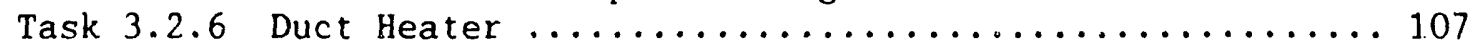

Task 3.2.7 0xygen Enriched Combustion Via Membranes ........... 111

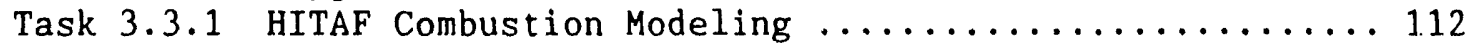

Task 3.3.1.1 Submodel Improvement ................... 112

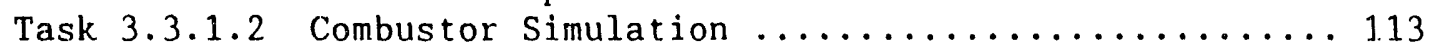

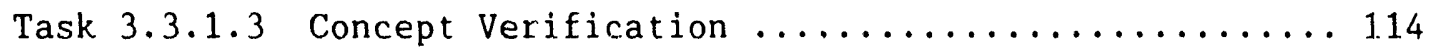

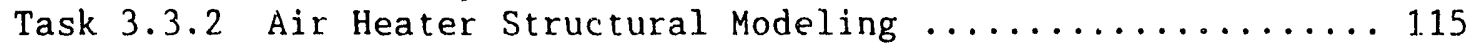

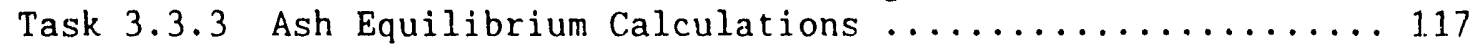

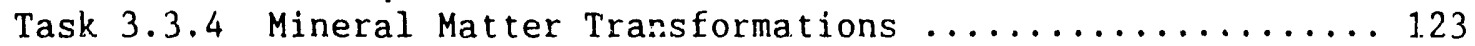

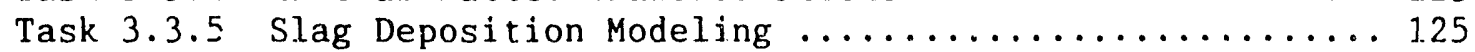


Fig. 1

Fig. 2

Fig. 3

Fig. 4

Fig. 5

Fig. 6

Fig. 7

Fig. 8

Fig. 9

Fig. 10

Fig. 11

Fig. 12

Fig. 13

Fig. 14

Fig. 15

Fig. 16

Fig. 17

Fig. 18

Fig. 19

Fig. 20

Fig. 21

Fig. 22

Fig. 23

Fig. 24

Fig. 25

Fig. 26

Fig. 27

Fig. 28

Fig. 29

Fig. 30

Fig. 31

Fig. 32
Block diagram of HITAF and power system ........... 2

Effect of methane fraction on heat rate $\ldots \ldots \ldots \ldots \ldots \ldots \ldots 4$

Steam cycle performance .................... 4

Cross-section in front of combustors .............. 5

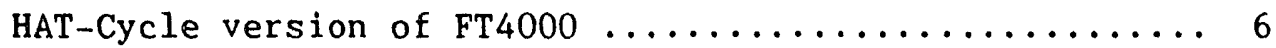

Axial distribution of wall heat flux for the four

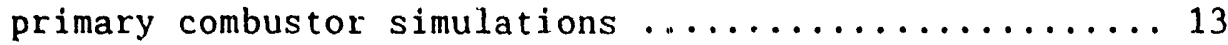

Integrated No as function of axial distance .......... 14

Integrated carrbon burnout as function of axial distance . 15

Particle deposition rates as function of axial distance . 16

Design analysis of radiant air heater ............. 23

Radiant air heater temperature profiles: parallel

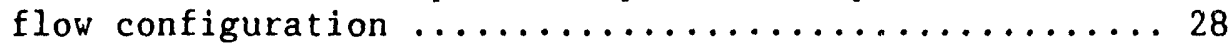

Radiant air heater temperature profiles: counter

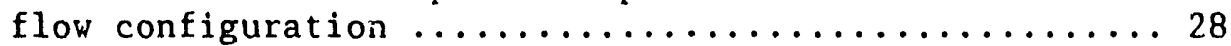

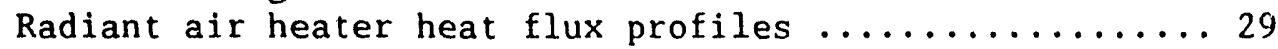

Radiant air heater ash thickness ................ 29

Counterflow radiant air heater size dependence on operating conditions ........................... 30

Parallel flow radiant air heater size dependence

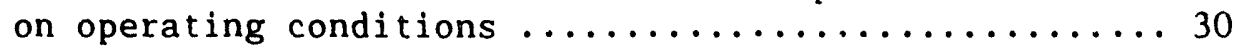

Radiant air heater dry ash thickness dependence

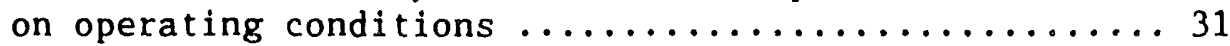

A process and instrumentation flow diagram for an air swept vertical spindle mill operating under negative pressure ....................... 36

Modes of coal utilization for pulverized-coal

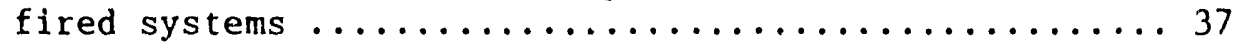

Strength of silicon carbide as a function of time exposed to sodium silicate at $960 \mathrm{C} \ldots \ldots \ldots \ldots \ldots \ldots . \ldots 44$

Surface recession rate of coated and uncoated sintered $\alpha$-SiC tubes as a function of temperature over $2000 \mathrm{hr} .44$ Ash management modules for duct burner case .........47 Ash management modules for all coal case ........... 48 Structure of ash deposit in radiant air heater section .. 50

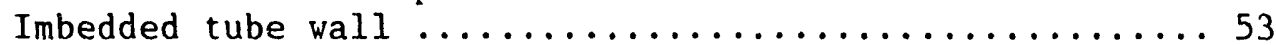

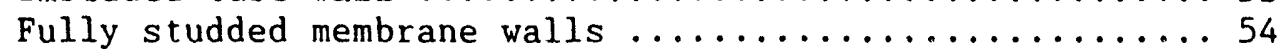
Furnace pin-stud and refractory construction ......... 54 Impaction efficiency as a function of particle size ... 57 Growth of wake downstream of cylinder in crossflow ..... 59 Preliminary slag screen design ................. 60 Parameters for heat loss calculations ............. 62 Calculated ash adhesion efficiencies for four Eastern bituminous coals under oxidizing conditions ... 65 
Fig. 33

Fig. 34

Fig. 35

Fig. 36

Fig. 37

Fig. 38

Fig. 39

Fig. 40

Fig. 41

Fig. 42

Fig. 43

Fig. 44

Fig. 45

Fig. 46

Fig. 47

Fig. 48

Fig. 49

Fig. 50

Fig. 51

Fig. 52
Size range of particles that impact the channel wall ...667 Approach to design deposition rates for convective

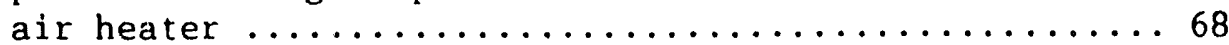

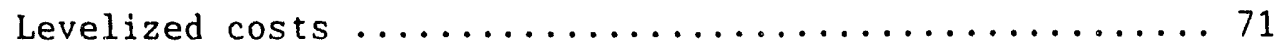

Incremental costs of steam turbines $\ldots \ldots \ldots \ldots \ldots \ldots \ldots 72$

Incremental cost ratio for HRSG ................ 73

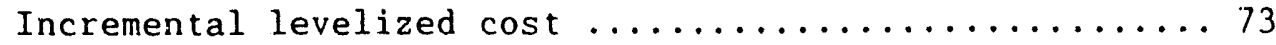

Incremental levelized cost $\ldots \ldots \ldots \ldots \ldots \ldots \ldots \ldots \ldots 74$

Incremental levelized cost $\ldots \ldots \ldots \ldots \ldots \ldots \ldots \ldots \ldots$

Entrained flow reactor ....................... 91

Experimental apparatus for alkali exposure tests ......995

Variations in liquid phase viscosity with temperature

for Illinois No. 6 coal, including calcined dolomite

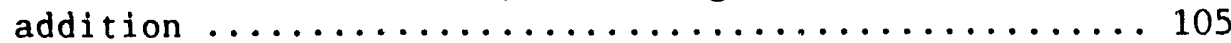

HITAF duct heater test apparatus $\ldots \ldots \ldots \ldots \ldots \ldots \ldots 108$

Heated gas test apparatus schematic .............. 109

Phase diagram for the system $\mathrm{CaAl}_{2} \mathrm{Si}_{2} \mathrm{O}_{6}-\mathrm{SiO}_{2} \ldots \ldots \ldots 119$

The inertial impaction process that leads to the formation of large slag deposits ............. 126

Backscattered electron micrograph of the interface between ash deposited via inertial impaction and a

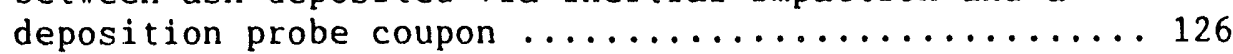

Comparison of the compositions ( $\mathrm{SO}_{3}$-free) of the aerodynamically sized entrained ash particles and ash deposited on a deposition probe via inertial

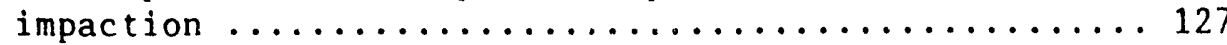

The eddy deposition process that leads to the formation of slag deposits in regions of lowintensity turbulence ....................... 128

Backscattered electron micrograph of the interface between a eddy deposition deposit and a deposition probe coupon .............................. 129

Backscattered electron micrograph of the interface between a deposit formed from small particle transport mechanisms and a deposition probe coupon ....... 130 
TASR 2 REPORT

\section{Concept Definition and Analysis}

In this task the effort has focused on defining the range of cycles and system designs that match the optimized designs of the individual components. Because of the close coupling of the constraints (i.e., heat transfer, combustion efficiency, $\mathrm{NO}$ control, ash management and materlaìs properties) the system cycle will require considerable iteration and probably will be coal dependent to some unknown extent.

\section{Task 2.1 Cycle Optimization}

The analysis of system performance is carried out using the SOAPP system, described in some detail in Appendix A. Input parameters for the analysis have been provided by all team members. Power system information was furnished by TPM, Bechtel, and UTRC with parametric cost information suitable for the preliminary economic analysis from Bechtel and UTRC. Because of the interdependency of all the systems, especially the HITAF and the power systems, the approach considers the overall system with evaluations based on the incremental differences among the alternatives and the baseline system described in the proposal.

\section{System Configuration}

A diagram of the system in its current configuration is shown in Fig. 1. Major differences between this diagram and that of the baseline system presented in the proposal are:

- All turbine exhaust air passes through the HITAF;

- All steam is raised outside of the HITAF;

- Ambient air is used to transport coal.

Because the furnace configuration will not be fully defined until later in the program, it is not possible to develop a system model that accurately represents a final furnace configuration. The approach taken in this analysis assumes all of the gas turbine exhaust air is used in the furnace. From an overall system viewpoint, this may not be the most cost effective approach; i.e., the air to fuel ratio is approximately 3.5 times stoichiometric, and will require sulfur cleanup subsequent to stack discharge. Thus, there may be good reason to keep some of the air free of combustion products in order to reduce the size of clean up equipment. However, the need to provide a means of solidifying the ash leaving the radiant section of the furnace requires a large flow of quench air and therefore tradeoff calculations will be carried out.

The other major assumption was that a separate gas stream would be used for coal transport. An alternative transport gas source using part of the turbine exhaust will be evaluated. While the currently envisioned furnace will have both a radiant and convective section to heat the compressor discharge air, the current system model treats that process as a single component. Thus, the full gas stream leaving the furnace (gas turbine exhaust flow plus coal transport air) is available to raise steam. The model is able to accommodate any combination of input airflows. 


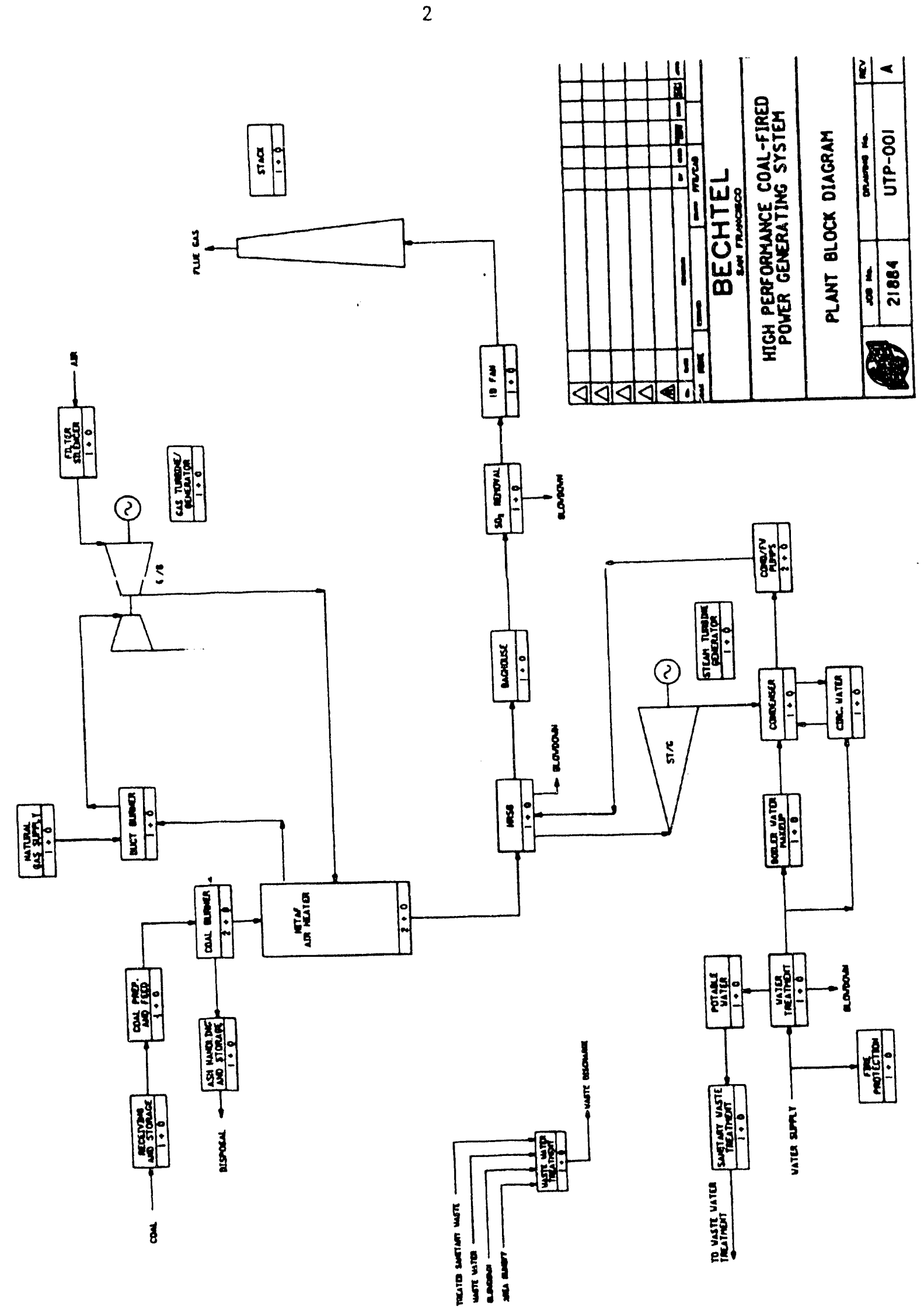

Fig. 1. Block ilagram of HITAF and power system. 
The combustor model uses conventional combustion calculations to determine exit gas temperature and composition. It provides for unburned carbon to be lost with the ash, but currently assumes complete carbon combustion. The characteristics of the coal used in the analysis and of the stack gas are given in Tables 1 and 2 .

Table 1

Ultimate Analysis of Coal

(Percent)

$\begin{array}{lllllll}\mathrm{H} 20 & \mathrm{C} & \mathrm{H} 2 & \mathrm{~S} & 02 & \mathrm{~N} 2 & \text { Ash } \\ 2.6 & 76.6 & 4.9 & 1.3 & 3.9 & 1.6 & 9.1\end{array}$

Pennsylvania High Volatile Bituminous A - HHV 13,610 Btu/lb

Table 2

Stack Gas Composition

(Mols)

$\begin{array}{llllll}\mathrm{H} 20 & \mathrm{C02} & 02 & \mathrm{~N} 2 & \mathrm{Ar} & \mathrm{S} 02\end{array}$

$\begin{array}{llllll}6611.8 & 7019.1 & 15288 & 92864 & 1165.7 & 33.8\end{array}$

The compressor discharge air is heated to $1800 \mathrm{~F}$ in the furnace and the remaining heat is available for the steam cycle. Because of the fixed flow to the engine, the quantity of heat removed from the furnace gas stream remains constant, as does the heat supplied by the methane to raise the gas temperature from $1800 \mathrm{~F}$ to the turbine inlet temperature. Increased coal feed to the furnace results in a higher furnace exit temperature which, in turn, increases the amount of steam power that can be produced. Gas turbine flow and power produced remains constant. The resultant performance variations are shown in Fig. 2 as a function of methane fuel fraction when using an 1800 psi $1000 \mathrm{~F} / 1000 \mathrm{~F}$ steam cycle.

When the current constraints mentioned above are combined with the $35 \%$ methane ground rule, a furnace exit temperature of approximately $1300 \mathrm{~F}$ results. This is high enough to accommodate a variety of steam cycles. While it would be possible to examine the performance of various steam cycles while maintaining a constant exit temperature (and methane fraction), it is more worthwhile to consider steam cycle performance where the furnace exit temperature (coal fraction) is adjusted to match boiler and superheater pinch points. This was done for various pressures over the temperature range of 950 to $1200 \mathrm{~F}$. The results are presented in Fig. 3 .

\section{Task 2.2 Concept Screening}

This sub-task will include the evaluation of the many approaches to a consistent HITAF design which will achieve the program goals. 


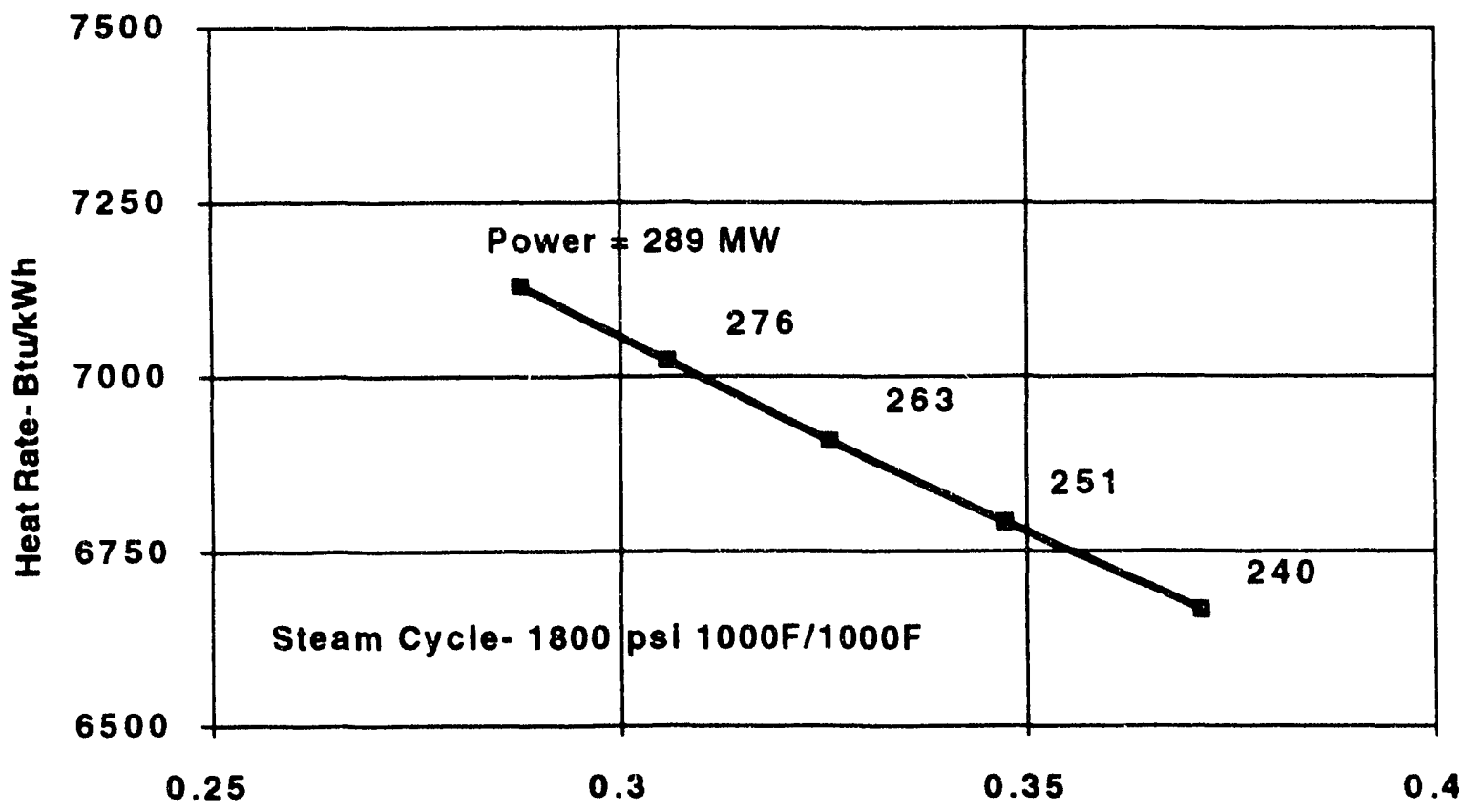

Nathane - Fraction of Total Fuel

Fig. 2. Effeci of methane fraction on heat rate

\section{Steam Cycle Performance}

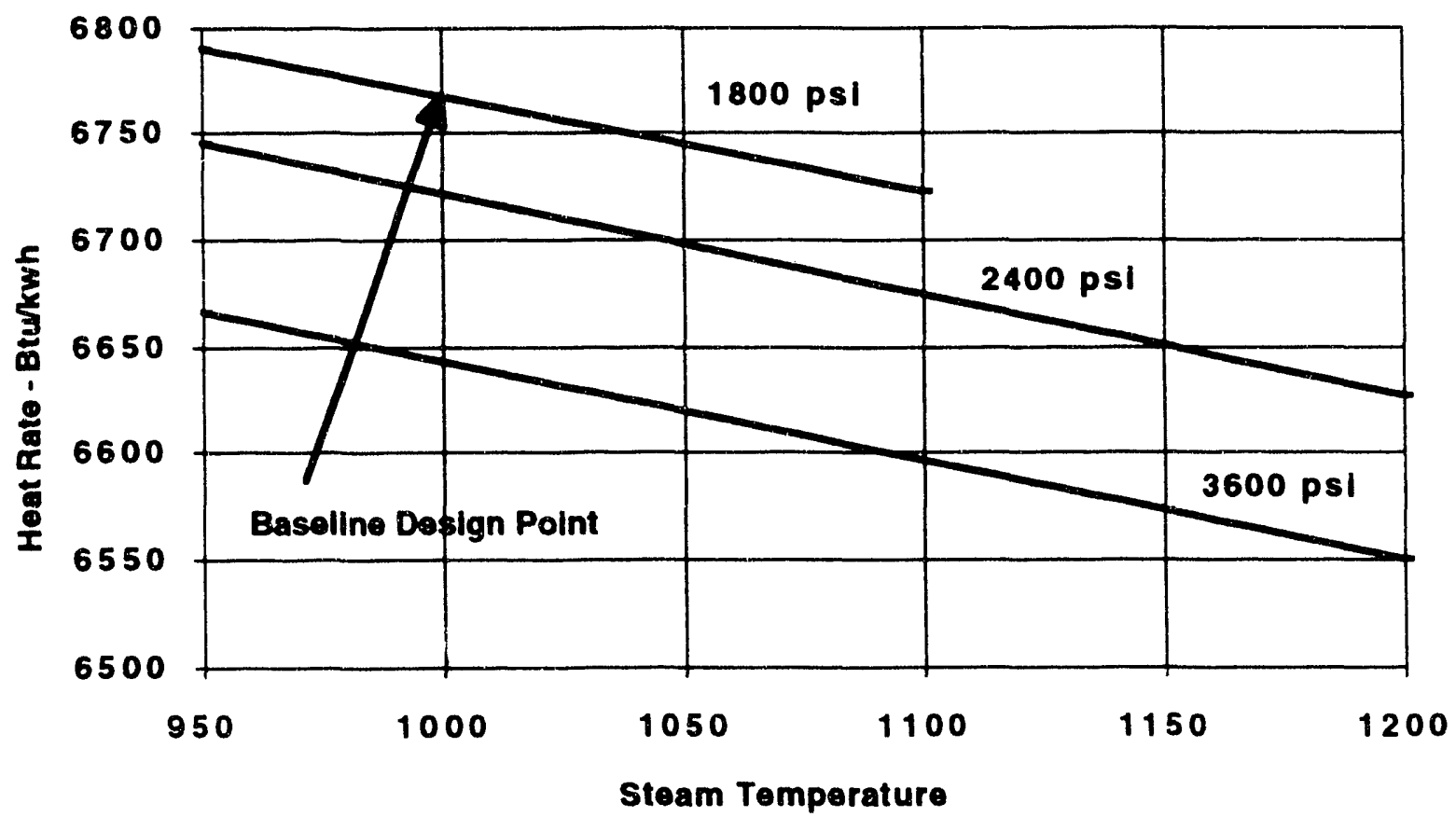

F1g. 3. Steam cycle performance 
Task 2.2.1 Power Generating Systems

The objective of this task is to define the operating characteristics, equipment type and requirements, and conceptual arrangement of HITAF and power generating equipment and perform analyses of alternatives to identify the optimum cycle configuration. The current state of understanding for the major components varies as a function of degree of development. The major components, as they will be used in the Task 2.1 - Cycle Optimization activities, are described briefly in the following paragraphs.

\section{Gas Turbine}

Both the heavy "Frame"-type and the "aero-derivative"-type gas turbine are being considered. The Frame-type gas turbine selected for this program is the V84.4, a nominal $150 \mathrm{MV}+$ machine operating at over 16 atmospheres with a turbine inlet temperature above $2400 \mathrm{~F}$. This machine, slated to appear in commercial configuration in the $1994 / 5$ time frame, has aircraft compressor and turbine technology from Pratt \& Whitney adapted to large frame application. Please note that the combustor arrangement, shown in a front view in Fig. 4, has been changed from the silo configuration shown in the UTRC proposal to a horizontal configuration. This change will have no impact on the program as the point of connection to the engine remains essentially unchanged, providing the same access to the HITAF as before.

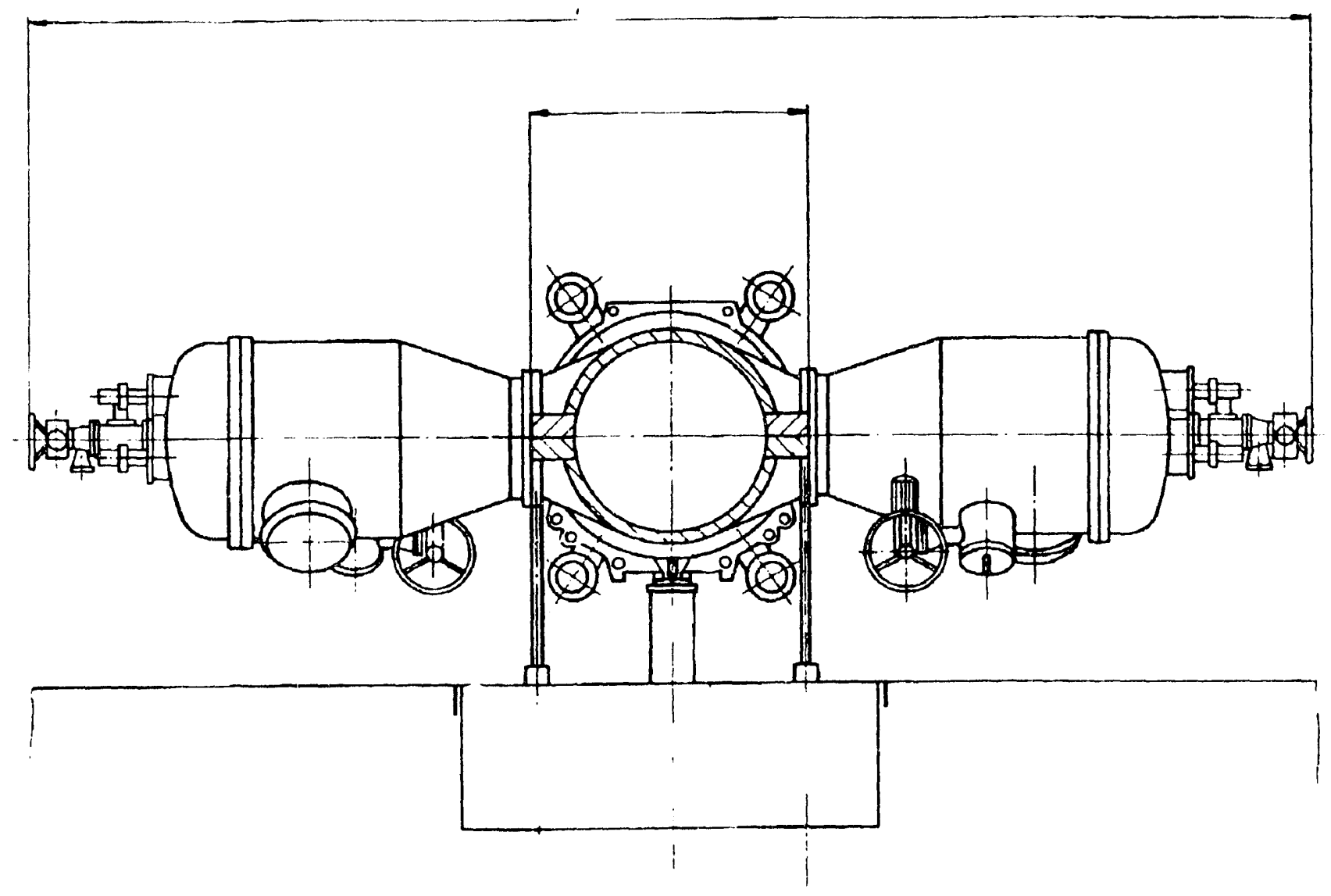

Fig. 4. Cross-section in front of combustors. 
There are no unresolved issues with the V84-type turbine. However, a second cycle configuration based on the industrialized version of the Pratt \& Whitney 4000 aircraft engine widely used in 747,767 , and MD 11 widebody aircraft is being included. This engine, to be known as the FT4000, is currently in the preliminary engineering phase and could be introduced for commercial service in the time frame consistent with Phase 3 of this program. Several variations are being considered ranging in output from approximately $45 \mathrm{MW}$ to over $200 \mathrm{MW}$. This engine would operate at nearly 40 atmospheres with a turbine inlet temperature of well beyond $2400 \mathrm{~F}$. The outstanding issues on this engine have to do with equipment configurations which is a function of cycle choice. This will be based mostly on marketing considerations as the turbine technology is continually being upgraded as part of the ongoing aircraft engine program. The high pressure air ducting is common to several cycle configurations and resembles commercial practice in industry. For this program, a Humid Air Turbine (HAT) cycle version, shown in conceptual form in Fig. 5, has been selected for consideration.

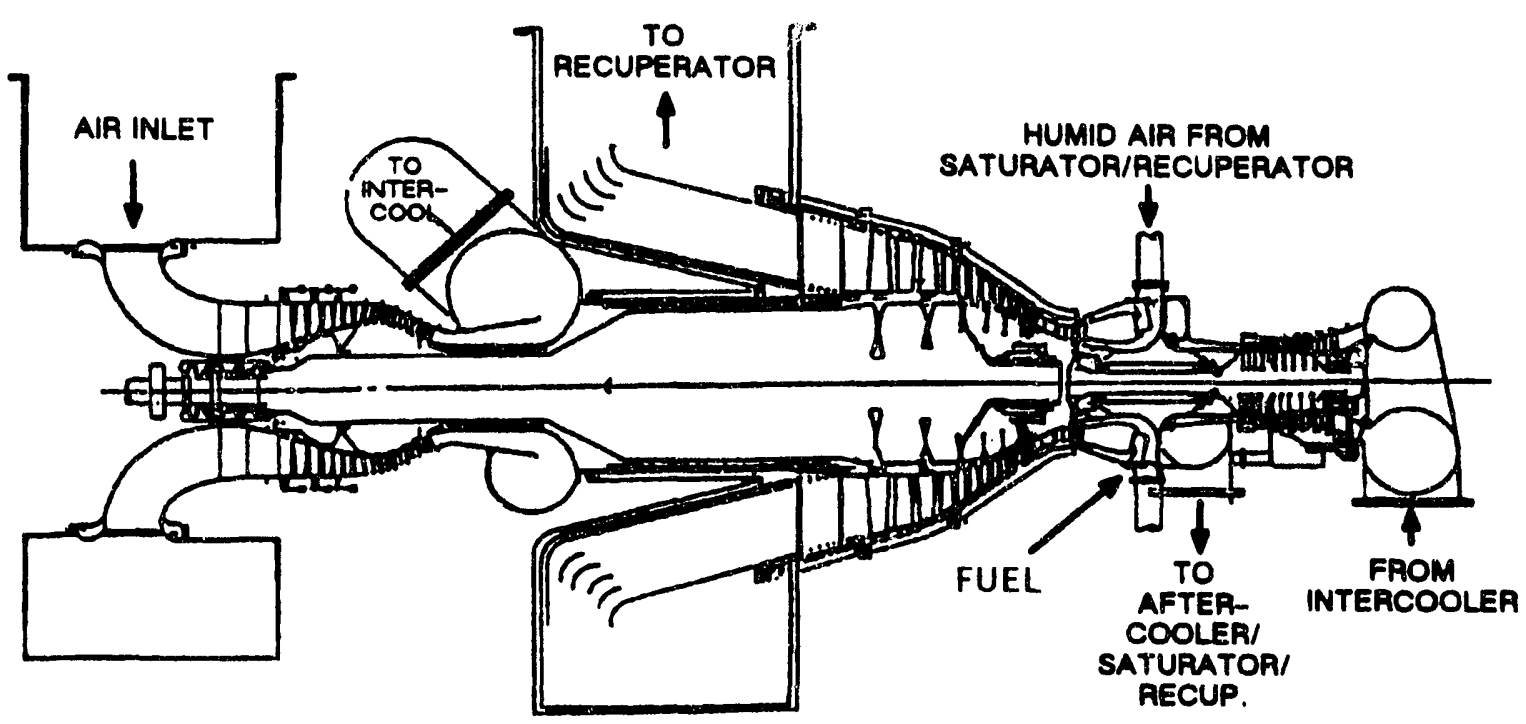

Fig. 5. HAT-Cycle version of FT4000.

Steam Turbine

The steam turbine technology selected for the proposed program is well proven, commercially available machinery. As will be shown, performance gains to be made by moving to high performance steam systems, e.g., supercritical pressure, $1100 \mathrm{~F}$ or $1200 \mathrm{~F}$ are relatively small $(<4 \%)$ and are obtained at high capital cost (turbine and heat recovery system), 
especially in the size range of interest around $100 \mathrm{MW}$. Final conditions have not yet been selected as they are second order dependent on the final HITAF configuration. However, it is anticipated that either $1800 \mathrm{psi} / 1000 \mathrm{~F} / 1000 \mathrm{~F}$ or $2400 \mathrm{psi} / 1000 \mathrm{~F} / 1000 \mathrm{~F}$ will be used.

There are no unresolved technical issues with the steam turbine or heat recovery steam generator portions of the power equipment.

Task 2.2.2 HITAF Combustor/Air Heater and Systems/Subsystems

This task combines the major efforts to reconcile the wide range of constraints dictated by the air heater designs, combustor designs and ash management as well as the necessary accessory components.

\section{Task 2.2.2.1 Combustor}

This section presents the results of calculations that were made to evaluate the 'ications of the addition of radiant heater panels to the primary comiu tor. The general features of the model used for these intial scree...1ng studies will be described before the results are discussed.

\section{Pulverized Coal Combustion Hodeling $\mathrm{Be}^{-1}$ oround}

The basis of REI's coal combustion models is the work performed by Dr. Philip J. Smith over the past iffeen years. The models include a family of predictive tools ranging from zero-dimensional models describing the gas and particle reaction mechanisms in axi-symmetric flow geometries, to full three-dimensional simulators for arbitrary, complex combustion furnaces. All of the codes have common elements; they solve the governing gaseous fluid mechanical and reaction equations in an Eulerian framework; turbulence is incorporated with a k-epsilon turbulence model for closure that has been modified for the presence of particles; the gaseous reaction rates are assumed to be limited by molecular scale mixing; different gas-phase mixture fractions are defined for the local mass fraction of inlet carrier gas and the local mass fraction of gas evolved from the solid coal particles; transport equations are solved for each mean mixture fraction and its variance about the mean; and statistical probability density functions ( $p d f^{\prime} s$ ) are used at each point in the flow field to obtain mean properties of chemical composition, temperature, and other variables based on local instantaneous equilibrium and then by convolution of the pdf.

The particle mechanics have been solved for these dilute systems by following the mean path or trajectory for a descretized group or ensemble of particles in a Lagrangian frame of reference. Coal devolatilization and heterogeneous reaction rate processes are included using a variety of suggested submodels from the literature. Heat, mass, and momentum transport effects are included for each particle. The transport of thermal radiation is solved usually with a discrete ordinates model that includes nonisotropic and multiple scattering from the particles. 
Specific unique factors and recent adoptions are discussed below.

\section{Particle Transport.}

Recently a new approach to describing particle transport in turbulent flows has been incorporated based on an extension of stochastic process modeling and turbulence theory. The model requires no adjustable parameters beyond specification of the turbulent flow field itself and is independent of any particular turbulence model. The description of the turbulent flow field required by the model is in terms of the mean square velocities and Lagrangian correlation functions. These are rarely available, especially for the particle phase. Approximations for these in terms of parameters from the $k-\varepsilon$ gas turbulence model and particle properties have been suggested and shown to yield reasonable results. Extensions to this theory and a 3-D generalization are currently under way in a separately funded research contract from DOE at the University of Utah.

The new model, called the stochastic particle transport (STP) model, reveals several important characteristics about particle dispersion in turbulent flow. The STP model has been evaluated by comparison to exact solutions, the most accurate alternative models, and experimental data. The model has been both an accurate and an efficient method of describing the turbulent transport of particles. It reproduced the exact solutions both numerically and as analytical functions. These analytical solutions have been used as calibrations for some of the most accurate alternative models for particle transport in turbulent flows. A comparison of the alternative models with the approach suggested in this work shows that, at least for the cases used to calibrate the alternative models, the STP approach is as accurate and much more efficient than the alternative models. In a comparison to turbulent dispersion data collected under nine different flow conditions, the model predicted the experimental data of all nine cases within the experimental error.

The turbulent dispersion model has been incorporated as the framework of the particle submodel of a comprehensive combustion code, again with no adjustable parameters except those required by the turbulent fluid mechanics submodels. Side by side comparisons of predictions of the comprehensive combustion code with the previous and new particle submodels conclude that the STP model increases the computational efficiency and robustness of the simulations while decreasing the total number of required particle simulations. This work represents the first implementation of this type of stochastic model for particle dispersion in a comprehensive combustion code. Perhaps most significantly, the STP model improves the fundamental basis for the predictions.

Prediction of particle variables in an Eulerian framework is also demonstrated with the STP model. These variables include particle temperature, burnout, velocity, residence time, etc. The model predicts not only the mean values of these variables, but also their statistical 
variation associated with turbulent fluctuations. This is the first time such information has been avallable from Lagrangian particle dispersion models.

\section{Particle and Particle-Product Reactions.}

The description of coal reaction processes includes devolatilization, char oxidation, and gas-particle interchange. The resulting submodel describes the response of a coal particle to its thermal, chemical and physical environment, and the of $f$-gas products that then further react in the gas phase. The unique features of this submodel lie in the incorporation of the turbulent fluctuations and the complete, local, complex chemical equilibrium. Many other comprehensive models use global mixing models without the capability to establish the chemical intermediates.

The development of the treatment of pulverized-coalichar behavior in reacting systems is based largely on independent experimental observations and kinetic parameters deduced from these observations. Since there are still unresolved questions regarding the kinetics of coal reaction, an at tempt has been made to formulate a general reaction scheme that can accommodate results of future measurements and improved kinetic parameters. The code is constructed specifically to be general enough to accommodate most devolatilization models currently proposed in the literature.

The coal reaction model is formulated to handle multiple coal components with multiple reactions. For example, in one common application, the coal particle submodel would consist of four components: coal, char, moisture, and ash. At this point the ash might be defined as that part of the coal particle that is inert in the combustion scheme (for further mineral matter transformations see the discussion that follows). Char would be the residual left in the coal particle when the volatile products are released. The reacting particle is assumed to be composed of specified amounts of raw coal, char, moisture, and ash at any particular time. The raw coal, or the dry, ash-free portion of the coal, undergoes devolatilization to volatiles and char by one or more reactions ( $M$ in total number). The volatiles react further in the gas phase. The char reacts heterogeneously after diffusion of the reactant ( 1 .e., $\mathrm{O}_{2}, \mathrm{CO}_{2}, \mathrm{H}_{2} \mathrm{O}$, and $\mathrm{H}_{2}$ ) to the particle surface by one or more reactions ( $L$ in total number).

Constitutive equations are solved for heat and mass transfer to and from the particle surface. It has been found important to correct the heat and mass transfer relationships for high rates of mass transfer, since the devolatilization rates are particularly rapid.

The oxidation and gasification scheme suggested thus far combines the effects of film diffusion at high temperatures with chemical kinetics at low temperature. The kinetics are modeled from an nth-order global reaction rate (based on external surface area) with the selected oxidation mechanisms. The effects of this mass transfer on diffusion (Stefan flow) can be included by use of film theory, which allows a smooth transition be ween the rapid "blowing" characteristics of pyrolysis and the subsequent slower characteristics of heterogeneous oxidation. In this method it is possible to incorporate the option of allowing the particle to either 
shrink at constant density or decrease in density at constant particle size. The option, however, does not include intraparticle transport nor pore structure monitoring. Little incentive has been provided for this level of modeling because experimental reactions rates and rate constants have usually been based on exterior surface area rather than on interior surface area (intrinsic kinetics). Intraparticle diffusion effects are supposedly absorbed into the global reaction expression.

\section{Radiation.}

Recently we have incorporated a discrete ordinates method to describe radiative heat transfer. This method conceptually belongs to the family of flux models, but corrects the lack of coupling between the directional intensities present in some of the conventional flux models. In the discrete ordinates method, the integral-differential radiation transport equation is solved in a number of directions, the angular integral being discretized through the assumption of non-variance of radiative intensities in prescribed solid angles surrounding representative directions. This results in a number of coupled partial differential equations of intensity transport, the number depending on the order of the discrete ordinates approximation, which are then solved by suitable numerical methods. The formulation can be found in a number of publications we have presented on this topic. This discrete ordinates method has been tested in two-dimensional axisymmetric geometries, 2-D Cartesian geometries, 3-D rectangular geometries and in 3-D geometries with generalized shapes. It has also been tested in non-scattering and scattering media.

\section{Ash Transformation and Deposition.}

For the comprehensive coal combustion model to be of practical use to the design of the HITAF, effects of mineral matter on coal combustion performance need to be addressed. Our modeling of mineral matter transformations and their inclusion into comprehensive codes is a unique feature that has not yet been performed by any other comprehensive modeling effort. The basic philosophy of our modeling effort to date has been to couple simple technology in modeling ash deposition into the complete heat transfer and reaction model. Currently fouling/slagging submodel predictions have not been compared to laboratory or full-scale furnace experiments. However, before subcomponents (such as deposition rate calculations or physical property predictions) were included in the fouling/slagging submodel, evaluation of subcomponent predictions to experimental data were performed as independently as possible to other subcomponent predictions.

The particle fragmentation subcomponent of the Fouling and slagging model is based on tracing the trajectory of the char/ash particles as they burn, the particle structure changes and the porosity increases to a critical porosity (taken here as $70 \%$ ), then fragments into a set number of smaller particles of the same characteristics. The process of changing porosity and then fragmenting continues. The significance of this modeling effort 
lies in its ability to predict particle deposition and thermal characteristics of the deposited material because the entire combustion process is predicted in a fully coupled manner.

Three-Dimensional Capabilities.

The three-dimensional combustion code incorporates the two-dimensional submodels discussed above for predicting the behavior of utility boilers and industrial furnaces firing pulverized-coal. The coding handles Cartesian and cylindrical coordinate systems and incorporates differencing for completely irregular grid spacing. Finite differencing is performed with a combined weighted central and nodal upwind scheme which has been adapted to handle irregular grids. Known exact solutions have been used to verify the coding, numerical algorithm and numerical accuracy. Convergence was verified to computer truncation error both by starting with arbitrary initial guesses for all functions and by starting with the exact solution itself. The nodal upwind scheme has been selected for convection terms after coding several alternatives and comparing results with exact solutions. The nodal scheme selected, minimized numerical diffusion while providing reasonable numerical stability. The resulting finite-difference coefficient matrices are solved with plane-by-plane sweeps with a modified Thomas algorithm employing Stone's partial cancellation to accelerate convergence. Substantial run time reductions were also achieved through code vectorization.

The model development explored the option of employing different variations of the SIMPLE algorithm to couple the momentum and continuity equations. Coupling options include the SIMPLE, SIMPLER, SIMPLEC, SIMPLEST, and various combinations of these algorithms. Grid resolution requirements have been established for many cases. Near grid independent simulations of a tangential-fired furnace were achieved for grid structures exceeding 150,000 nodes. More complex furnace flows as demonstrated by a wall-fired furnace required in excess of $250,000 \mathrm{grid}$ points.

We have shown the importance of fluid turbulence fluctuations on the non-linear mixing in gaseous combustion. This is a feature that we have always included in our modeling efforts but which some other models ignore. Mean composition and temperature predictions were quantitatively different between simulations that neglect or include the local fluctuations in stoichiometry. The conclusions that have been made previously regarding the importance of these fluctuations in laboratory scale furnaces were found to hold true in larger scale systems. Even though the fluctuations in the conserved scalar are only significant in the near-burner region, their effect on mean temperature and composition persists throughout the furnace.

\section{Screening Calculations}

The screening calculations were carried out with the axisymmetric version of the coal combustion code in order to reduce computational complexity and turnaround time. The furnace simulation is for $115 \mathrm{MBTU} / \mathrm{hr}$ furnace which represents one combustor in a pool of eight for the demonstration design. 
Some of the input conditions for these calculations are shown in Table 3 . Two major design options were explored in these representative simulations, namely:

- the impact of an increase in wall temperature representative of wall condi,ions with the radiant heater in the furnace section having a refractory slag layer, and

- the use of methane to achieve flame stabilization at the burner tip for $\mathrm{NO}_{x}$ control with an axial furl/air injection system.

Note, however, that the simulations simultaneously changed other variables as well. For example, the primary carrier gas was increased to that of the secondary air for the two cases with a methane pilot. This results in increased velocities of the primary jet and, as will be seen later in the discussion, different particle dispersion rates.

Table 3: Input Conditions for Furnace Calculations

\begin{tabular}{|l|l|l|l|l|}
\hline \multicolumn{1}{|c|}{ Parameters } & $\begin{array}{c}\text { Cold Wall } \\
\text { No } \mathrm{CH}_{4}\end{array}$ & $\begin{array}{c}\text { Hot Wall } \\
\text { No } \mathrm{CH}_{4}\end{array}$ & $\begin{array}{c}\text { Cold Wall } \\
\text { w/ } \mathrm{CH}_{4}\end{array}$ & \multicolumn{1}{|c|}{$\begin{array}{c}\text { Hot Wall } \\
\text { w/ } \mathrm{CH}_{4}\end{array}$} \\
\hline \hline Coal Flow $(\mathrm{kg} / \mathrm{s})$ & 1.00 & 1.00 & 1.00 & 1.00 \\
\hline Methane Flow $(\mathrm{kg} / \mathrm{s})$ & 0.0 & 0.0 & 0.06 & 0.06 \\
\hline Overall Excess Air (\%) & 0 & 0 & 0 & 0 \\
\hline Primary Velocity (m/s) & 20 & 20 & 20 & 20 \\
\hline Secondary Velocity (m/s) & 18 & 18 & 25 & 25 \\
\hline Temp. Primary (K) & 300 & 300 & 830 & 830 \\
\hline Temp.Secondary (K) & 830 & 830 & 830 & 830 \\
\hline Wall Temperature (K) & 925 & 1755 & 925 & 1755 \\
\hline
\end{tabular}

\section{Heat Transfer}

The major reason for making these calculations was to determine whether the radiant flux was sufficient to support the design of the radiant air heater. In these simple calculations hea'c extraction by the turbine air was decoupled from the flame calculations. The walls were assumed to have a constant specified wall temperature. Figure 6 shows the total wall heat flux as a function of axial distance down the early regions of the furnace wall for the 
four cases and the overall furnace efficiency. The wall heat flux includes both radiative and convective heat transfer. In all four cases the heat flux is relatively flat subsequent to the distances shown in the figure.

For the hot wall cases in these simulations, the furnace acts as a heat source in the early stages of the flame. This is mainly because of the assumption of a constant wall temperature. The variations in total wall flux with furnace location will likely be reduced when the coupled combustion heat transfer systems are modeled in Task 3.

The question regarding the success of the radiant heater concept can be posed another way. With the wall temperatures fixed at reasonable values to obtain outlet air temperatures of 1800F, can the combustion chamber provide bulk gas temperatures in excess of $3000 \mathrm{~F}$ which would be necessary to obtain sufficient heat fluxes to heat the air to the required temperature? These simulations show that gas temperatures (not shown) for the hot wall case exceed $1922 \mathrm{~K}$ (3000F).

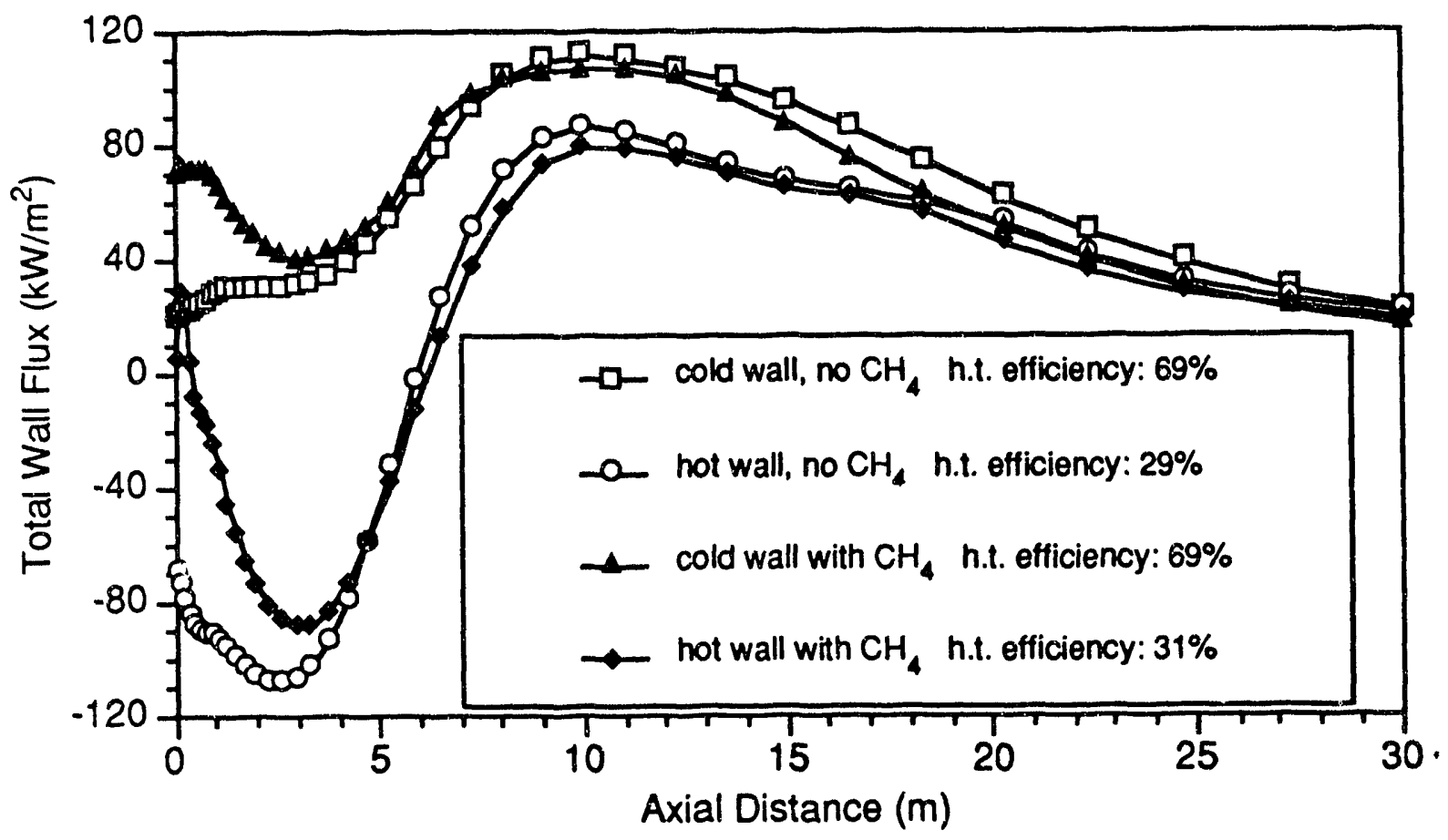

Figure 6. Axial distribution of wall heat flux for the four primary combustor simulations

No $x$ Formation

The No submodel used for the calculations takes into account the composition and temperature fluctuations due to fluid turbulence using multiple pdf's. The thermal NO mechanism is the standard Zeldovich mechanism with three kinetic steps. Fuel nitrogen is evolved from the code as HCN at some prescribed rate 
and converted either to NO or $\mathrm{N}_{2}$ by an overall mechanism based on the work of DeSoete. Reactions are included to take into account both prompt No formation and reburning No by fuel fragments.

Figure 7 compares the predicted NO concentration in ppm integrated across the diameter of the furnace, and as function of axial distance for the four cases. Increasing wall temperature increases NO formation; but in both the hot and cold wall cases, the addition of pilot methane reduces No formation. This is primarily because the ignition distance is shortened, a heated annulus around the fuel jet allows the coal to undergo initial devolatilizaton in a region that has not yet been mixed with much oxygen from the surrounding secondary jet and an aerodynamic fuel rich region is established in which the fuel nitrogen evolves from the coal minimizing No formation.

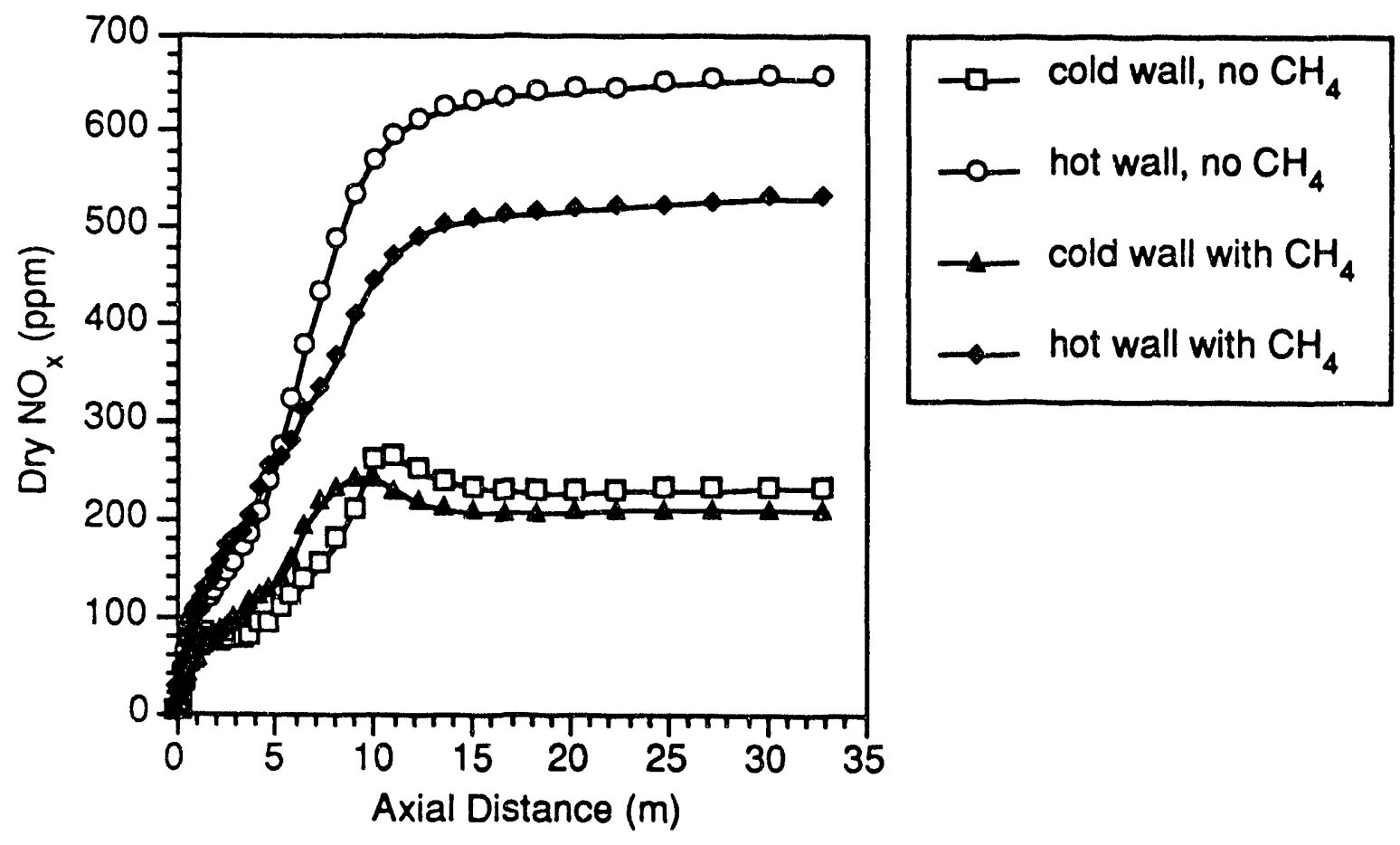

Figure 7. Integrated $\mathrm{NO}_{x}$ as function of axial distance

Clearly if the radiant air heater concept is selected then it will be necessary to operate the HITAF under staged combustion conditions in order to reduce the formation of nitric oxide. The addition of staged air will then become an important design parameter.

\section{Carbon Burnout}

Increasing furnace wall temperature by putting the radiant panels in the furnace resulted in hotter bulk gas temperatures. These higher temperatures increased the NO formed in these flames but it also increased the rate of carbon burnout. Figure 8 shows integrated carbon burnout values as a function of axial distance for the four cases discussed in this report. This figure 
highlights only the last stages of burnout. The particle size distribution simulated in these calculations included some coal particles of $112 \mu \mathrm{m}$ in diameter. These larger diameter particles are the ones that take the longest to be consumed, resulting in the longer distances needed for complete burnout for the cold wall cases. In the hot wall cases the burnout was completed, even for the largest particles, by a distance of 20 meters.

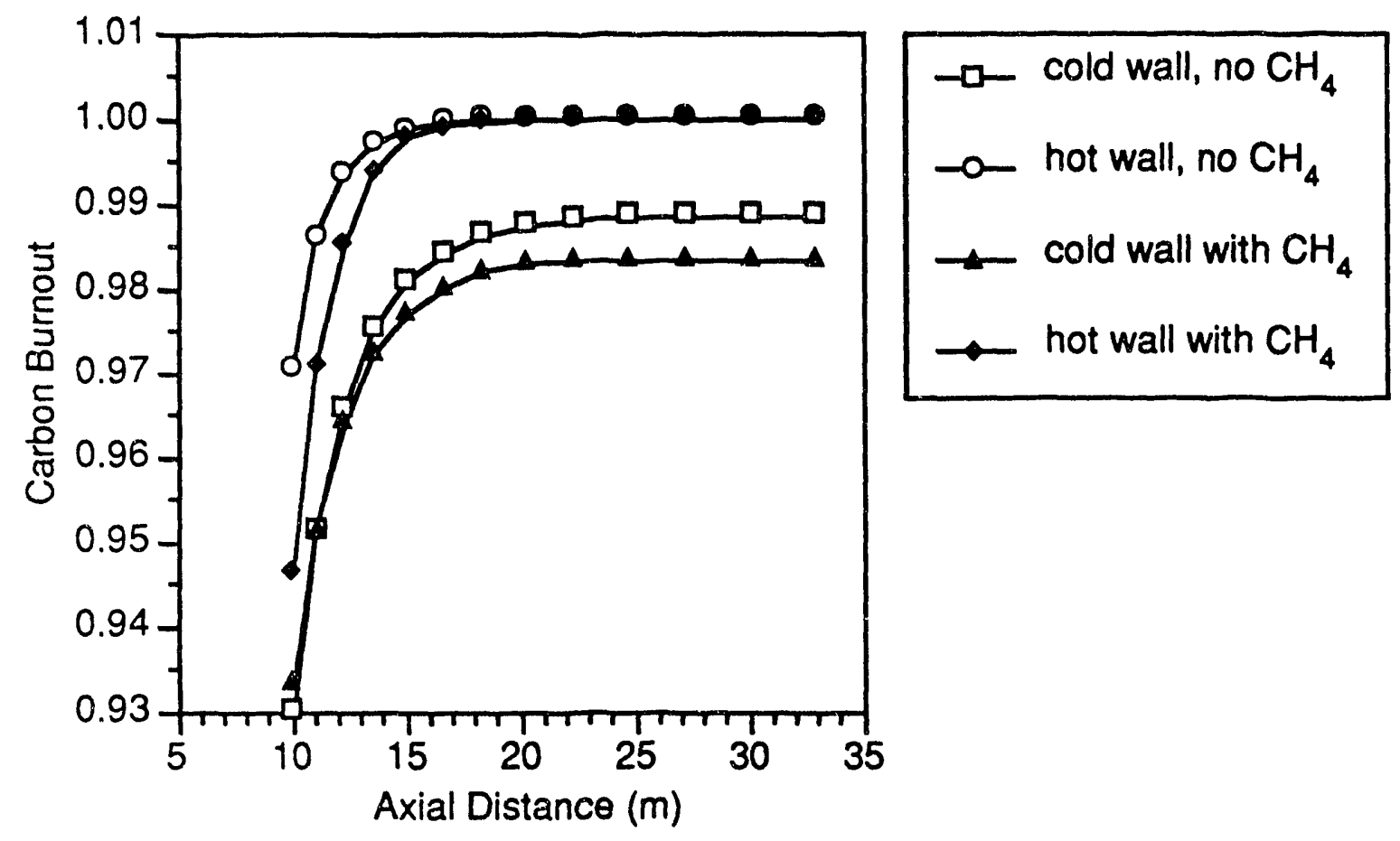

Figure 8. Integrated carbon burnout as function of axial distance

\section{Particle Deposition}

Particle deposition rates are important because of: 1) heat transfer implications as the wall resistance increases and 2) ash management issues regarding furnace operation. The current model includes a simple particle deposition model which takes into account inertial impaction, turbulent dispersion and thermophoresis. Particle deposition rates are compared in Figure 9. Calculated particle trajectories (not shown) are similar for all four cases, with the higher velocity primary cases (with methane pilot) resulting in slower particle dispersion. However, the simulations showed no direct inertial impacting for the trajectory of the mean path of any particle cloud for any starting location in the primary jet or for any particle size. Thus, the major contributors to deposition rates are turbulent eddy transport and thermophoresis effects.

The highest rates in the initial region of the furnace are in the cold wall case andan artifact of the concept of isothermal walls. The simulations do, however, give an indication of the extremes that might be expected. The real case should lie between the two extremes. The cases with the hot wall resulted 
in more moderate deposition rates. Yet even these reduced rates are not insignificant. Again, this submodel is relatively crude and, because of the lack of suitable data, has not been extensively verified.

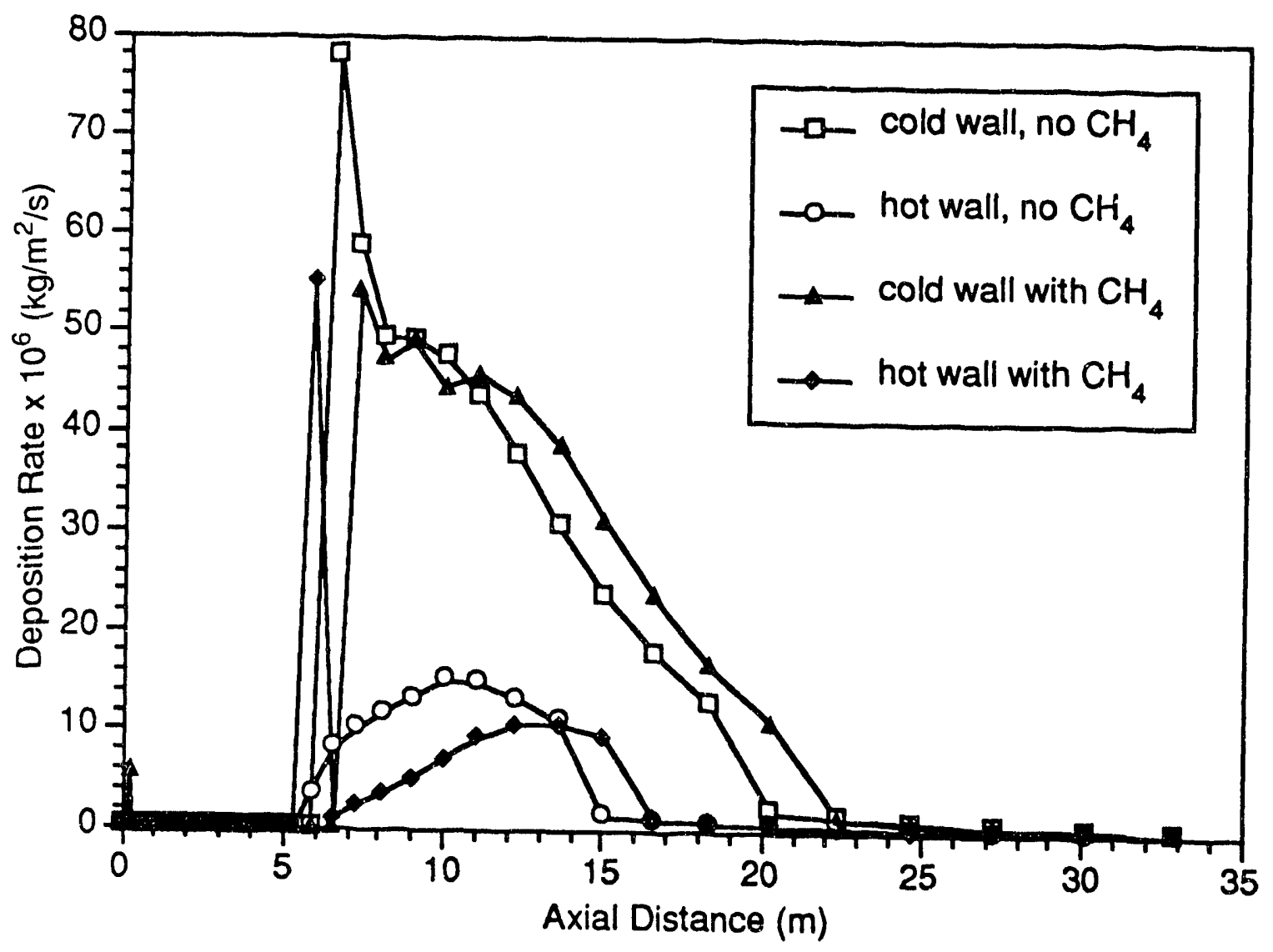

Figure 9. Particle deposition rates as a function of axtal distance 
Task 2.2.2.2 Air Heater Concept Screening

Introduction/Background

Inasmuch as the high temperature products which are generated from the combustion of pulverized coal will provide the heat source for the proposed HITAF concept, the air heater must be capable of operation under unusually severe conditions. In addition to the obvious material requirements which are imposed by the expected coal combustion temperatures of from 2600 to $3200 \mathrm{~F}$, the air heater must be designed so as to avoid excessive mechanical and thermal stresses. Moreover, the mineral content of coal at typical combustion temperatures produces ash particles and alkali vapors which, when deposited on heat transfer surfaces, will result in heat transfer performance degradation and possible erosion and corrosion of the surfaces. If the coal combustion temperature exceeds the ash fusion point, molten or sticky ash particles will be contained in the hot gas stream, and a tenacious slag deposit can form on cooler heat transfer surfaces. Obviously, if the entire heat transfer surface cannot be maintained hot enough to exceed the ash fusion temperature (e.g. 2000 to $2800 \mathrm{~F}$, depending on coal type), either slag formation must be avoided by limiting the coal combustion temperature or removal of wet ash particles must be provided so that the air heater is exposed to only dry ash. Regardless of the type of deposit whi=h will form on heat transfer surfaces, however, either deposit may contain species which promote corrosion of the surfaces. In addition, if surface temperatures are below the dew point of alkali vapors contained in the combustion products (e.g. about 1400 to 1800 $\operatorname{deg} F$ ), corrosion of heat transfer surfaces due to reactions of condensed alkali species such as sodium sulfate with the structural material can occur. Although erosion of air heater surfaces by impinging ash particles is not expected to be a serious problem because the gas velocity in the air heater can be controlled, special precautions will be made to prevent corrosion of heat transfer surfaces. Since at least some form of deposit will invariably form on portions of the heat transfer surfaces, provisions must be made to minimize deposit formation and its adverse effects on the performance and lifetime of heat transfer surfaces. The subjects of ash management and material compatibility, including ash corrosion effects and the effects of ash deposits on air heater performance, are discussed in other sections.

Thermal Performance Requirements

Based on results of system performance analyses of the HITAF which are discussed elsewhere in this report, the thermal performance requirements of the air heater have been tabulated below for the the two combustor design concepts which assume different levels of heat input by natural gas. 
Thermal Performance Requirements

of

HITAF Air Heater

For Combustion Concept \#1: $35 \%$ Heat Input by Natural Gas Hot Gas Side Cold Air Side

$\begin{array}{ccc}2,832,000 & \text { Mass Flow Rate (lb/hr) } & 2,615,000 \\ 2,490 & \text { Inlet Temperature F) } & 732 \\ 1,553 & \text { Outlet Temperature F) } & 1,800 \\ 17 & \text { Inlet Pressure (psia) } & 235 \\ 2.5 & \text { Pressure Drop (\%) } & 3.75 \\ & 757 \text { MBtu/hr Heat Load } & \\ & 60.7 \% \text { Effectiveness }\end{array}$

l'or Combustion Crncept \#1: No Heat Input by Natural Gas

Hot Gas Side

Cold Air Side

$\begin{array}{ccc}2,832,000 & \text { Mass Flow Rate (lb/hr) } & 2,615,000 \\ 3,000 & \text { Inlet Temperature (deg F) } & 732 \\ 1,490 & \text { Outlet Temperature (deg F) } & 2,450 \\ 17 & \text { Inlet Pressure (psia) } & 235 \\ 2.5 & \text { Pressure Drop (\%) } & 3.75 \\ & 1,218 \text { MBtu/hr Heat Load } \\ & 75.8 \% \text { Effectiveness }\end{array}$

Obviously, the concept which does not utilize heat input from combustion of natural gas is more desirable. However, because of potentially severe problems with slag and ash deposition and resultant corrosion of heat transfer surfaces, the goals of the more conservative Concept \#1 will take 
preceder.ce over the goals of Concept \#2 whenever the success of the HITAF concept might be jeopardized by technical problems such as material limitations.

\section{Ceramic Materials for High Temperature Heat Exchangers}

Clearly, the materials of construction of the air heater must withstand higher temperatures and more severe environmental conditions than steam boilers which are used today with pulverized coal combustors. Besides the requirement for corrosion resistance at high temperatures, the materials must also be able to withstand mechanical and thermal stresses caused by structural loads and pressures and temperatures imposed by the fluid streams. Therefore, of the available materials which are known to be capable of withstanding corrosive environments at high temperatures, the general class of materials known as high temperature structural ceramics are believed to be the most suitable for use as heat transfer surfaces of the HITAF air heater. The leading ceramic candidate is silicon carbide ( $\mathrm{SiC}$ ) which can withstand temperatures up to 3000F. For pulverized coal combustion environments, however, the maximum useful service temperature is considerably lower since it depends on the coal ash properties and the hot gas atmosphere.

During the past decade there have been a number of research and development programs which have addressed the application of ceramic materials to high temperature flue gas streams from pulverized coal combustors. Al though some of these programs have shown that corrosion of the ceramics can be minimized by judicious control of variables such as temperature and hot gas compositions, ash- or slag-induced corrosion of ceramic materials is not completely understood. Prime examples of these programs are the work of $V$. $\mathrm{J}$. Tennery and coworkers at Oak Ridge National Laboratories (ORNL) who conducted extensive research and development on the long-term chemical and structural stability of ceramic materials for use in heat exchangers which are exposed to high temperature products from coal- and oil-fired combustion processes. These studies at ORNL showed that the fate of the different materials depended very much on the nature of the slag which deposited on the ceramic. They evaluated ten different ceramic materials in tube form at temperatures as high as $2260 \mathrm{~F}$ for up to $500 \mathrm{hrs}$ per material. Two different coal-oil mixtures were used, one contained a coal which produces an acidic slag, and the other contained a coal which produces a basic slag. The candidate ceramic materials included siliconized SiC, sintered alpha-SiC, chemical vapor deposited (CVD) SiC, high purity alumina, and sialon. When firing with a coal which produces a dry acidic slag, the SIC materials survived without degradation whereas the alumina and sialon tubes were cracked extensively (Ferber and Tennery, 1981). When firing with a coal producing a low viscosity, basic slag, tube degradation was much more pronounced for all materials (Ferber and Tennery, 1982). The greatest loss of ceramic material occurred on surfaces which faced upstream, varying from 7 to 78 percent reduction in wall thickness. Unlike the results of the acidic slag firing tests, the SiC materials were more degraded than the high purity alumina when firing under basic slag conditions. The principal slag-induced corrosion mechanism of the SiC appeared to be the formation of iron silicides at the ceramic-slag interface with subsequent transport of the silicides away from the ceramic 
material into the slag. This lead to the formation of pits in the SiC surface. Similarly, the alumina was corroded due to the activity of iron in the basic slag, forming an iron aluminate spinel layer on the surface of the ceramic which then dissolved into the slag.

The relatively higher degradation of alumina as compared to SiC observed by ORNL for acidic slag is in marked contrast to a study reported by Bonar et al. (1980). They found that clumina is relatively stable in an acidic slag but corroded much more in a basic slag. The differences in the Bonar et al. study and the ORNL study for alumina corrosion indicate that simple differentiations between the chemical nature of slags as basic or acidic does not provide adequate information about the corrosiveness of the slag. Instead, the reactor atmosphere, slag viscosity, and subtle differences in the composition of the slag may play roles in determining slag corrosiveness of specific ceramic materials. Moreover, these variables are likely to be mutually dependent in determining the rate of ceramic corrosion because both chemical kinetics and mass transport usually play important roles in these reaction systems.

More recently Easler and coworkers at Argonne National Laboratories (ANL) conducted a series of well-controlled experiments on slag-induced corrosion of silicon carbide ceramics. In these experiments SiC ceramic samples were coated with synthetic ash mixtures, both acidic and basic types, and heated in air at 2012 to $2282 \mathrm{~F}$ for 200 hours. Corrosion was evaluated by determining the weight change of the ceramic samples and examining the slag-ceramic interfaces by optical and electron microscopy. For the entire temperature range considered, the SiC samples which had been exposed to acidic slag experienced a small net weight gain from the formation of Si02 scale. With the acidic slag, the ash did not melt and fuse to the SiC except at the highest temperature $(2282 \mathrm{~F})$, but there was no evidence of corrosion. However, samples which were exposed to the basic slag at the highest temperature experienced a loss in weight, indicating corrosion of the SiC ceramic. Examination of the slag-ceramic interface of these corroded samples showed localized regions of high iron and silicon content which was identified as iron silicide. Easler and coworkers attributed these differences in SiC corrosion behavior to differences in the slag viscosity. They showed that corrosion occurred only at temperatures where the viscosity of the slag is less than approximately 100 poise and the slag will flow easily.

In a related program at $\mathrm{ORNL}$ on the development of ceramic materials for use in heat recovery equipment for high temperature process furnaces, Federer found that silicon-based ceramics are corroded by alkali compounds which are contained in combustion gases. Specifically, he found that silicon carbide and silicon nitride ceramics are severely corroded by alkali vapor compounds and the corrosion rates of oxide ceramics increase with increasing silicon dioxide content. Federer attributed this alkali-induced corrosion to the formation of alkali silicates which result from the reaction of alkali oxides, such as $\mathrm{Na} 20$ and $\mathrm{K} 20$, with the normally protective SiO2 ceramic film. These alkali silicates, which are molten at temperatures as low as $1470 \mathrm{~F}$ (e.g. Na20.2Si02), cause softening of the Si02 film. The resulting enhanced diffusion of oxygen through the 
altered film causes oxidation of the silicon-based ceramic. Gaseous products of oxidation, such as $\mathrm{CO}$, form bubbles in the molten silicate. Similarly, for composite ceramics which combine silicon and oxide components, the alkali oxides react with the silicon component to form new, lower melting point silicates, which dissolve the more refractory oxide components, such as $\mathrm{Al} 203$ and $\mathrm{Zr02}$. Therefore, Federer suggests that the oxide-based ceramics, such as alumina and zirconia with limited amounts of S102, are the best candidate ceramic materials for heat exchangers for use with combustion gases which contain alkali vapors.

\section{Rationale for Air Heater Concepts}

Clearly, air heater components in the high temperature sections of the HITAF will have to be made of ceramic materials if performance requirements are to be achieved. These heat transfer components will require special design considerations, however, if corrosion of the ceramic materials is to be avoided. Based on the results of the studies on corrosion reviewed above, high temperature corrosion of ceramic materials by coal combustion products can be viewed as twc more or less separate regimes which depend approximately on the types of corrosive compounds in the combustion gas and the temperature ranges wherein these compounds are chemically active. The first of these regimes involves slag-induced cormosion of ceramics at high temperatures, of the order of about 2000 to $2800 \mathrm{~F}$, where the ash is in a fluid or liquid phase which wets the ceramic surface. The second regime consists of alkali-induced corrosion of ceramics as a result of condensation of alkali vapors on the ceramic surfaces at somewhat lower, but still high, temperatures of the order of about 1400 to $1800 \mathrm{~F}$.

If slag-induced corrosion associated with the highest temperature regime is to be avoided, special provisions will be needed in the air heater design in order for the heater to survive in the harsh environment and still achieve effective heat transfer. Certainly, based on the review of corrosion of ceramic materials above, the air heater design for this regime should be based on a prudent concept which avoids direct contact of liquid or wet slag on ceramic surfaces. Inasmuch as this regime is associated with the highest temperature combustion gases (c.a. 3000F), radiant heat exchange with the air stream is a possible concept which is amenable tc isolating the air heater ceramic surfaces from direct contact with slag. Analogous to what is done currently for steam boilers which use radiant heat transfer from pulverized coal combustion, the structural ceramic air passages can be protected from liquid slag by a layer of ceramic refractory. Although the thermal resistance of the refractory reduces the heat flux to the air somewhat, the refractory serves the more important dual functions of preventing corrosion of the structural ceramic and keeping the air heater surface temperature high enough for the slag to flow readily. This latter function is important because slag cannot be allowed to solidify in thick layers on the refractory surface of the air heater since this will impede heat transfer drastically and solidified slag is difficult to remove. In practice the refractory will gradually dissolve into the liquid slag which flows over it, and the refractory will have to be replaced periodically. By proper selection of the refractory, however, experience with steam boilers has shown that the cost and frequency of replacement of the refractory can be acceptable. A survey has been undertaken to identify 
refractories with high resistance to corrosion by slag and high thermal conductivity as part of an evaluation of this radiant air heater concept. High thermal conductivity is desirable to maximize heat transfer and to minimize frequency of refractory replacement.

In the second regime, which is characterized by alkali-induced corrosion of ceramics, the air heater in this regime will have to be based on convective heat transfer because the combustion gas temperature is too low for effective radiant heat transfer. Inasmuch as heat fluxes for convective heat transfer are typically low, as compared to radiant heat transfer, deposition of ash on convective heat transfer surfaces will have to be controlled. Fortunately, there are available techniques for ash collection upstream of the convective air heater and soot blowing of heat transfer surfaces. The convective air heater configuration which is being pursued has been described in detall in the proposal for this program. Provisions for ash management are covered in another section of this report.

The selection of ceramic materials suitable for construction of the radiant and convective sections of the air heater will be made after completion of the ceramic materials evaluation tests which are described elsewhere in this report. Meanwhile, conceptual studies of these air heater designs have been based on the use of silicon carbide as the ceramic material for structural air passages. The refractory material for the radiant air heater was assumed to be a SiC/Si3N4 ceramic which is produced by Carborundum. Although oxide-based ceramics (e.g. SiO2 and $\mathrm{Zr02}$ ) have shown better resistance to alkali-induced corrosion than SiC and Si3N4, concept design studies of the convective air heater have also been based on SiC as the tube material because thermal conductivity of the ceramic material has been found to be a factor which would limit air heater performance. In the lower temperature section of the convective air heater, where the temperature of the air passage is below about $1500 \mathrm{deg} F$, super alloys are also being considered for construction of the passages for this section.

\section{Conceptual Design Analysis of Radiant Air Heater}

A design analysis of the radiant air heater was conducted to assess the performance capabilities of this heater concept which utilizes a refractory to ensure heater survivability in a high temperature, corrosive slag environment. Although this conceptual design analysis lacks the rigorous detail required for construction of actual air heater equipment, it is consistent with the level of detail required at this stage of the program. Accordingly, the conceptual design analysis is based on the following assumptions:

1. The hot gas stream produced by pulverized coal combustion is an optically thick media which emits and absorbs thermal radiation according to the theory for a gray surface.

2. Changes in the thermal energy content of the gas streams are treated as one dimensional with respect to the direction in which the streams flow. 
3. Radiant heat exchange between the hot gas stream and the air heater surface occurs in the one direction which is perpendicular to the direction in which the gas streams flow.

4. Combustion is essential by complete before any radiant heat transfer occurs. Thus, the adiabatic flame temperature can be used as the boundary condition for the hot gas stream.

5. Ash which is deposited on the radiant air heater surface flows due to gravity as a falling film if the viscosity of the resultant slag is less than 250 poise. This assumption implies that the slag will solidify on the radiant air heater surface, forming a dry ash deposit, if the temperature of the slag is below the value at which the slag viscosity is 250 poise.

Figure 10 is a schematic diagram of an elemental section of the radiant air heater considered for the conceptual design analysis. The overall heat balance of an elemental section of the radiant air heater is governed by the expression
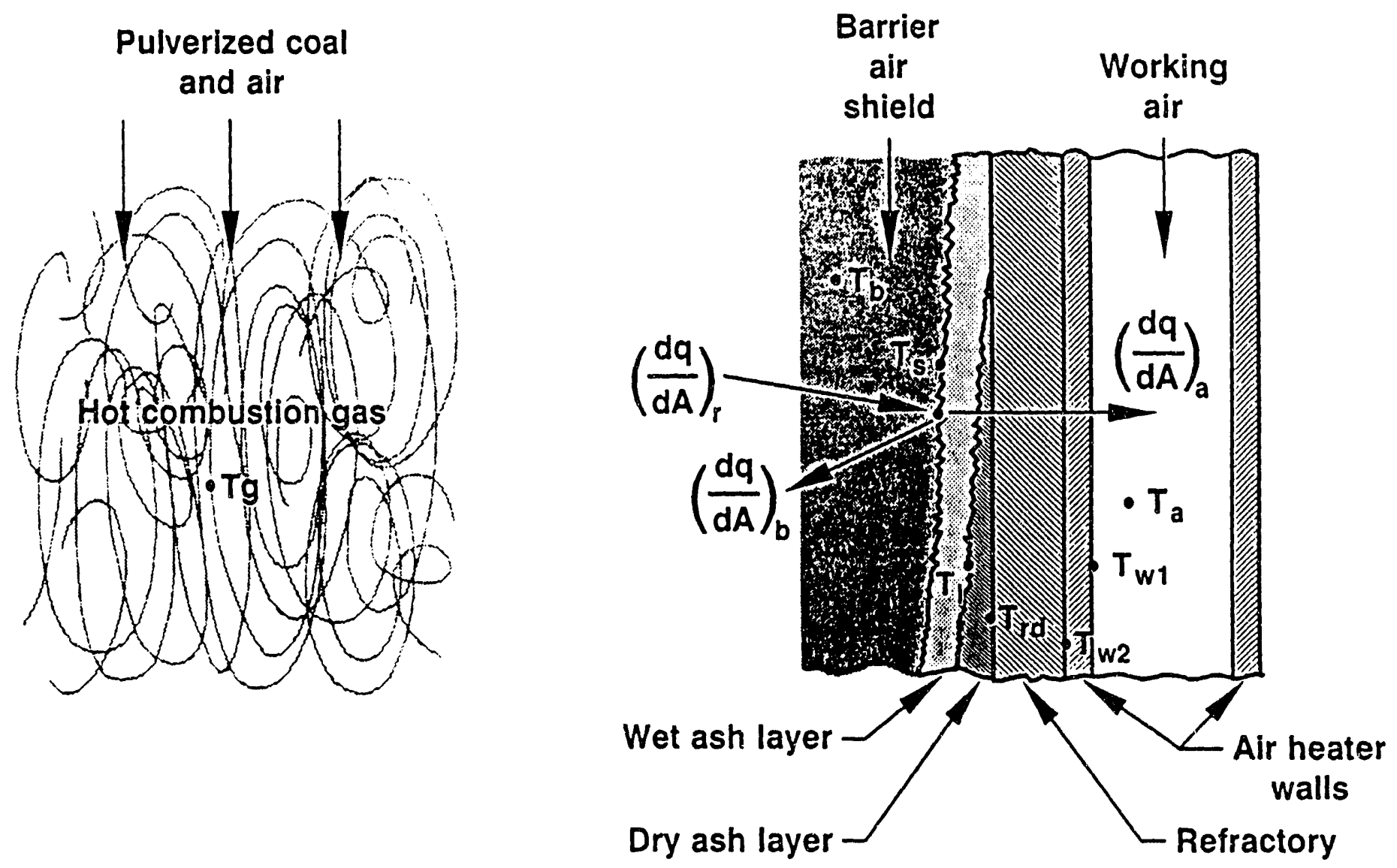

RB1425ETX.001

Figure 10. Desigñ Analysis of Radtant Alr Heater 


$$
\left(\frac{\mathrm{dq}}{\mathrm{dA}}\right)_{\mathrm{r}}=\left(\frac{\mathrm{dq}}{\mathrm{dA}}\right)_{\mathrm{a}}=\left(\frac{\mathrm{dq}}{\mathrm{dA}}\right)_{b}
$$

Based on the theory for radiant heat transfer between concentric cylinders which are gray surfaces, the net radiant heat flux from the hot gas stream to the radiant air heater surface can be written as

$$
\left(\frac{\mathrm{dq}}{\mathrm{dA}}\right)_{\mathrm{r}}=\Im_{\mathrm{sg}} \sigma\left(\mathrm{T}_{\mathrm{B}}^{4}-\mathrm{T}_{\mathrm{s}}^{4}\right)
$$

where the transfer function

$$
\Im_{\mathrm{sg}}=\left[\frac{\mathrm{R}_{\mathrm{g}}}{\mathrm{R}_{\mathrm{g}}} \frac{1}{\epsilon_{\mathrm{g}}}+\frac{1}{\epsilon_{\mathrm{d}}}-1\right]^{-1}
$$

$\varepsilon$ is the emissivity, $R$ is the cylinder radius, $T$ is the absolute temperature, and the subscripts $g, s$, and denote, respectively, the hot gas stream, the surface of the radiant air heater, and the ash or slag deposit which exchanges radiant heat flux.

The heat flux transferred across an elemental section of the radiant air heater, by conduction and convection, to an adjacent element of the working air stream can be written as

$$
\left(\frac{\mathrm{dq}}{\mathrm{dA}}\right)_{\mathrm{a}}=\mathrm{U}_{\mathrm{o}}\left(\mathrm{T}_{\mathrm{s}}-\mathrm{T}_{\mathrm{n}}\right)
$$

where the overall heat conductance

$$
U_{0}=\left[\left(\frac{\delta}{\mathrm{k}}\right)_{\mathrm{wd}}+\left(\frac{\delta}{\mathrm{k}}\right)_{\mathrm{d} d}+\left(\frac{\delta}{\mathrm{k}}\right)_{\mathrm{rf}}+\left(\frac{\delta}{\mathrm{k}}\right)_{\mathrm{w}}+\frac{1}{\mathrm{~h}_{\mathrm{a}}}\right]^{-1},
$$

and $k$ are the thickness and thermal conductivity of the respective layers, $h$ is the heat convection coefficient, and the subscripts wd, dd, $r f$, and $w$ and a denote the wet or slag deposit, the dry ash deposit, the structural ceramic tube wall, and the working air stream, respectively.

The heat flux from an elemental section of the radiant air heater surface to an adjacent element of the barrier or shield air stream can be expressed as 


$$
\left(\frac{d q}{d \Lambda}\right)_{b}=h_{h}\left(T_{s}-T_{b}\right)
$$

where the subscript $b$ denotes the barrier air stream.

Thermal energy balances of an elemental length of each of the three gas streams are governed by the expressions

$$
\begin{aligned}
& \left(\frac{d q}{d x}\right)_{r}=\left(\dot{m} c_{p}\right)_{g}\left(\frac{d T}{d x}\right)_{g} \\
& \left(\frac{d q}{d x}\right)_{b}=\left(\dot{m} c_{p}\right)_{b}\left(\frac{d T}{d x}\right)_{b} \\
& \left(\frac{d q}{d x}\right)_{a}=\left(\dot{m} c_{p}\right)_{2}\left(\frac{d T}{d x}\right)_{a}
\end{aligned}
$$

Since temperatures throughout the layers of slag and ash deposits, refractory, and structural ceramic wall of the radiant air heater are also of interest, the following auxiliary heat flux equations are used in the conceptual design analysis

$$
\begin{aligned}
\left(\frac{\mathrm{dq}}{\mathrm{dA}}\right)_{\mathrm{a}} & =\left(\frac{\mathrm{k}}{\delta}\right)_{\mathrm{wdl}}\left(\mathrm{T}_{s}-\mathrm{T}_{1}\right) \\
& =\left(\frac{\mathrm{k}}{\delta}\right)_{\mathrm{dd}}\left(\mathrm{T}_{1}-\mathrm{T}_{\mathrm{rd}}\right) \\
& =\left(\frac{\mathrm{k}}{\delta}\right)_{\mathrm{rf}}\left(\mathrm{T}_{\mathrm{rd}}-\mathrm{T}_{\mathrm{w} 2}\right)
\end{aligned}
$$




$$
\begin{aligned}
& =\left(\frac{k}{\delta}\right)_{w}\left(T_{w 2}-T_{w 1}\right) \\
& =h_{n}\left(T_{w 1}-T_{a}\right)
\end{aligned}
$$

where the additional subscripts 1, rd, $w 2$, and $w 1$ denote the interface between liquid slag and dry ash deposits, the interface between dry ash and refractory, the outside surface of the structural ceramic wall, and the inside surface of the structural ceramic wall, respectively.

The first step in evaluating these equations which describe the performance of a radiant air heater is to compute the surface temperature. If all of the quantities which determine the thermal resistances are known, including the slag and ash deposit thicknesses, the following equation for the surface temperature can be obtained by substituting Eqs. (2), (3), and (4) into Eq. (1):

$$
\mathrm{T}_{\mathrm{s}}=\frac{\mathrm{U}_{\mathrm{o}} \mathrm{T}_{\mathrm{a}}+\mathrm{h}_{\mathrm{b}} \mathrm{T}_{\mathrm{b}}}{\mathrm{U}_{0}+\mathrm{h}_{\mathrm{b}}}+\frac{\Im_{s g} \sigma}{\mathrm{U}_{0}+\mathrm{h}_{\mathrm{b}}}\left(\mathrm{T}_{\mathrm{g}}^{4}-\mathrm{T}_{\mathrm{s}}^{4}\right)
$$

Alternatively, if only the wet slag deposit thickness, ${ }^{2}$ and the temperature at which the viscosity of the slag deposit 1 ' 250 poise, $T$, are known, the surface temperature can be computed from the following equation:

$$
\mathrm{T}_{\mathrm{s}}=\frac{(\mathrm{k} / \delta)_{\mathrm{wd}} \mathrm{T}_{1}+\mathrm{h}_{\mathrm{b}} \mathrm{T}_{\mathrm{b}}}{(\mathrm{k} / \delta)_{\mathrm{wd}}+\mathrm{h}_{\mathrm{b}}}+\frac{\Im_{\mathrm{gg}} \sigma}{(\mathrm{k} / \delta)_{w d}+\mathrm{h}_{\mathrm{b}}}\left(\mathrm{T}_{\mathrm{g}}^{4}-\mathrm{T}_{\mathrm{s}}^{4}\right)
$$

A typical thickness for the wet slag deposit calculated elsewhere in this report is of the order of $1.5 \mathrm{~mm}(1 / 16 \mathrm{inch})$.

Because the radiant heat flux depends on the fourth power of temperature, an iterative solution is required to compute the surface temperature from Eq. (9) or Eq. (10).

Finally, to complete the set of equations which govern the heat transfer performance of a radiant air heater, the following boundary condition must be specified at $x=0$ :

$$
\begin{aligned}
& T_{g}(0)=\text { the maximum hot gas temperature } \\
& T_{b}(0)=\text { barrier shield air supply temperature }
\end{aligned}
$$




$$
\begin{aligned}
T_{a}(0) & =\text { air outlet temperature for a counterflow configuration } \\
& =\text { air inlet temperature for a parallel flow configuration. }
\end{aligned}
$$

Integration of the set of governing equations with respect to the length of the radiant air heater, using a numerical procedure which is described below, is performed until a desired air inlet or outlet temperature is computed for the counterflow or parallel flow configurations, respectively.

The numerical procedure used to integrate the set of equations which describe the performance of a radiant air heater is based on known values for the wet or slag deposit layer and the temperature at which the viscosity of the slay is 250 poise. This procedure at each value of $x$, starting at $\mathrm{x}=0$, is as follows:

(1) Compute the radiant air heater surface temperature using Eq. (10).

(2) Compute the heat flux into the radiant air heater using Eq. (8a).

(3) Compute the temperatures at the inner wall, outer wall, and refractory/ash deposit interface using Eqs. (8e), (8d), and (8c), respectively.

(4) Compute the thickness of the dry ash deposit using Eq. (8b).

(5) If the thickness of the dry ash deposit is negative, repeat the above computations without a dry ash deposit, using Eq. (9) to compute the radiant air heater surface temperature in (1).

(6) Compute the temperature gradients in the three fluid streams using Eqs. (5) to (7).

(7) Using a small incremental length, of the order of $3 \mathrm{~cm}(0.1 \mathrm{ft})$, compute the change in the temperatures of the three fluid streams.

(8) Compute the temperatures of the three fluid streams at the end of the incremental length.

\section{Performance Characteristics of a Radiant Air Heater}

The performance characteristics of the radiant air heater depend on the relative orientations or flow directions of the working air stream and the hot gas stream; these two streams can either flow parallel or counter to each other. The values of the parameters which were held fixed for the assessment of the feasibility of the radiant air heater concept are as follows:

Emissivities:

$$
\begin{array}{lll}
\varepsilon_{g} & =0.90 \quad \varepsilon_{g}=0.65
\end{array}
$$


Conductivities (Btu/hr-ft-deg F):
$\mathrm{k}_{\mathrm{wd}} \quad=2.0$
$k_{d d}=2.0$
$k_{\text {rf }} \quad=6.4$
$k_{W}=30.0$

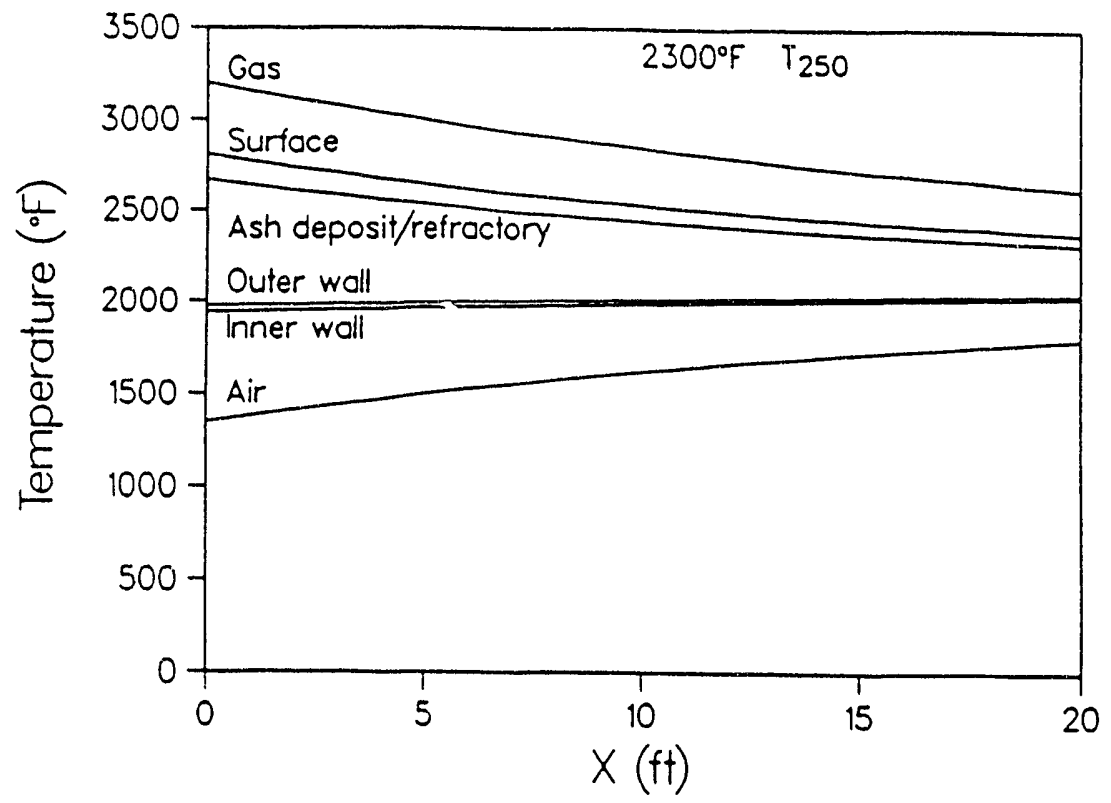

Figure 11. Radiant Air Heater Temperature Proflles: Parallel Flow Configuration

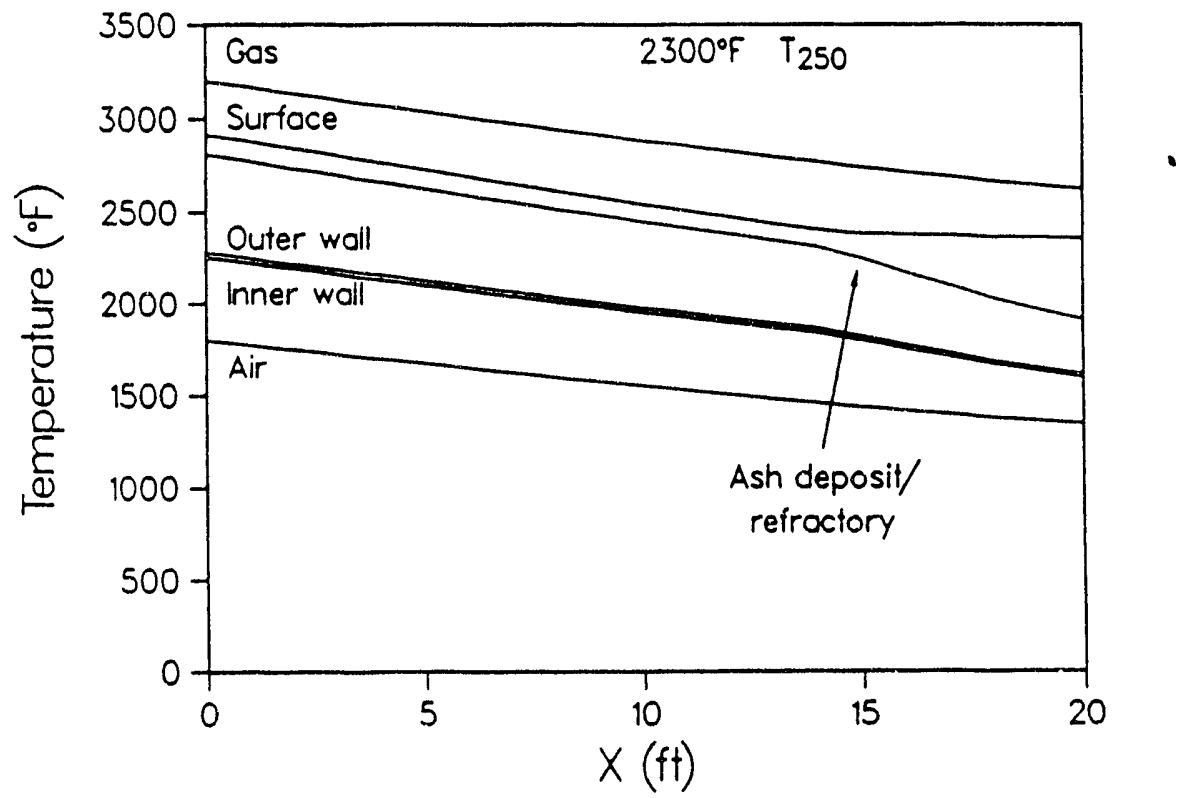

Figure 12. Radiant A1r HEater Temperature Profiles:

Counter Flow Configuration 
29

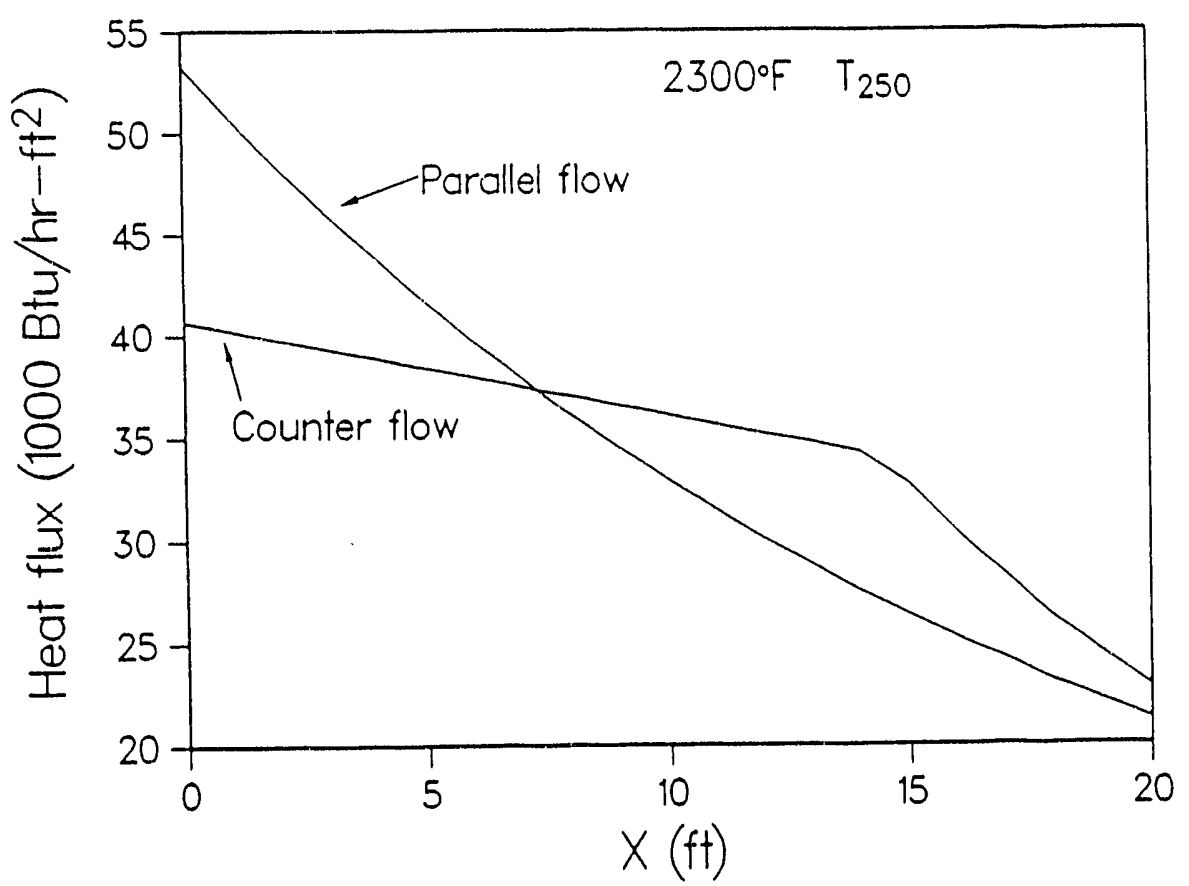

Figure 13. Radiant Air Heater Heat Flux Profiles

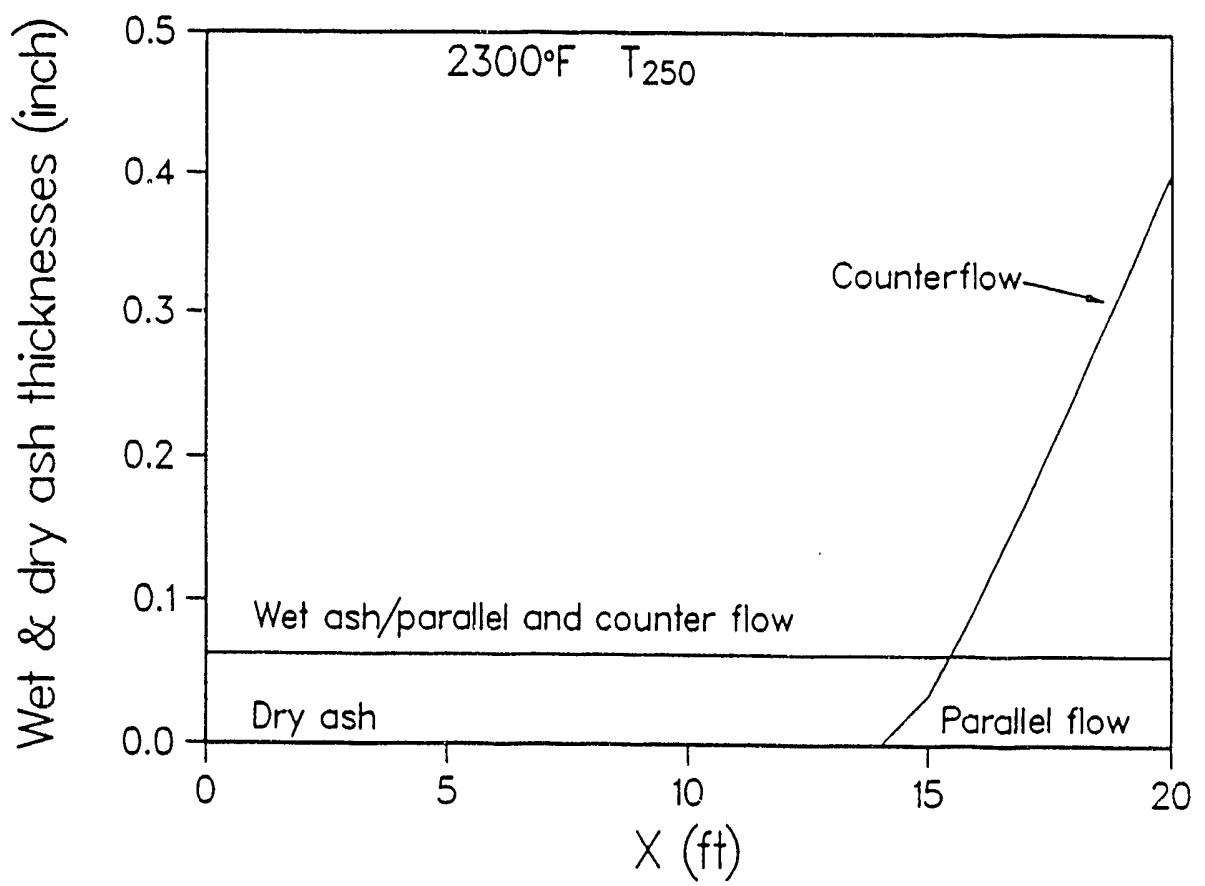

Figure 14. Radiant Air Heater Ash Thickness 


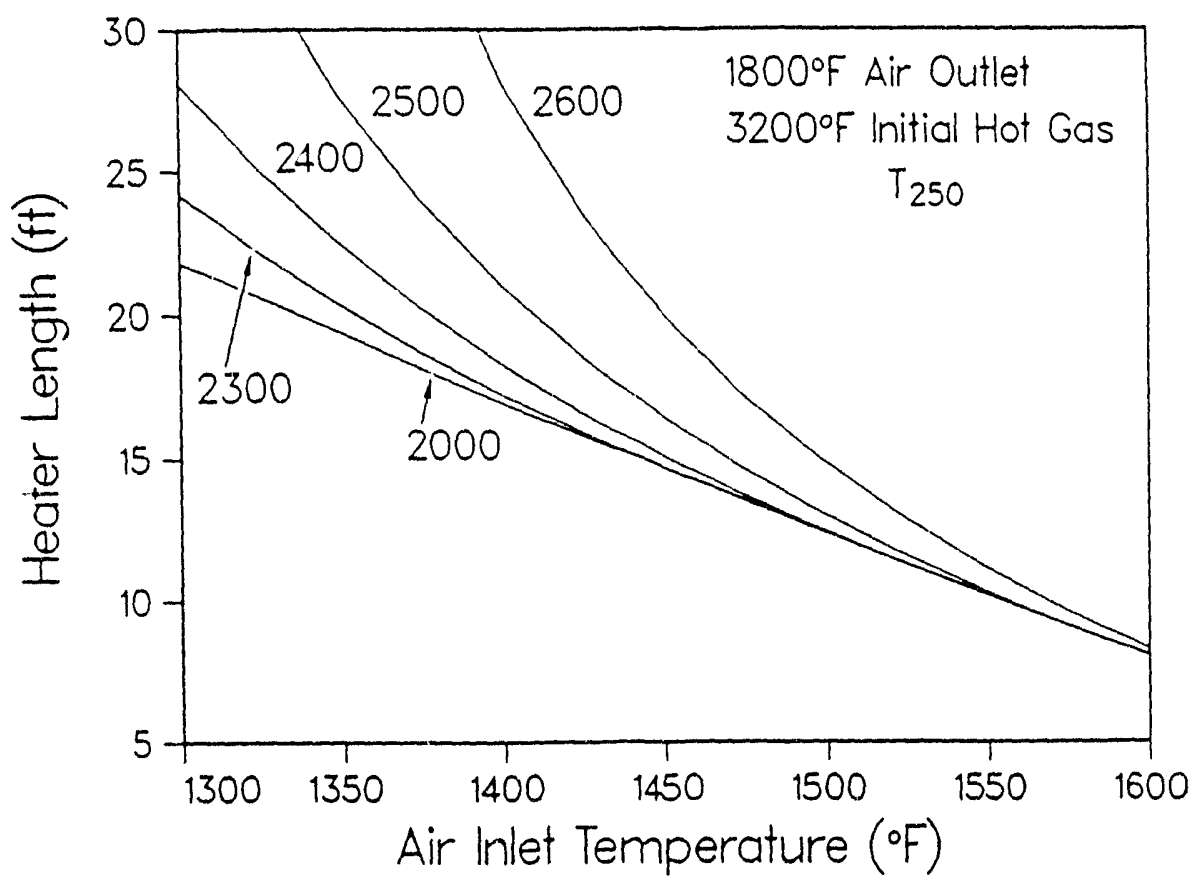

Figure 15, Counterflow Radiant A1r Heater S1ze Dependence on Operating Conditions

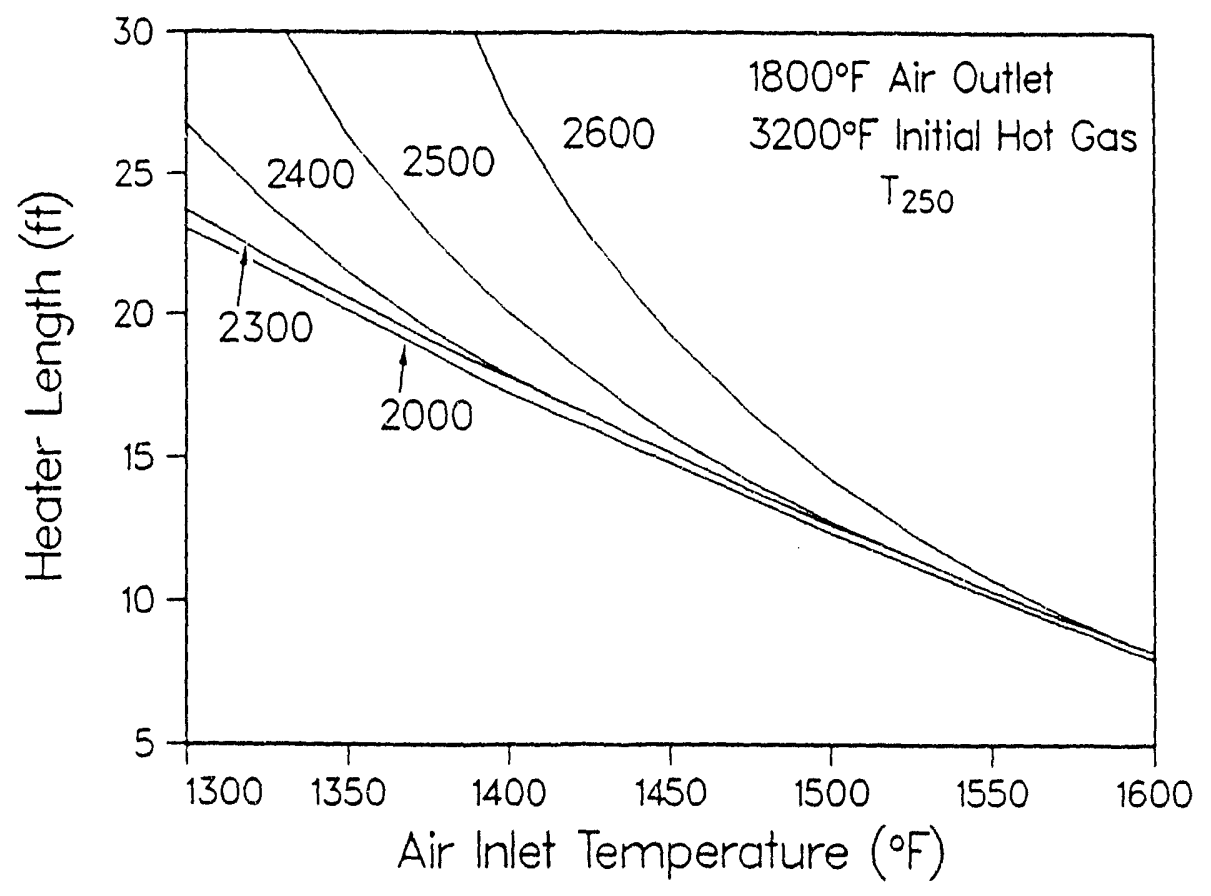

Figure 16. Parallel Flow Radiant Alr Heater Size Dependence on Operating Conditions 


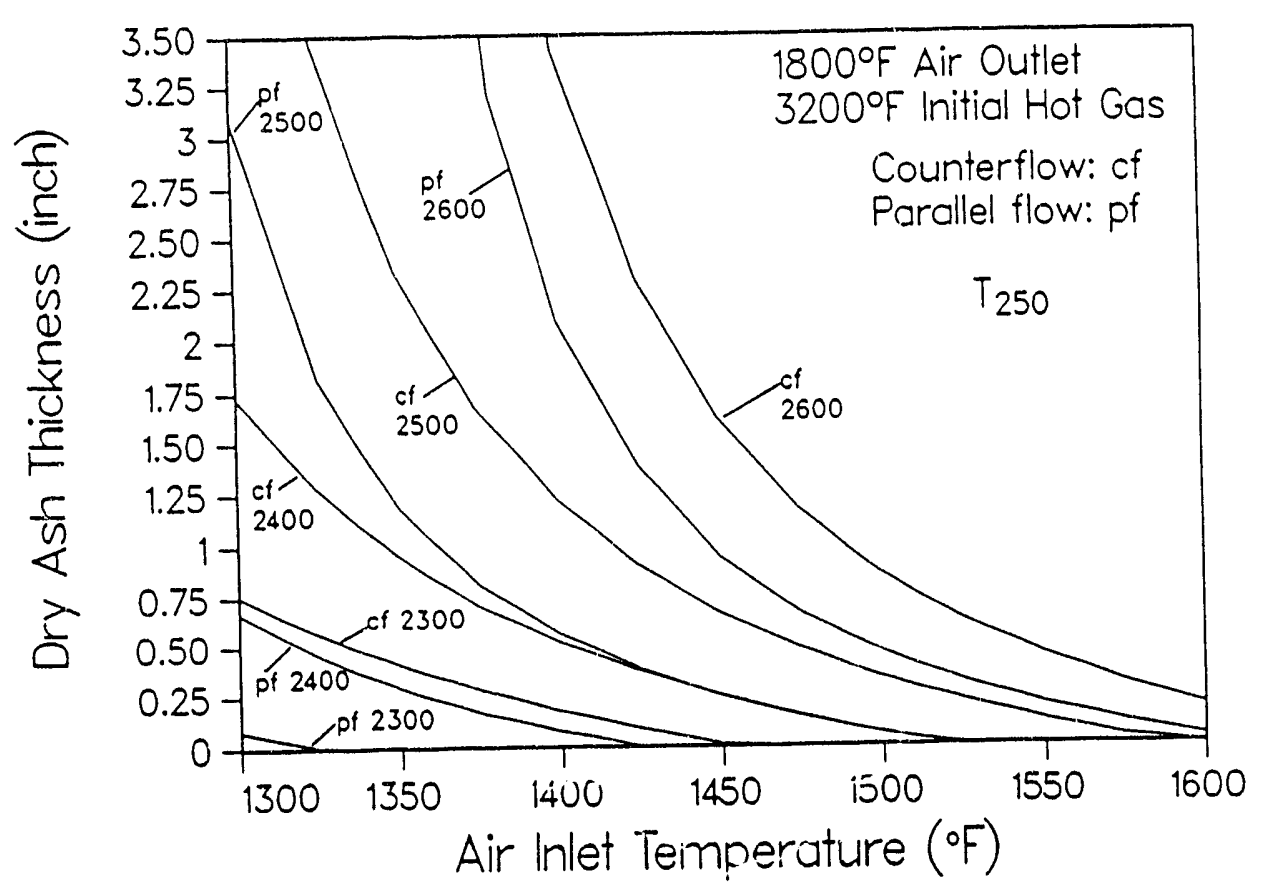

Figure 17. Radiant A1r Heater Dry Ash Th1ckness Dependence on Operating Conditions

Specific Heats (Btu/lb-deg F):

$$
\begin{aligned}
& c_{p, a}=0.271 \quad c_{p, q}=0.285 \\
& c_{p, b}=0.265 \\
& \text { Heat Convection Coefficients }(B t u / h r-f t 2-\operatorname{deg} F):
\end{aligned}
$$

$$
h_{a}=90 . \quad h_{b}=20 .
$$


Dimensions $(f t)$ :

Number of Radiant Air Heaters per Turbine System $=8$

$$
\begin{array}{ll}
R_{g}=6.5 & R_{s}=9.0 \\
\delta_{w}=0.0208 & \delta_{r f}=0.0833 \\
\delta_{w d}=0.00521 &
\end{array}
$$

Flow Rates $(\mathrm{lb} / \mathrm{hr})$ :

$$
\begin{aligned}
& \dot{\mathrm{m}}_{\mathrm{a}}=2.62 \mathrm{E}+6 \\
& \dot{\mathrm{m}}_{\mathrm{b}}=0.88 \mathrm{E}+6
\end{aligned}
$$$$
\dot{\mathrm{m}}_{\mathrm{g}} \quad=1.952 \mathrm{E}+6
$$

Temperatures (deg F):

$$
\begin{aligned}
& \mathrm{T}_{\mathrm{g}}(0)=3200 . \\
& \mathrm{T}_{\mathrm{b}}(0)=1030 .
\end{aligned}
$$$$
\mathrm{T}_{\mathrm{a}}(\mathrm{L})=1800
$$

The use of a barrier air shield to protect the radiant air heater from direct deposition of ash on the heater surface was shown to be impractical. First, since the flow regime of the barrier air could not be maintained laminar over the entire length of the heater, turbulent deposition of ash would still occur on a portion of the heater surface. Moreover, heat convection from the heater surface to the barrier air would represent a large heat loss, which under the best of conditions would reduce the heat flux to the working air by about $50 \%$.

Results of the assessment of the radiant air heater concept are shown in Figs. 11 to 17. A comparison of the performance characteristics of radiant air heaters using the parallel and counter flow configurations, for an air inlet temperature of $1350 \mathrm{deg} F$ and a slag temperature of $2300 \mathrm{deg} F$ at a viscosity of 250 poise, are shown in Figs. 11 to 14 . Interestingly, the lengths of the air heaters for the two flow configurations are essentially the same (i.e. 20 $\mathrm{ft.}$.). But the temperature profiles over the heaters lengths, particularly the structural wall temperatures, are quite different for the two configurations. While the wall temperature for counter flow varies by nearly $700 \mathrm{deg} F$ over the heater length, the variation for parallel flow is less than $100 \mathrm{deg} F$. Thermal stresses for parallel flow will certainly be much less than for counter flow. Low thermal stresses are very desirable for long life of the radiant air heater and particularly for survivability of structural ceramic air passages. The parallel flow configuration is also superior because it serves to keep the temperature of the ash deposit/refractory interface sufficiently high to prevent buildup of a dry ash deposit. When the temperature of this interface falls below the value at which the slag viscosity is 250 poise, dry ash begins to buildup, producing a potentially high thermal resistance. Note that the thickness of the dry ash deposit will remain constant as long as the heat flux and the temperature distribution across the radiant air heater wall are unchanged. 
The variation of radiant air heater size and dry ash thickness as functions of air inlet temperature and slag temperature at a viscosity of 250 poise are shown in Figs. 15 to 17 for the two flow configurations. These figures show that for lower air inlet temperatures, higher heat loads, and higher slag fusion temperatures, the required length of the radiant air heater would be quite large because of substantial buildup of dry ash deposit. While the dry ash thickness for parallel flow is clearly less than for counter flow, significant ash buildup will still occur for the parallel flow configuration with high slag fusion temperatures above about $2500 \mathrm{deg} F$. Thus, the amount of heat exchange by the radiant air heater is dependent on coal properties; specifically, radiant air heater capacity depends on the temperature at which the slag viscosity is sufficiently low for the slag to flow off the heater surface due to gravity. For coals with a high slag fusion temperature, above about 2500 deg $F$, the radiant air heater capacity would have to be less while the convective air heater capacity would be greater. Such a situation is consistent with the aforementioned provision for removal of slag as dry ash between the radiant and convective air heaters.

Task 2.2.2.3. Duct Heater Concept Screening

The objective of this task is to develop the concept for an in-duct gas fired heater which will raise the air temperature from 1800F (the discharge of the air heat exchanger) to $2450 \mathrm{~F}$ which is the temperature required at the turbine inlet for the proposed cycle efficiency. This heater is to have very low pressure loss and produce very low levels of $\mathrm{NO}_{\mathrm{x}}$.

In any combustor, the primary source of $\mathrm{NO}_{\mathrm{x}}$ is thermal NO $\mathrm{x}$, principally by the Zeldovich Mechanism. Because of the strong dependence of ${ }^{x}$ No production on temperature, it is very important that temperatures at any point in the combustion process be kept at minimum levels conducive to the energy release required. This means that the combustor should operate in a lean stoichiometry at all times and at all locations. The key to this is to provide very rapid mixing of the fuel with the oxidizer, thereby reducing local inhomogeneities in the mixture and limiting residence time at these less-than-optimum conditions. Rapid mixing in conventional combustors has usually required very high swirl levels, numerous fuel injectors, resulting in a high pressure loss device. This impacts overall cycle efficiency. Experiments have been performed at UTRC and P\&W Aircraft in advanced combustors which utilize the density gradients present in swirling reacting flow to enhance mixing. This concept is called "Centrifugally-enhanced Mixing". Results have shown that complete mixing of two streams (fuel and oxidizer) can occur in less that two duct diameters, providing that the combustor and fuel injection module are carefully designed. With such rapid mixing, it may be possible to inject fuel (methane or natural gas) into the heated air stream with such efficiency that the stoichiometry of the fuel-air mixture can be kept very lean. This will result in low peak temperatures, and therefore low No production. The advantage of this type of mixer/injector design is that experiments have shown the devices to have very low pressure drop through the combustor. The key items to be examined are the effectiveness of mixing with the injector, and the overall penetration of the fuel-air mixture into the main air flow path. 
Task 2.2.2.4 Coal Delivery

There are three design decisions that influence the requirements of the coal delivery system:

1 The use of air for coal transport. If this is pure air then there are implications for cycle efficiency. An alternative would be to use recycled flue gas for transport.

2 The amount of primary air. Provided a stable flame can be achieved, and there are no limitations for transport requirements since the amount of primary air impacts nitric oxide formation, there are reasons to optimize the percentage of primary air.

3 The coal particle size distribution. The larger particles increase burnout time, and therefore combustor size. The power requirements for grinding are very sensitive to the particle size distribution; thus finer grinds increase the cost of power.

Information that will be generated in Task 3 is required before final design decisions can be made concerning the use of recycled flue gas as a transport medium, the amount of primary "air" and the coal particle size distribution.

Commercial coal grinding equipment will be used for coal preparation. The function of a grinding device obviously is to produce a finer material from a coarser material. There are two types of grinding system. Feeding coarser material and producing a desired fine material at a continuous rate directly from the mill, is termed an "open" grinding circuit. Some grinding machines operate as retention devices; 1.e., t'iere is a holdup of material within the mill, and the grinding time is equal to this toldup weight divided by the feed rate; hence, increasing the feed rate will produce a coarser product. In general, a desired product specification can be achieved in open circuit. However, it can also be achieved by increasing the feed rate to the mills, thereby reducing the grinding time in the mill, and passing the mill product through a size classification device -- a classifier. The classifier separates the mill product into two streams, one a fine product meeting the specification and the coarser product is returned to the mill for regrinding. When a classifier is incorporated into a grinding circuit in this manner the system is termed a "closed" grinding circuit. The closed circuit can produce a grind with a specified top size at a greater rate than the open circuit, but there will be a difference in the size distribution with the higher rate circuit product having less fines. In order to obtain a size distribution with a minimum proportion of fines, the ratio of coarse material returned to the mill to fine product should be high and the classifier device should be efficient. An efficient classifier is one which does not recycle fi.le material for overgrinding. Also, the quantity of product is increased only when a closed circuit is operated to give a product with a steeper size distribution (less fine material) for the same top size. 
Removing fines from the grinding zone can be achieved by

- increasing the solid mass flow rate through the mill and using an external classifier, or by

- sweeping the mill contents with gas, carrying the fines and letting the coarse particles fall back into the grinding action.

The former is external classification; the latter is internal classification. Some devices can only achieve the desired product size distribution by operaing in a closed circuit and the classifier is frequently engineered as an integral part of the grinding machine. Hence the system appears as if it were an "open" circuit when it is in reality closed circuit grinding because an extra piece of machinery gives the classification action. On the other hand, air sweeping alone can give internal classification. This is indirect internal classification incorporating centrifugal action or fluid sweeping.

Air-swept grinding devices have the advantage of simultaneously drying a wet coal feed and grinding. This is achieved by proper design and utilizing heated gases. Convenient air-swept designs require the use of the normal closed circuit grinding system. Figure 18 presents a diagram for a typical air swept system with an integral classifier operating under negative pressure. The main features of such a system are:

- The control of the solid feed rate by the ratio of the mill differential pressure to the sweeping air rate.

- The control of the mill outlet temperature, thereby preventing over drying and potentially hazardous situations.

There is a possible drawback to the use of a closed circuit operation for coal grinding. Most of the fluid being used to convey the coal through the pulverizer and the classifier will exit witi the product stream and the resulting ratio of fluid to solid may or may not be acceptable. Hence there are three modes of operation after the classifier: direct; semi-direct, and indirect. As the name implies, the direct system utilizes the solid-fluid stream coming from the size reduction conduit directly (Figure 19a). Such an approach is simple, low cost and embodies maximum safety when the fluid is heated air. However, the user must accept the quantity and quality of the fluid as it leaves the size reduction circuit. If the quantity of fluid is too much, a semi-direct system can be employed (Figure 19b). The semi-direct system separates the solid from the fluid and then recomlines the solids with a portion of the fluid; the recombined stream is used directly. This is more complex than the direct approach and it introduces a fuither consideration the disposal of the effluent to the environment. The indirect system (Figure 19c) separates the solids from fluid and stores them. The solids are then withdrawn and used directly at a later time. Storage and handling of dry fine coal can be tazardous and appropriate precautions shouuld be taken. 


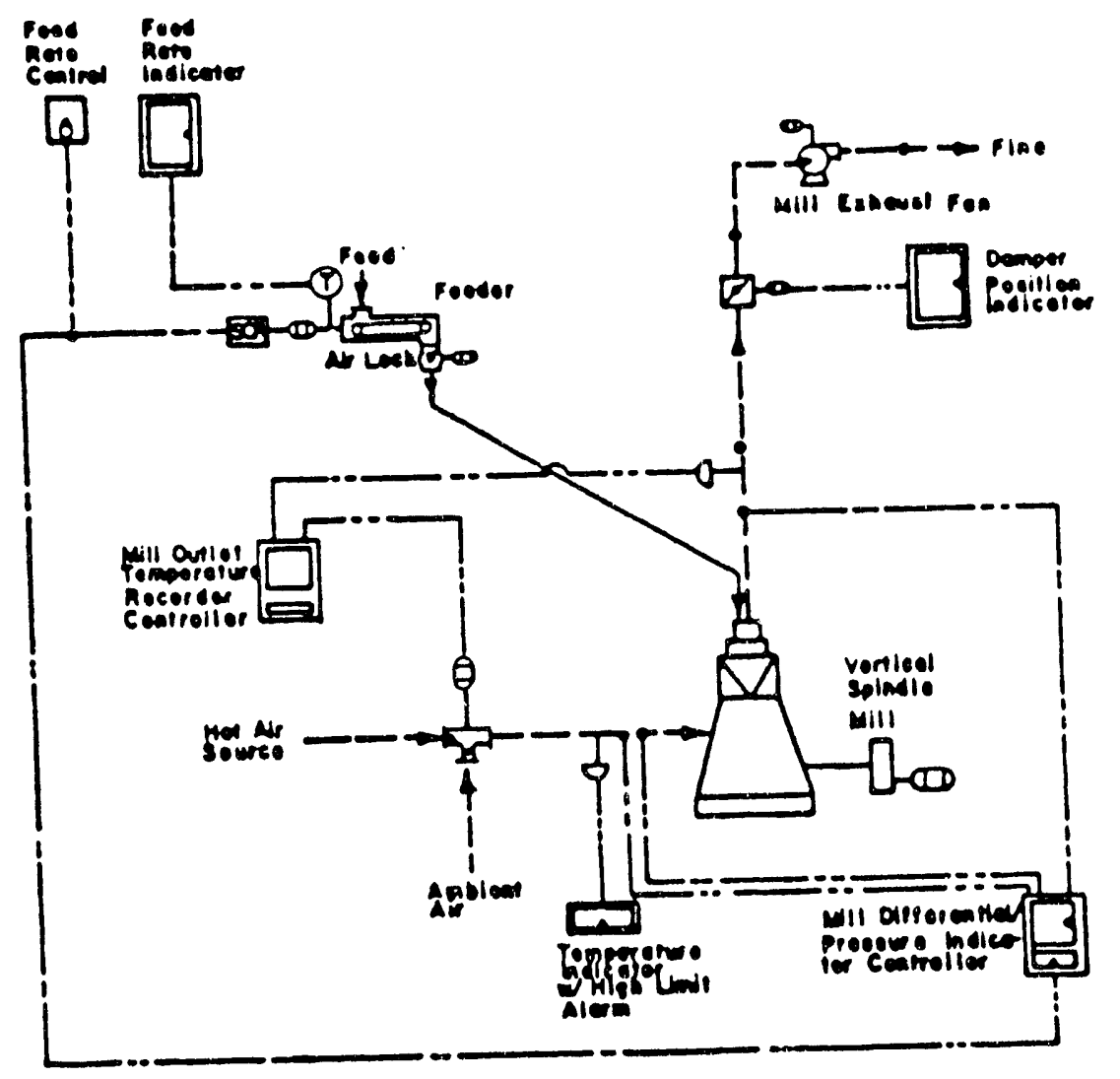

\begin{tabular}{|c|c|}
\hline \multicolumn{2}{|c|}{ LEGEND } \\
\hline & Wolootol Floo \\
\hline & Air Plod \\
\hline & 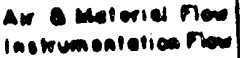 \\
\hline & Proveres Comedin \\
\hline (1) & Techemelor \\
\hline BCa & $\begin{array}{l}\text { Qc. Vonable soos } \\
\text { contrellef }\end{array}$ \\
\hline & Demper \\
\hline
\end{tabular}

Figure 18. A process and instrumentation flow diagram for an air swept vertical spindle mill operating under negative pressure. 


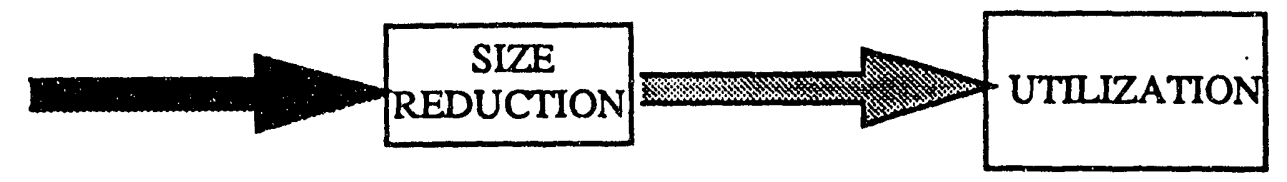

19a. Direct utilization
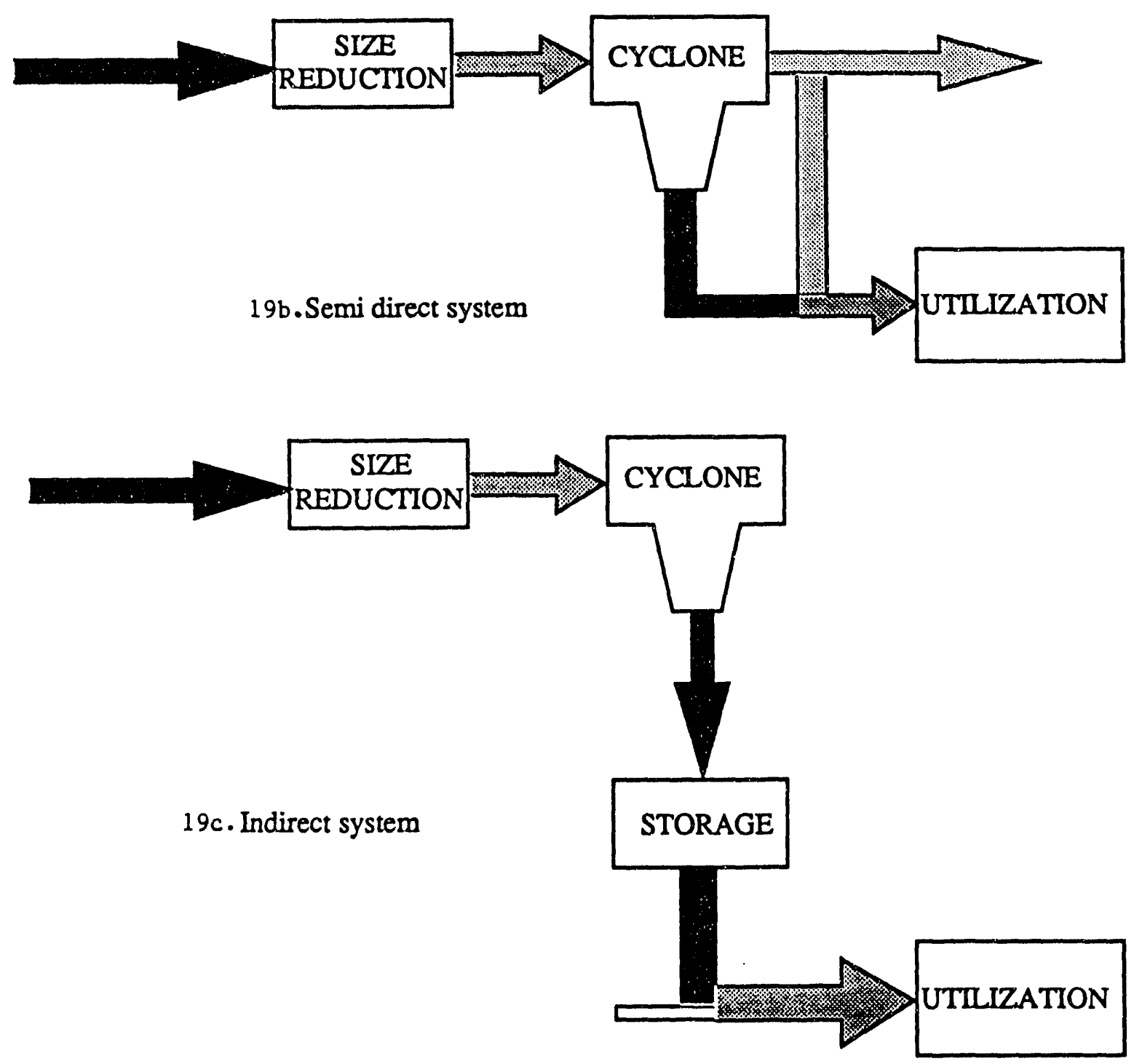

Figure 19. Modes of coal utilization for pulver1zed-coal fired systems 
Task 2.2.2.5 Coal Selection

Although the ultimate goal is utilization of most U.S. coals, it is prudent to begin with a limited range and expand this as both ash research and the HITAF design progress. The goal of burning a wide range of coals can be met by careful design of the combustor and by selective use of cleaning or additives. In this section, preliminary criteria for selection of coals for HITAF is discussed.

In p.c. boilers, coals are currently selected on the basis of several criteria including higher heating value, Hardgrove grindability, percent moisture, percent volatiles, percent ash, percent sulfur, and ash fusion temperatures. For Western coals, percent alkali may be added to the $11 \mathrm{st}$. Unfortunately, these criteria do not begin to address the particulate nature of deposit initiation, and as such, are insufficient for the proper development of a HITAF system.

Percent ash is useful only in assessing the quantity of ash that will need collection and disposal; it does not address the issues of deposition propensity or corrosion. Percent sulfur is a rough indicator of the pyrite level of coals, but provides no information as to whether pyrite is included and hence prone to form corrosive iron aluminosilicates, or excluded with the potential for deposition of iron oxysulfides within the combustor. Ash fusion temperatures help define the temperature at which a slag layer will flow, but provide no information as to whether that layer will be comprised of all the ash constituents contained within a coal. Each individual ash particle formed during the combustion process will have a viscosity-temperature relationship that differs, sometimes by hundreds of degrees, from the bulk viscosity-temperature relationship as expressed by the ash fusion temperature.

Results from recent PSIT and UNDEERC efforts have suggested other, more specific ash conditions which must be avoided for successful combustor and HITAF operation. These include formation of high levels of alkali vapor which can propagate downstream to the air heater, deposition of excluded pyrite particles on the wall of the combustor, and formation and deposition of corrosive iron-rich aluminosilicate particles and slags. Formation of calcium-rich aluminosilicate ash particles must also be avoided wherever possible, as these tend to deposit on surfaces over a wide range of conditions, as reported in recent work at both PSIT and UNDEERC (Zygarlicke et al., 1990; Boni et al., 1990). These results indicate that calcium-rich aluminosilicate formation must be avoided if particles impact wall surfaces after combustion, while pyrite oxidation must be accelerated if particles inpact wall surfaces at the early stages of combustion.

Considerations specific to the HITAF are related to the use of a ceramic heat exchanger. The literature on corrosion of ceramics, particularly silicon carbide, provides some guidance as to coal selection issues. These issues are discussed in more detail under Task 2.2.2.7 but the key points can be summarized as follows. Extensive corrosion of silicon carbide by coal slag has been observed at temperatures of $1200^{\circ} \mathrm{C}\left(2192^{\circ} \mathrm{F}\right)$ or greater (Ferber and Tennery, 1982; Easler et al., 1985). Basic slags with low 
silica contents and high iron and calcium contents have been identified as the most corrosive. Acid slags with silica contents of 40 to $50 \%$, on the other hand, have shown no corrosion of silicon carbide at temperatures up to $1250^{\circ} \mathrm{C}\left(2282^{\circ} \mathrm{F}\right)$.

Details of the corrosion of silicon carbide by slag, in particular dependence on slag composition, are not known. The preliminary specification, therefore, will exclude coals whose ash is extremely basic. As part of Phase I, the effect of ash composition on silicon carbide at high temperatures will be explored.

Corrosion of the silicon carbide by alkali vapors has been well documented in the literature. Experiments have been conducted under more severe conditions than expected in a coal combustion system, however. At this point, it is not possible to define a clear specification for sodium in coal. The ratio of sodium to silica in the coal ash will be used as a preliminary specification until further testing is conducted in Phase I.

Based upon these observations, the ash management issues that affect coal selection can be summarized as follows:

1. Avoid deposition of molten extraneous pyrite in the combustor

2. Avoid formation of low silica slags with very low viscosities

3. Minimize generation of alkali vapors, or at the least, propagation of alkali vapors to the ceramic surfaces of the HITAF system.

Clearly, coals which avoid the above three problems will be easier to work with in the initial stages of the program, enabling HITAF design and materials development to proceed as required. In the later stages, coal preparation, as described below, and HITAF aerodynamic modifications will be employed to expand this range. Some knowledge of ash particle size and composition as well as alkali vapor release potential is therefore essential to the coal selection task.

In Phase I of this program, CQ, Inc. will assist PSIT and UNDEERC in coal selection. Based on preliminary selection criteria, CQ Inc. will identify at least 6 to 8 coals (but not more than 15) that meet these criteria. From this list PSIT and UNDEERC will choose four coals for experiments in Phase I of the program and CQ Inc. will choose two to four coals for a coal cleaning study.

The coals chosen should be significant from the end user's point of view in that such coals will have large reserves. At this stage, lignites will not be considered. The combustion behavior of lignites is substantially different from bituminous coals and this usually implies a different combustor design. Restricting the search to bituminous and subbituminous coals includes almost all the important U.S. reserves. In addition to 
large reserves, one or more of the coals should meet acid rain emission levels unscrubbed (i.e., a compliance coal). Because of the corrosive nature of low silica ash, the base-to-acid ratio of the coal will be restricted. The criteria are as follows.

1. No lignites will be considered. Out of the six to eight coals, there should be at least three bituminous coals and two western coals.

2. Coal must have "large" reserves and "major" annual production to be quantified by $C Q$ Inc. (e.g., "large" mighi mean 20-yr life expectancy for the mine).

3. At least two compliance coals (for sulfur); one compliance coal should be bituminous.

4. Three to four of the coals should be coals for which PSIT and/or UNDEERC have CCSEM data.

5. The base-to-acid ratio should be less than 1.0 and the sodium oxide to-silica ratio should be less than 0.15 . Base-to-acid ratio defined as:

$$
\mathrm{b} / \mathrm{a}=\left[\mathrm{CaO}+\mathrm{MgO}+\mathrm{Fe}_{2} \mathrm{O}_{3}+\mathrm{K} 2 \mathrm{O}+\mathrm{Na} 2 \mathrm{O}\right] /\left[\mathrm{SiO}_{2}+\mathrm{Al}_{2} \mathrm{O}_{3}+\mathrm{TiO}_{2}\right] .
$$

For each of the coals identified, the following information will be supplied to PSIT:

Ultimate and proximate analysis

ASTM ash analysis, including ash fusion temperature and T250

Trace element composition

Reserves

Grindability

Approximate cost to clean (in terms of high, medium, or low) to three different ash levels: $20 \%, 10 \%$, and $5 \%$.

Based on the results of Task 2.2.2.4, PSIT and CO Inc. will select four coals for further study in Task 3.

\section{Task 2.2.2.6 Coal Cleaning Evaluation}

The important parameters for conventional coal cleaning are heating value, ash fusion temperature, ash reduction, and $\mathrm{S} 02$ emissions. In addition, the cost of cleaning coal must be weighed against the improved combustion or emission characteristics. Since the HITAF is not a conventional pulverized coal combustor, the desired cleaned product may differ from the 
conventional product. As the combustor design and ash management strategies become more clearly defined, the coal cleaning requirements will become more specific. At this time, some of the key considerations in making the decision to clean coals will be discussed.

In this coal cleaning study, the following processes will be considered. Heavy-media and water-only cyclones will separate coal (with a specific gravity of about 1.25) from mineral fragments (with specific gravity of greater than 2). Froth flotation will be used to recover energy from the coal fines. The variables that affect the cost and energy recovery are crushed and topsize, cyclone geometry heavy media specific gravity, and additives used in the flotation process.

One of five coal-cleaning process flow sheets will be evaluated by $C Q$ Inc. for each coal. The choice of flow sheet will depend on the coal size.

1. Coarse jig plant in which fines are scalped of $f$

2. Jig plus water-only cyclone

3. Heavy media vessel plus heavy media cyclones

4. Jig followed by water-only cyclone and froth flotation circuit

5. Heavy medial vessel, heavy media cyclones, plus froth flotation circuit.

PSIT and CQ Inc will select conventional coal cleaning processes for consideration based on the cleanability definition which PSIT will supply in terms of a) total ash reduction, b) energy recovery, and c) decrease in detrimental ash constituents. CQ Inc will assess the cleanability and costs of cleaning the specified coals and provide the following information:

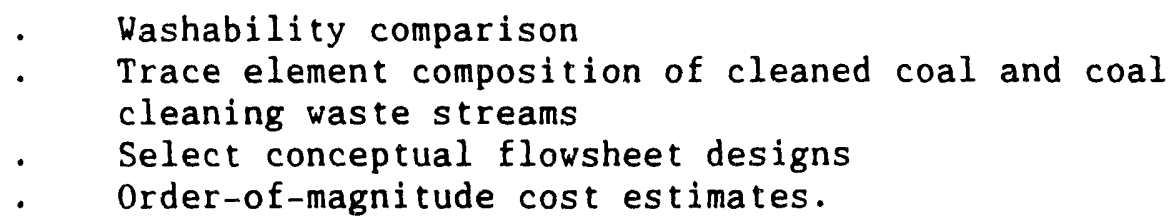

Task 2.2.2.7 Ash Management

Overview

Understanding and controlling ash to prevent deposition and corrosion is even more critical to success of the HITAF than in conventional pulverized coal (p.c.) systems. Higher temperature combustors and heat exchangers, particularly when constructed of ceramic materials, may be more vulnerable to catastrophic damage by deposition and/or erosion than the metal components traditionally used. Furthermore, corrosion of ceramic surfaces by vapor-phase alkali species may pose a significant problem. 
The overall goals of ash management in the HITAF are to allow high availability of the power generation system and to permit the use of as wide a range of coals as possible. The former goal can be translated into specific directions, i.e., continuously remove ash without a significant pressure drop in the combustor and heat transfer sections and without extensive corrosion/erosion of materials of construction. The use of a wide range of coals implies an understanding of the interactions of the components of coal ash with the combustor and heat exchanger materials. This understanding will be refined during Phase $I$ of this program. The following section discusses the interactions between silicon carbide materials and the various components in the high temperature, oxidizing environments expected in the HITAF. The framework for ash removal in the combustor and heat transfer surfaces is then presented.

Summary of Slag Ceramic Interactions in Silicon Carbide

There are three basic types of silfcon carbide available: Siliconized or reaction bonded; Sintered SiC (usually $\alpha-S i C$ ); CVD Sic. Experiments on the effect of temperature and environment on Sic corrosion fall into one of three categories. Fundamental studies of the behavior of SiC in oxidizing environments have been carried out (e.g., Fergus and Worrell, 1990; Kim and Moorhead, 1990; Tressler, 1990). Tests of exposure to alkali salts (halides and sulfides) have been extensive (e.g., Butt et al., 1989; Fox et al., 1990; Federer, 1990). A lesser number of tests have been conducted on the interactions between coal slag and silicon carbide (Ferber and Tennery, 1981; Ferber and Tennery, 1982; Easler et al. 1985).

The mechanism for passive oxidation is the formation of a layer of amorphous $\mathrm{SiO}_{2}$; reaction occurs at the SiC-SiO2 interface (Fergus and Worrell, 1990). The rate-limiting step is the diffusion of $0_{2}$ through the layer at temperatures below $1400^{\circ} \mathrm{C}\left(2550^{\circ} \mathrm{F}\right)$. Active oxidation (formation of SiO) occurs at oxygen partial pressures less than about 0.1 torr (Kim and Moorhead, 1990). The important mechanisms for strength reduction below $1400 \mathrm{C}$ are surface flaw generation, slow crack growth, and creep (Tressler, 1990).

Siliconized silicon carbide does not show clear evidence for strength degradation by slow crack growth. One hypothesis is that the free silicon phase undergoes plastic deformation which can blunt flaws. Studies of creep behavior show two regimes of behavior: dislocation motion or diffusion and creep cavitation. Nucleation sites for cavities have been associated with iron impurities in the SiC regions. Siliconized silicon carbide contains a substantial amount of free silicon metal and sometimes iron inclusions. The silicon phase may be good at blunting cracks, improving the high temperature strength up to the melting point of silicon metal at $1410^{\circ} \mathrm{C}\left(2570^{\circ} \mathrm{F}\right)$. However, softening or melting of the free silicon phase will cause the material to lose strength and to creep at these temperatures. 
Sintered $:-5 i C$ contains some free boron and carbon and possibly other sintering aids. Small amounts of $B(0.5 \mathrm{wt} \%)$ do not affect the oxidation rate (Fergus and Worrell, 1990). For sintered $\alpha$-SiC, slow crack growth depends on the nature of the grain boundary phases and composition and their interaction with the environment. The creep behavior of this material in oxidizing environments has not been studied.

Alkali attack has been studied in the burner rig and thin film studies of Fox and coworkers (Fox et al., 1990). In these tests, material was exposed to sodium sulfate at $1000^{\circ} \mathrm{C}\left(1832^{\circ} \mathrm{F}\right)$ and $4 \mathrm{~atm}$ total pressure. Burner rig studies exposed samples to $2 \mathrm{ppm} \mathrm{Na}$. After $40 \mathrm{hr}$, a $50 \%$ strength reduction was noted for siliconized SiC and only $30 \%$ for sintered SiC. The hypothesis was that the free silicon was attacked more readily than SiC, resulting in a higher corrosion rate.

Butt et al. (1989) exposed siliconized SiC and $\alpha$-SiC in a burner facility in which sodium silicate was injected into the burner. Volatile and particulate sodium was delivered to the samples at a velocity of $30 \mathrm{~m} / \mathrm{s}$. The temperature of the samples was $960^{\circ} \mathrm{C}\left(1760^{\circ} \mathrm{F}\right)$ and exposure times were 243 to $373 \mathrm{hr}$. Both sintered $\alpha-S i C$ and siliconized SiC showed strength reductions and visual analysis showed that failures were of ten from large surface pits. For sintered $\alpha$-SiC, the loss of strength was greater than $50 \%$ while for siliconized SiC, the strength loss was in the range of $25 \%$ to 45\% (Figure 20). The thickness of the tubular samples was reduced by a maximum of $10 \%$ for sintered à- SiC and $20 \%$ for siliconized SiC. For sintered $\alpha-S i C$, the grain boundaries were attacked preferentially, while for siliconized $\mathrm{SiC}$, the silicon matrix was oxidized rapidly.

Federer (1990) studied various materials under aluminum remelt or steel soaking conditions. These environments are characterized by very high concentrations of vapor phase alkali and halides species. Note that these conditions are more severe than would be encountered when burning coal in the HITAF. All silicon carbides studied had high surface recession rates. Corrosion was characterized by a glassy layer containing gas bubbles.

Price and van Roode (1990) exposed coated and uncoated tubes silicon carbide to an aluminum remelting flue gas at $760^{\circ}$ to $1204^{\circ} \mathrm{C}$. The uncoated specimens of siliconized $\mathrm{SiC}$ and $\alpha$-SiC had high surface recession rates that decreased as temperature increased and were maximum (approximately 4 $\mathrm{mm} / \mathrm{yr}$ ) at $760^{\circ}$ to $820^{\circ} \mathrm{C}$. Figure 21 shows the surface recession rates for coated and uncoated sintered $\alpha$-SiC. Reaction of SiC with vapor-phase alkali species is only important at temperatures below $1000^{\circ} \mathrm{C}\left(1800^{\circ} \mathrm{F}\right)$; below this temperature, condensed alkali salts can form on the substrate surface, but above this, the alkali species prefer the vapor phase. 


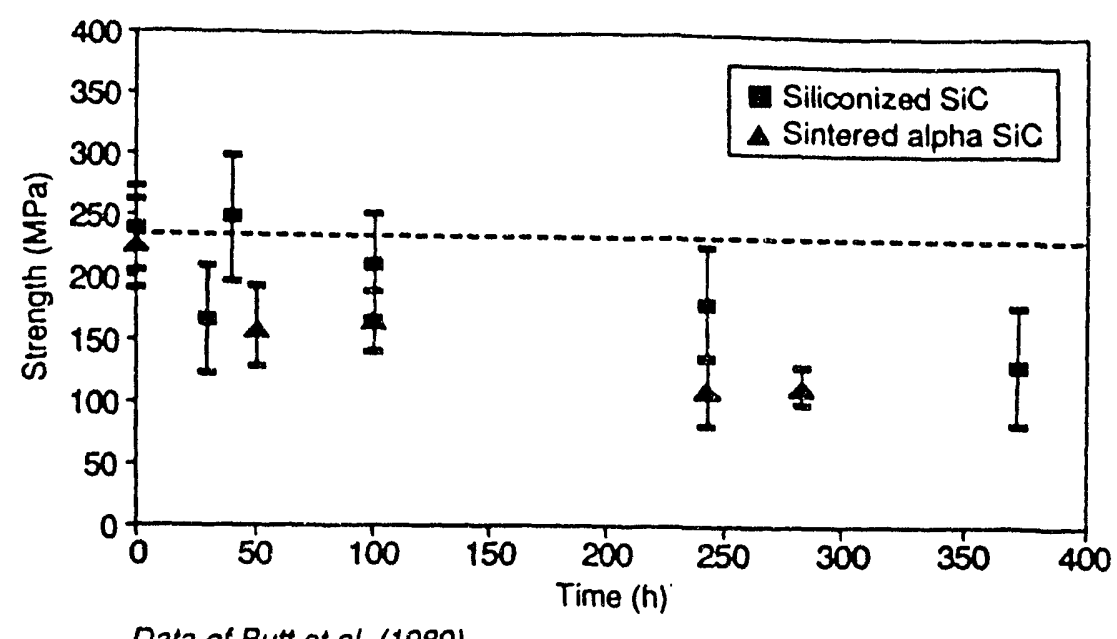

Data of Butt et al. (1989)

C.1288

Figure 20. Sirength of silicon carbide as a function of time exposed to sodium silicate at $960^{\circ} \mathrm{C}$

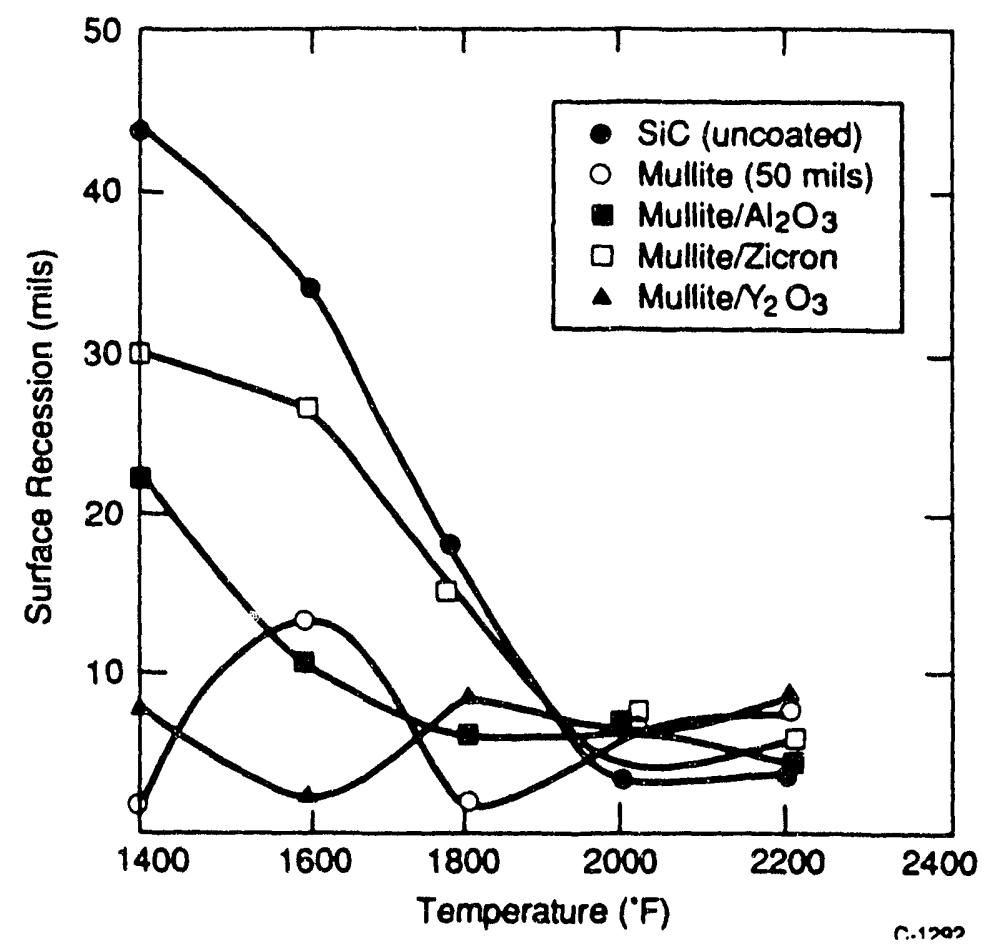

Figure 21. Surface recession rate of coated and uncoated sintered $\alpha-\mathrm{SiC}$ tubes as a function of temperature over $2000 \mathrm{hr}$ (Source: Price and van Roode, 1990).

Ferber and Tennery $(1981,1982)$ exposed various types of silicon carbide to coal ash for 250 to $500 \mathrm{hr}$. The tube temperature was approximately $1200^{\circ} \mathrm{C}$ $\left(2192^{\circ} \mathrm{F}\right)$. Both acidic (high silica) and basic (low silica/high calcium) ash were generated. For acidic slag (Ferber and Tennery, 1981), there was no appreciable change in the microstructure of sintered $\mathrm{SiC}$ as a result of 
the exposure. Negligible change in room temperature tensile strength was observed. Siliconized SiC was also relatively stable with respect to acidic slag in a 500-hr test. Localized corrosion was observed characterized by small pits containing glass. The corrosion seemed to occur preferentially at iron-rich inclusions. A slight increase in the room temperature tensile strer $\xi_{\text {th }}$ was attributed to crack blunting by formation of a glassy materia. out of the silicon phase.

After exposure to basic ash for $250 \mathrm{hr}$, tube thinning due to corrosion was noted for all silicon carbide tubes. The silica content of the slag increased as a result of the exposure due to dissolution of silicon carbide in the slag. Inclusions of metal silicides ( $\mathrm{FeSi}_{2}, \mathrm{NiSi}{ }_{2}$ ) were observed in the slag near the silicon carbide interface. Transport of iron silicide inclusions from the silicon carbide interface to the bulk slag represents a mechanism for accelerated corrosion. No significant decrease in room temperature strength was noted for $\alpha-S i C$ or CVD SiC as a result of the exposure. Siliconized silicon carbide, on the other hand, show strength uecreases of 15 to $60 \%$. The silica content of the slag at the end of the experiment was higher than the silica content of the coal ash. This illustrates the tendency for low silica slags to dissolve silicon carbide.

Samples of sintered $\alpha$-SiC from Sohio were coated with two different kinds of ash, "acidic" and "basic", and exposed to air or a gasification-type mixture at $1100^{\circ}$ to $1250^{\circ} \mathrm{C}\left(2012^{\circ}\right.$ to $\left.2282^{\circ} \mathrm{F}\right)$ in experiments by Easler et al. (1985). The weight change and fracture stress of the materials were measured after exposure. As a control, samples were exposed without being coated with ash. Exposure times were $200 \mathrm{hr}$. The samples in contact with acidic slag or no slag showed modest weight gains, but did not show evidence of corrosion products other than a silica layer. The acidic slag only melted at the highest temperature of $1250^{\circ} \mathrm{C}\left(2282^{\circ} \mathrm{F}\right)$. The basic slag-coated samples also showed a weight increase at lower temperatures (consistent with the formation of a silica scale), but at $1250^{\circ} \mathrm{C}\left(2282^{\circ} \mathrm{F}\right)$, these had a very large weight loss. At the highest temperatures, corrosion in the presence of basic slag dominated the SiC-slag interaction while at the lower temperatures, passive oxidation was more important. The reaction products from the basic slag experiments showed evidence of iron silicides as noted also by Ferber and Tennery (1982). The fracture stress of the samples after exposure to air at $1250^{\circ} \mathrm{C}\left(2282^{\circ} \mathrm{F}\right)$ was measured. In all cases, the fracture stress increased after exposure to the hot gases. After no slag or acidic slag, the strength increased by about $25 \%$, while exposure to basic slag only increased the strength by $8 \%$. The hypothesis was that the strength increase was due to crack blunting. No significant corrosion was observed below $1250^{\circ} \mathrm{C}\left(2282^{\circ} \mathrm{F}\right)$ for acidic and basic slags, but the basic slag corroded the substrate considerably at $1250^{\circ} \mathrm{C}\left(2282^{\circ} \mathrm{F}\right)$.

CVD silicon carbide has not been tested as extensively because it is not as widely available as the other types. In the slag corrosion tests of Ferber and Tennery, CVD SiC showed little strength decrease or changes in microstructure in contact with acidic slag; however, basic slag produced significant decreases in room temperature strength. 
In summary, the corrosion literature is not particularly complete for silicon carbide in salt or ash-laden environments. Sintered $\alpha$-Sic has performed better than siliconized SiC in sodium sulfate corrosion tests. In the work by Ferber and Tennery $(1981,1982)$, sintered silicon carbide showed negligible decreases in room temperature strength as a result of exposure to acidic and basic slag. Easler and coworkers demonstrated increases in the strength of sintered SiC after exposure to coal ash.

Ferber and Tennery (1981) saw a slight increase in the strength of a siliconized SiC tube exposed to acidic coal slag at a tube temperature of $1200^{\circ} \mathrm{C}\left(2192^{\circ} \mathrm{F}\right)$. Exposure to basic coal slag, however, resulted in strength decreases as large as $60 \%$. In exposure to sodium sulfate, siliconized silicon carbide showed larger strength losses than sintered silicon carbide (Fox et al., 1990), possibly due to free silicon. The iron impurities have been linked to creep cavitation and corrosive attack by acidic slag.

Coatings have not been fully explored as yet, but the work of Solar Turbines is encouraging. Price and van Roode (1990) exposed coated and uncoated tubes to an aluminum remelting flue gas at $760^{\circ}$ to $1204^{\circ} \mathrm{C}$. Both coated siliconized SiC and coated sintered SiC had surface recession rates of approximately 1 to $2 \mathrm{~mm} / \mathrm{yr}$ over the temperature range (as compared to up to $4 \mathrm{~mm} / \mathrm{yr}$ with uncoated samples). The best coatings were mullite with a glassy coating, graded mullite-alumina, and graded mullite-yttria. Coatings survived better on siliconized SiC than on sintered SiC. No coated sample survived exposure at $1204^{\circ} \mathrm{C}$. Coatings will be particularly useful at temperatures of $750^{\circ}$ to $1000^{\circ} \mathrm{C}\left(1400^{\circ}\right.$ to $\left.1800^{\circ} \mathrm{F}\right)$ where a].kali at tack can occur. The use of graded mullite coatings to match thermal expansion should be explored.

Since we are concerned about attack of silicon carbide by vapor-phase alkali species, we will focus our attention on the material temperature range $750^{\circ}$ to $1000^{\circ} \mathrm{C}\left(1400^{\circ}\right.$ to $\left.1800^{\circ} \mathrm{F}\right)$. On the other hand, since molten slag is also our concern (i.e., in the radiant air heater), probably higher temperatures which will produce more corrosion must also be studied. The data of Easler et al. (1985) show that slag corrosion gets worse as temperature increases. At temperatures up to $1250^{\circ} \mathrm{C}(2282)$, an acidic ash did not produce noticeable corrosion or loss of strength over 200 to $500 \mathrm{hr}$ (Ferber and Tennery, 1981; Easler et al., 1985). Basic (i.e., low silica) slag, however, reacted extensively with silicon carbide at temperatures above $1200^{\circ} \mathrm{C}\left(2192^{\circ} \mathrm{F}\right)$. For the radiant air heater, sintered $\alpha-\mathrm{SiC}$ seems to the better choice of material based on ORNL work.

Some major gaps in existing knowledge are:

High temperature creep behavior of CVD and $\alpha-S i C$ in oxidizing environments

Temperature and compositional dependence of slag corrosion. The effect of iron versus calcium on corrosion in low silica slags. 
The extent of corrosion of vapor-phase alkali under realistic coal combustion conditions.

Protection from molten slag by mullite or other oxide coatings.

Ash Deposition and Removal

Schematics of the HITAF systems for all the coal cases and with supplemental natural gas burning are provided in Figures 22 and 23 . In this report, the effects of ash deposition and strategies for ash removal will be considered for three critical regions of the HITAF system - the radiant air heater, the impaction section, and the convective air heater. Ash deposition in the radiant furnace and its effect on heat transfer will be described first.

\section{Ash Deposition Estimates in the Radiant Section of HITAF}

Ash transport to heat transfer surfaces can occur by several mechanisms: Brownian diffusion, turbulent or eddy diffusion, thermophoresis, vapor condensation and inertial impaction. The dominant transport mechanism for flow parallel to the walls under the conditions of the HITAF is by turbulent diffusion. For particle-laden flow across heat transfer tube banks, inertial impaction must be considered. The contribution of all other deposition mechanisms is comparatively minor in both the convective and radiant sections of the HITAF.

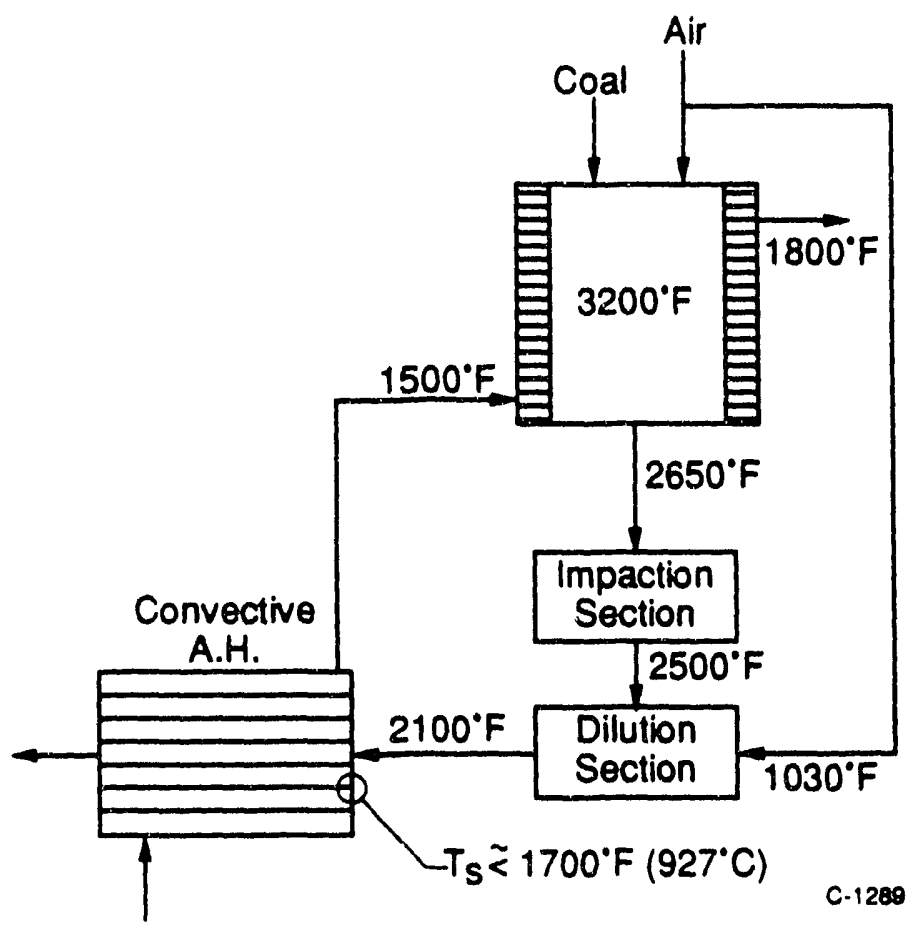

Figure 22. Ash management modules for Duct Burner case 


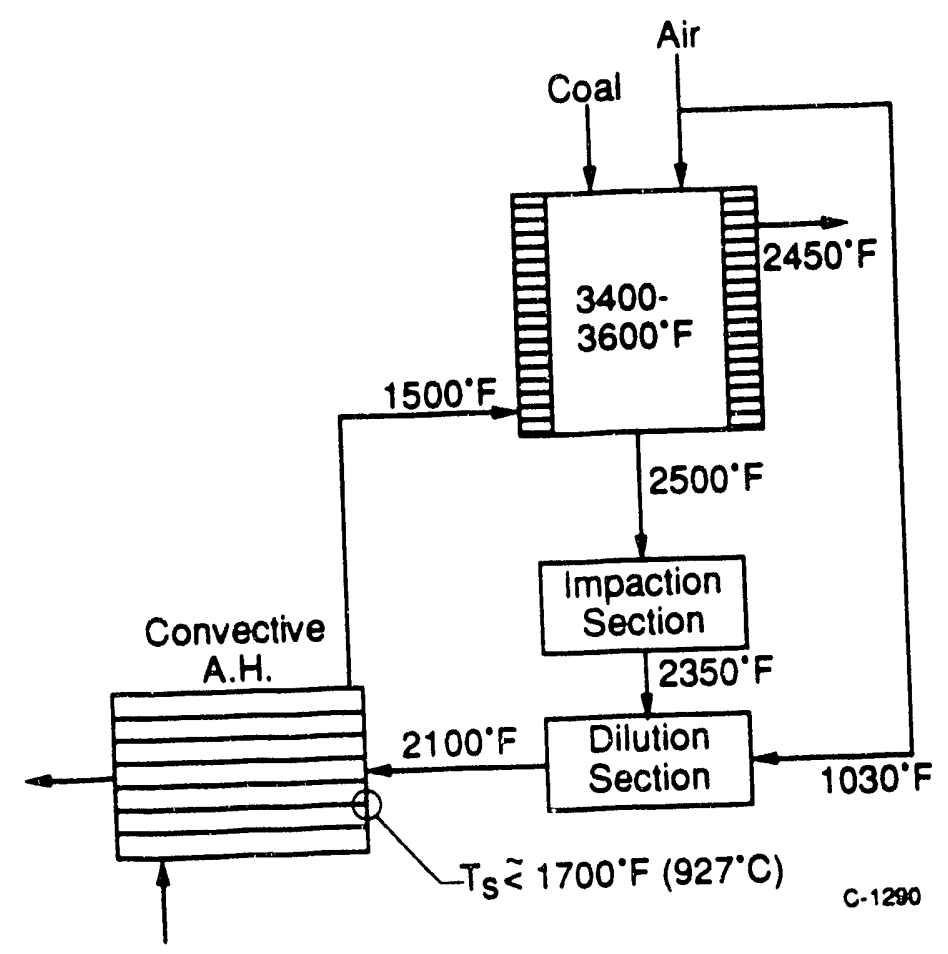

Figure 23. Ash management modules for All Coal case

Ash buildup in the radiant air heater section is considered first. Assuming the flow to be turbulent and all particles to follow the turbulent fluctuations (i.e., no size dependency of a particle's ability to follow turbulent eddies), the mass flux of ash to the wall is

$$
m_{A}=\rho^{\prime} u^{\prime} \mathbf{f A}
$$

where $\rho^{\prime}$ and $u^{\prime}$ are turbulent fluctuation intensities in gas density and velocity respectively and "As the mass fraction of ash in the gas flow. Estimates for the turbulent ${ }^{A}$ fluctuations as a fraction of the mean flows vary from 0.01 to a maximum value of 0.15 . Denoting this fraction as $\varepsilon_{0}$, we rewrite $m_{A}$ as

$$
m_{A}=\varepsilon_{0}^{2}\left(\rho u f_{A}\right) .
$$


The above qquation states that the turbulent flux of ash particles to the wall is $\varepsilon$ times the axial flux of ash in the main flow. For the case where he turbulent fluctuation is $4 \%$ of the mean value, the ash flux to the wall will be $0.16 \%$ of the total mass flux of ash in the bulk gas flow. For a typical velocity of $20 \mathrm{~m} / \mathrm{s}$ at $2700^{\circ} \mathrm{F}(1750 \mathrm{~K})$ and an ash loading of $0.01 \mathrm{~kg}$ ash $/ \mathrm{kg}$ air in the radiant section (i.e., a coal containing approximately $10 \%$ ash), the ash flux is calculated as $6.4 \times 10^{-5} \mathrm{~kg} /\left(\mathrm{m}^{2} \mathrm{~s}\right)$. This translates to a growth of a $1 / 16$ in. ash layer in $8 \mathrm{hr}$ assuming a deposit density of $1000 \mathrm{~kg} / \mathrm{m}^{3}\left(62 \mathrm{lb} / \mathrm{ft}^{3}\right)$. Note that because of the high temperatures in the radiant section, the sticking coefficient of unity is assumed for all particles that arrive at the wall.

The above estimate represents an upper limit because ash transport was based on turbulent parameters in the bulk flow. Lower effective turbulent diffusivities in the wall boundary layer are expected to lead to even lower ash deposition rates than estimated. A better evaluation of ash buildup due to turbulent diffusion is presently underway based on work in the literature. For example, particulate deposition from turbulent streams onto solid wall surfaces was analyzed by Im and Chung (1983). Their model describes the flow near a wall as consisting of three regions, a laminar sublayer next to the wall, a buffer or transition layer in which turbulence is lower compared to the main flow, and a fully developed turbulent region. The fluid turbulence causes particles to diffuse to the vicinity of the laminar sublayer and penetrate it to the wall. Their analysis shows that the deposition rate increases with particle size up to a limiting particle size, because drag in the viscous sublayer is more likely to slow down smaller particles. Beyond a certain particle size however, the momentum imparted to the particles decreases as the particles cannot effectively follow the turbulent fluctuations, and the deposition rate decreases. Two points are worth noting in their treatment vis-a-vis Eq. (2): turbulent diffusion through the boundary layer is slower than in the bulk flow and the diffusion coefficients are a function of particle size. The above calculation (Eq. (2)) theref e represents a very conservative upper estimate of the ash mass deposition rate.

\section{Structure of Ash Deposits in the Radiant Air Heater}

For the all coal-fired HITAF system, air that is to be supplied to the turbine must be heated to $2450 \mathrm{~F}$. This implies that the fireside surface (deposit-gas interface) can reach upwards of $3000^{\circ} \mathrm{F}$ at the top of the combustor. A substantial portion of the ash particles will be sticky at these temperatures and any deposit formed is likely to flow. At the exit of the radiant air heater section, gas temperatures around 2300 to 2600 o $F$ are expected. Deposits from some coals exposed to these gas temperatures may consist only of sintered ash particles with no molten/flowing component. A deposit structure may therefore be envisioned (Figure 25) which consists of the following: 1) flowing slag right next to air heater wall at the top of the reactor, 2) a frozen/sintered ash layer next to the air heater wall with running slag on the fireside further down, and 3) a sintered deposit with no flowing slag at the bottom. Slag is assumed to flow when its viscosity is around 250 poise. The temperature corresponding to this viscosity, $T_{250}$, for various coals is provided in Table 4. Bulk 
ash composition for these coals is provided in Table 5. As expected, increased proportions of glass midifie $\xi_{+}$components in the ash lowers $\mathrm{T}_{250^{\circ}}$ These modifiers include $\mathrm{Ca}^{2+}, \mathrm{Fe}^{2+}, \mathrm{Mg}^{2+}, \mathrm{Na}^{+}$and $\mathrm{K}^{+}$. Also, note that ${ }^{250}$ under oxidizing conditions, iron exists as Fe3+ in the slag and is no longer a glass network modifier. Consequently, $\mathrm{T}_{250}$ under

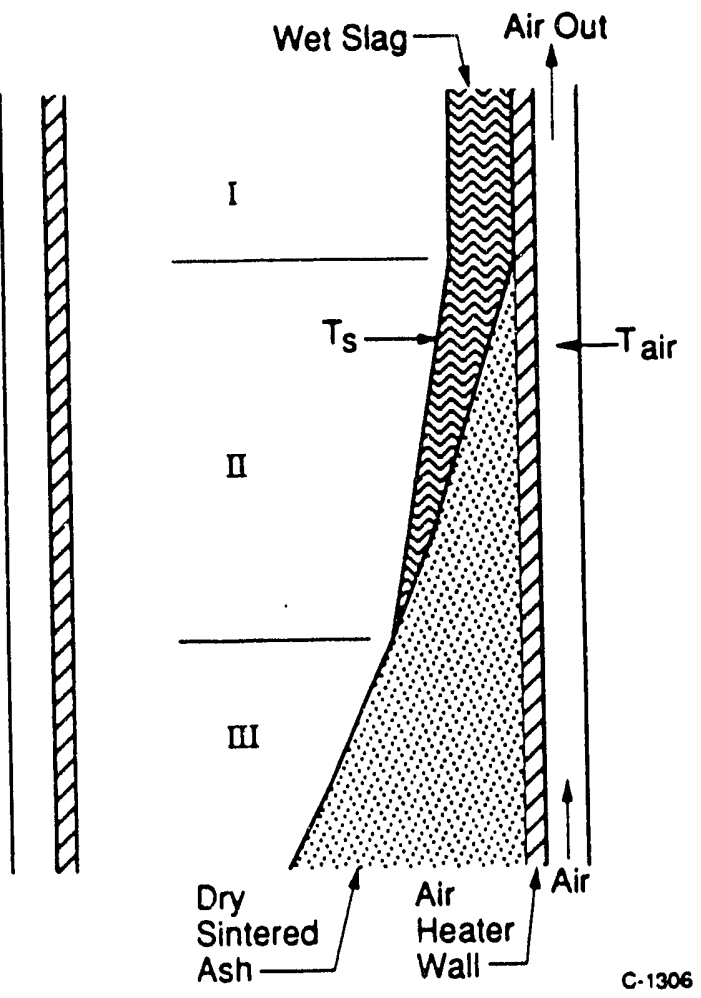

Figure 24. Structure of Ash Deposit in Radiant Air Heater Section.

Table 4. Calculated Temperatures Corresponding to Ash Viscosity of 250 poise (T250) for Various Coals Under 0xidizing and Reducing Conditions.

\begin{tabular}{|l|c|c|}
\hline \multicolumn{1}{|c|}{ Seam/Mine } & $\begin{array}{c}\mathrm{T}_{250}\left({ }^{\circ} \mathrm{F}\right) \\
\text { Reducing }\end{array}$ & $\begin{array}{c}\mathrm{T}_{250}\left({ }^{\circ} \mathrm{F}\right) \\
\text { Oxidizing }\end{array}$ \\
\hline Smith and Roland, Eagle Butte & 1928 & 2020 \\
Illinois \#6, Crown & 2469 & \\
W. Kentucky 9, Kentucky 9 & 2458 & 2740 \\
Illinois 2,3,5,5a, Jader & 2516 & \\
Pocahontas, Pocahontas & 2361 & \\
Pittsburgh 8, Powhattan & 2467 & \\
Pittsburgh 8, Emerald & 2545 & \\
Upper Freeport, Helene & 2706 & 2830 \\
Cedar Grove and Alma, Mingo Logan & 2797 & \\
\hline
\end{tabular}


Table 5. Composition (in weight \%) of Coal Ash (S03-free basis).

\begin{tabular}{|l|c|c|c|c|c|c|c|c|}
\hline & $\mathrm{SiO}_{2}$ & $\mathrm{TiO}_{2}$ & $\mathrm{Al}_{2} \mathrm{O}_{3}$ & $\mathrm{Fe}_{2} \mathrm{O}_{3}$ & $\mathrm{CaO}$ & $\mathrm{MgO}^{\prime}$ & $\mathrm{Na}_{2} \mathrm{O}$ & $\mathrm{K}_{2} \mathrm{O}$ \\
\hline \hline Upper Freeport & 51.8 & 1.2 & 25.2 & 13.8 & 2.3 & 1.4 & 0.3 & 3.2 \\
Eagle Butte & 33.1 & 1.1 & 18.1 & 7.1 & 30.8 & 7.2 & 2.3 & 0.2 \\
Kentucky 9 & 46.8 & 1.2 & 21.6 & 23.5 & 3.3 & 1.2 & 0.9 & 2.7 \\
Illinois 6 & 48.2 & 0.9 & 18.8 & 21.4 & 5.5 & 0.6 & 1.3 & 2.2 \\
Mingo Logan & 53.7 & 1.3 & 29.6 & 9.1 & 1.7 & 0.9 & 0.5 & 3.1 \\
Fowhatton & 46.4 & 1.1 & 24.8 & 25.0 & 2.9 & 1.0 & 0.0 & 2.0 \\
Pocahontas & 44.8 & 1.5 & 29.7 & 17.2 & 10.7 & 2.1 & 1.2 & 2.0 \\
Emerald & 49.3 & 0.9 & 25.1 & 21.5 & 3.5 & 0.7 & 0.4 & 1.5 \\
Kentucky 11 & 49.2 & 1.0 & 20.4 & 21.1 & 4.6 & 1.0 & 0.3 & 2.3 \\
Jader & 51.0 & 0.7 & 19.9 & 24.4 & 2.7 & 1.1 & 0.3 & 2.1 \\
\hline
\end{tabular}

oxidizing conditions are higher, particularly for coals with a large iron component in the ash (Kentucky 9 versus Eagle Butte). $T_{250}$ values for the spectrum of coals provided here, which include Powder River Basin subbituminous and eastern bituminous coals, range from 2000 to $2800^{\circ} \mathrm{F}$. In the radiant air heater one can therefore expect a wide range of ash deposit behavior. Flowing slag is likely throughout the length of the radiant air heater for calcium rich subbituminous coals like Eagle Butte. Almost no flowing slag would be expected for bituminous coals like Mingo Logan. A radiant section design which will perform optimally for every coal is therefore unlikely.

\section{Estimate of Flowing Slag Layer Thickness}

An estimate of the thickness of the flowing slag layer on the radiant air heater walls may be obtained by performing a momentum balance; viscous forces balanced by the force of gravity. Note that as there is a constant radial flux of ash to the wall, the mass flow of ash increases with increasing distance from the burner. The radial flux may be estimated from Eq. (2) as:

$$
m_{a}=\varepsilon_{0}^{2} \rho \cdot u \cdot f_{A}
$$

where

$$
\begin{aligned}
& \varepsilon_{0} \sim 0.04 \\
& \rho \sim 0.2 \mathrm{~kg} / \mathrm{m}^{3} \\
& \mathrm{u} \sim 15 \mathrm{~m} / \mathrm{s} \\
& \mathrm{f}_{\mathrm{A}} \sim 0.01
\end{aligned}
$$

which results in a value of $4.8 \times 10^{-5} \mathrm{kgs}$ ash $/\left(\mathrm{m}^{2} \cdot \mathrm{s}\right)$. If we assume the length of the radiant air heater section to be $10 \mathrm{~m}$, the flow out at the bottom of the section per unit width of the combustor is $4.8 \times 10^{-4} \mathrm{kgs}$ $a s h / s$. The film thickness, $\delta$, may be calculated from Bird et. al, (1960) 


$$
\delta=3 \sqrt{\frac{3 \mu \theta}{\rho g W \cos B}}
$$

where

$$
\begin{aligned}
g & =\text { gravitational constant } \\
\mu & =\text { slag viscosity } \\
\Theta / W & =\text { volume flow rate of slag per unit width } \\
\beta & =90^{\circ} \text { for vertical walls }
\end{aligned}
$$

For a slag density of $2500 \mathrm{~kg} / \mathrm{m}^{3}$ and slag viscosity of 1 go N/m.s $\left(10^{3}\right.$ poise), the film thickness is calculated to be $1.3 \times 10^{-3} \mathrm{~m}(0.05 \mathrm{in})$.

The above calculation does not account for changing temperatures radially and axially across the slag layer and hence variable slag viscosity. It also assumes that the flow is Newtonian and laminar (Re: $<1$ for our case). However, it provides us with an estimate for expected flowing slag layer thickness for performing the heat transfer calculation.

\section{Wet Versus Dry Combustor Wall}

\section{OBJECTIVE}

To assess the advantages of a radiant air heater surface designed to withstand dry ash deposits or wet ash deposits.

\section{BACKGROUND}

An all-coal HITAF design requires the air from the convective section to be heated from $1800^{\circ}$ to $2460^{\circ} \mathrm{F}$.

- Therefore, the fireside surface temperature is expected to range from $2000^{\circ} \mathrm{F}$ at the bottom of the combustor to $2600^{\circ} \mathrm{F}$ at the top (1500 to 2100 for baseline design)

- A substantial fraction of the fly ash particles will be sticky at either temperature, making ash deposition inevitable.

- The main questions, therefore, are:

1. How can the ash deposition rate be minimized?

2. Is it best to remove the ash in a wet or dry form?

- Air wall construction must allow for structural support, adequate heat transfer, corrosion resistance, and insulation to minimize system heat losses.

- Two choices:

1. Embedded tube wall (Figure 25)

2. Studded membrane wall (Figures 26 and 27) 
The two choices are similar structurally, but the studded membrane wall affords more protection from molten slag. For this reason, it is commonly employed in wet-bottom coalfired boilers as well as recovery boilers used in the pulp and paper industry.

How the membrane wall would work:

- The SiC air tubes are studded with cylindrical SiC protrusions.

- The studs provide an anchor for slag-resistant chromeplastic refractory rammed on to protect the air tubes.

- The studs also increase the rate of heat transfer to the air.

- During coal combustion, a layer of slag will form on the fireside of the wall. This slag layer should form rapidly and must be removed continuously for the baseline design.

- For the all-coal design, however, wet running slag will be unavoidable. Running slag will interact with the protective refractory layer. After many freeze and melt cycles, the protective refractory and the SiC studs will wash away.

- It is expected that the air-tubes would have to be restudded and refractoried every 1 to 5 years during scheduled maintenance outages.

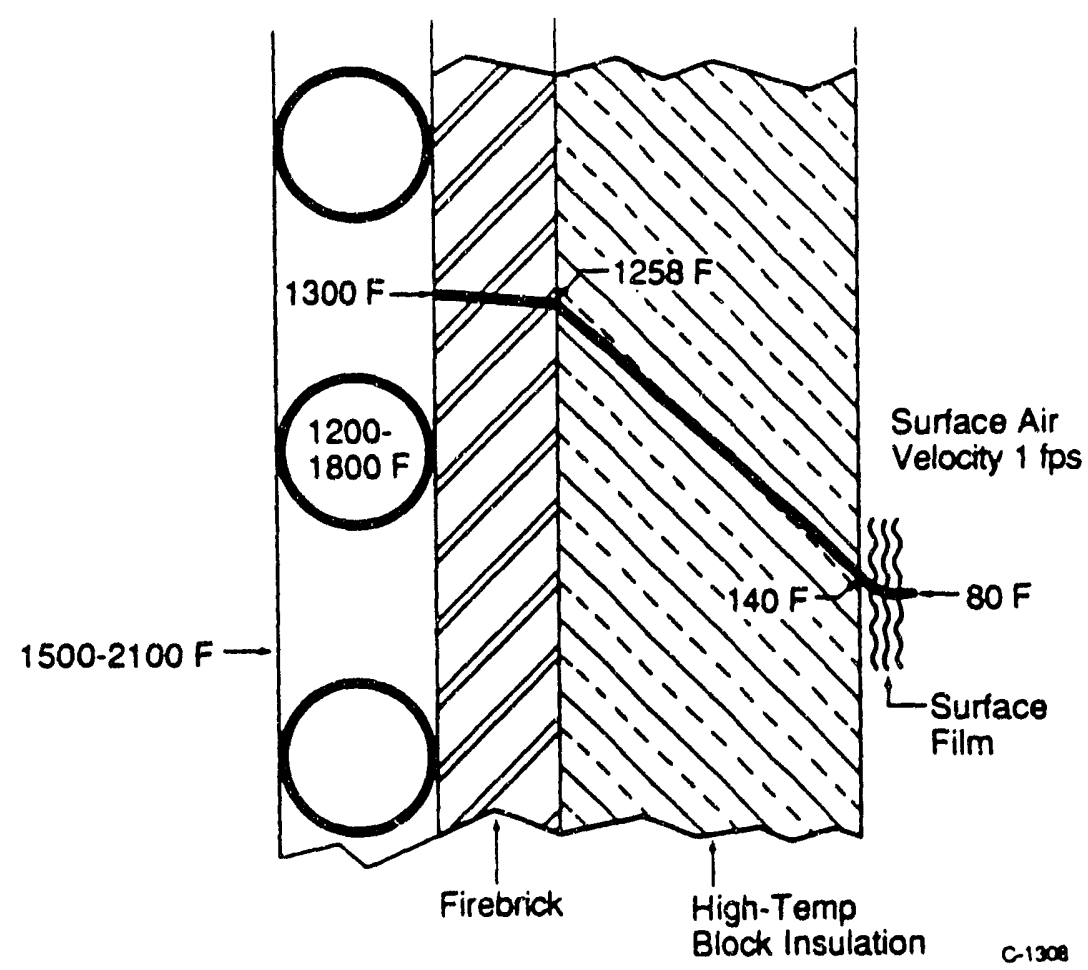

Figure 25. Imbedded Tube Wall 


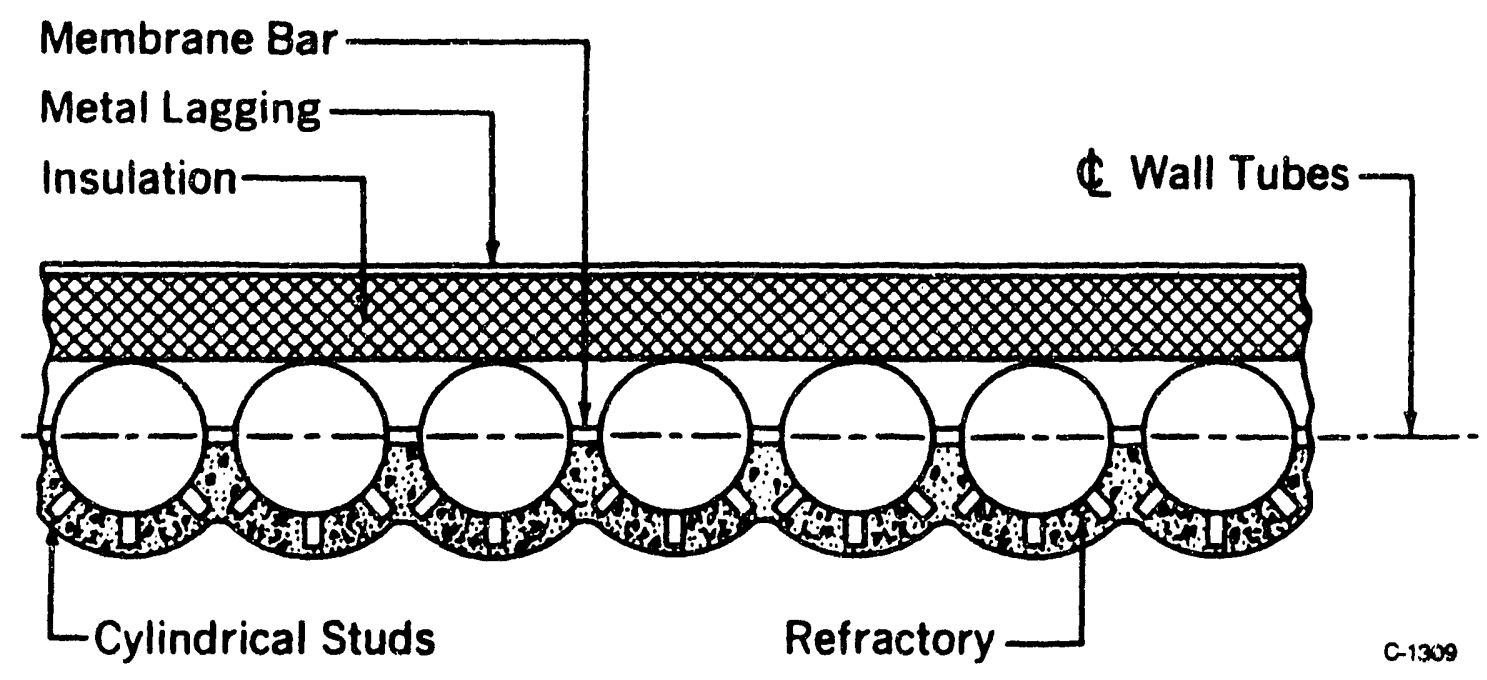

Figure 26. Fully Studded Membrane Walls

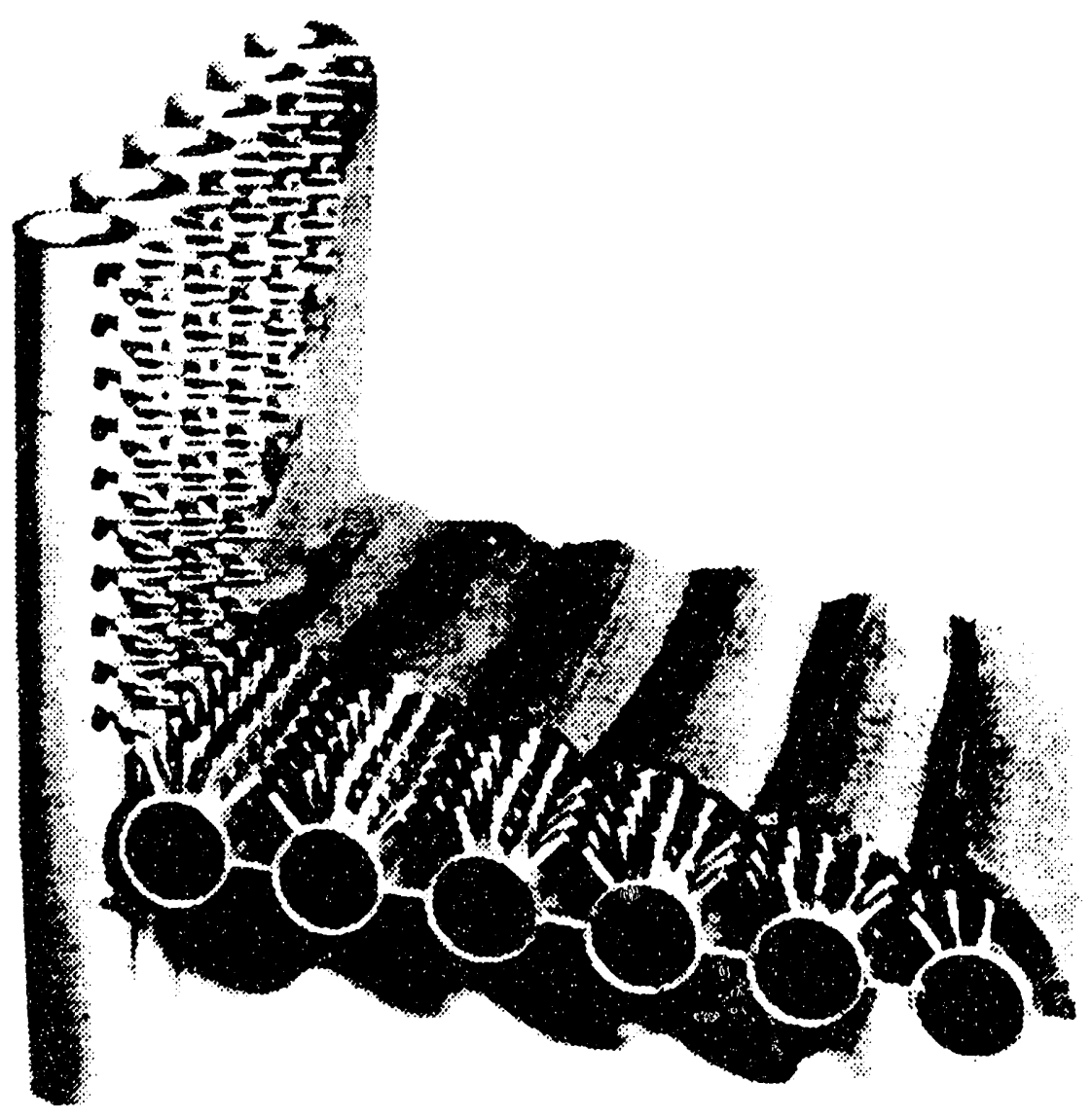

Figure 27. Furnace Pin-Stud and Refractory Construction 
Table 6. Issues Relative to Ash Deposit Removal

\begin{tabular}{|c|c|c|}
\hline Questions & Design Options & Technical Issues \\
\hline $\begin{array}{l}\text { Minimize deposition } \\
\text { rate }\end{array}$ & $\begin{array}{l}\text { Increase furnace cross section } \\
\text { Continuous sootblowing }\end{array}$ & $\begin{array}{l}\text { Increasing from } 28 \times 28 \mathrm{ft} \text {. to } \\
36 \times 36 \mathrm{ft} \text {. decreases fly ash mass flux } \\
\text { to the wall by } 27 \% \text { - cost? } \\
\text { Erosion? Effectiveness? }\end{array}$ \\
\hline Wet ash removal & $\begin{array}{l}\text { High flame temperature } \\
\text { Slag tap torch }\end{array}$ & $\begin{array}{l}\mathrm{NO}_{\mathrm{x}} \text { control } \\
\text { How do you keep slag running? } \\
\text { Will wet slag penetrate the protective } \\
\text { slag layer and wash out refractory? } \\
\text { Where is wet-dry interface? Can we } \\
\text { control it? }\end{array}$ \\
\hline Dry ash removal & $\begin{array}{l}\text { Sootblowers } \\
\text { Additives }\end{array}$ & $\begin{array}{l}\text { Wall erosion, how frequent? } \\
\text { Is slag removable? How long? } \\
\text { Design of sootblowing access - holes? } \\
\text { Added dust loading? Heat transfer } \\
\text { effects? } \\
\text { Does this exist? }\end{array}$ \\
\hline
\end{tabular}

\section{Slag Screen Design}

One of the approaches that may be taken to decrease ash buildup on the convective ceramic air heater walls is through the use of slag screens or impact separators. A staggered array of water cooled metal tubes serves as ash collection surfaces. Water cooling is used to protect the metal tubes and to facilitate sootblowing. Impact separators are most effective for removing large ash particles. The collection efficiency of smaller ash particles may be increased by either increasing the flow velocity or decreasing the target dimensions, both of which decrease the ability of particles to follow the gas stream. The issues relative to slag screen design include particle removal efficiency as a function of size by the overall screen section, pressure drop and heat loss. Each of these are considered below. 
Slag Screen Performance (Ash Removal)

The capture efficiency of a collector in a high velocity flowfield is mainly determined by an inertia parameter characterizing the particle motion, termed the Stokes number. The Stokes number can be viewed as the ratio of the characteristic stopping time of the particle to the characteristic flow time around the collector. For low Reynolds number flow, the particle stopping time may be computed by applying the Stokes drag law. The drag experienced by the particle in high Reynolds number flow is non-Stokesian. Israel and Rosner (1983) developed engineering correlations for the inertial parameter for particle capture by a cylinder of a sphere as

$$
\text { Stk }_{\text {eff }}=\psi\left(\operatorname{Re}_{p}\right) \cdot \text { Stk }
$$

where Stk $=\rho_{p} d{ }^{2} U /(18 \mu), R e{ }_{p}=d \rho^{\rho} U \infty / \mu g$, and $\psi\left(R e_{p}\right)$ is the correction factol for non-Stokes behavior given by

$$
\psi\left(\operatorname{Re}_{\mathrm{p}}\right)=\frac{3}{0.0628 \operatorname{Re}_{\mathrm{p}}}\left[\left(0.0628 \operatorname{Re}_{\mathrm{p}}\right)^{1 / 3}-\tan ^{-1}\left(0.0628 \operatorname{Re}_{\mathrm{p}}\right)^{1 / 3}\right]
$$

For a circular cylinder collection geometry and Stkeff $>0.14$, the following correlation for the capture fraction (if each impacting particle "sticks") was presented:

$$
\begin{aligned}
\eta_{\text {cap }} & =\left[1+1.25\left[\text { Stk }_{\text {eff }}-\frac{1}{8}\right]^{-1}-1.4 \times 10^{-2} \cdot\left(\text { Stk }_{\text {eff }}-\frac{1}{8}\right)^{-2}+0.058\right. \\
& \left.\times 10^{-4}\left(\text { Stk }_{\text {eff }}-\frac{1}{8}\right]^{-3}\right]^{-1}
\end{aligned}
$$

For the near critical range (Rosner and Tassopoulos)

$$
\begin{aligned}
& 0.125<\text { Stk }_{\text {eff }}<0.14 \\
& \eta_{\text {cap }}=0.043\left(\text { Stk }_{\text {eff }}-\frac{1}{8}\right)^{0.11} .
\end{aligned}
$$

These correlations were used to calculate the impaction efficiency of ash particles for three cases to provide an estimate of the particle size likely to be removed by the slag screen under HITAF conditions. The three conditions considered were a) $\left.d_{\text {tube }}=2 \mathrm{in.}, \mathrm{v}_{\text {gas }}=200 \mathrm{ft} / \mathrm{s} ; \mathrm{b}\right) \mathrm{d}_{\text {thbe }}=$
$\left.2.875 \mathrm{in.}, \mathrm{v}_{\text {gas }}=200 \mathrm{ft} / \mathrm{s}, \mathrm{c}\right) \mathrm{d}_{\text {tube }}=2.87 \mathrm{ing}, \mathrm{v}=160 \mathrm{ft} / \mathrm{s}$. Figure 28 shows the gaspaction efficiency as a function of pasticle size. As a 
reference, the $10 \mu \mathrm{m}$ particles were collected with an efficiency of $28 \%$ for case a) and an efficiency of $15 \%$ for case $c$ ). The corresponding values for the $20 \mu \mathrm{m}$ ash particles were $63 \%$ and $48 \%$, respectively.

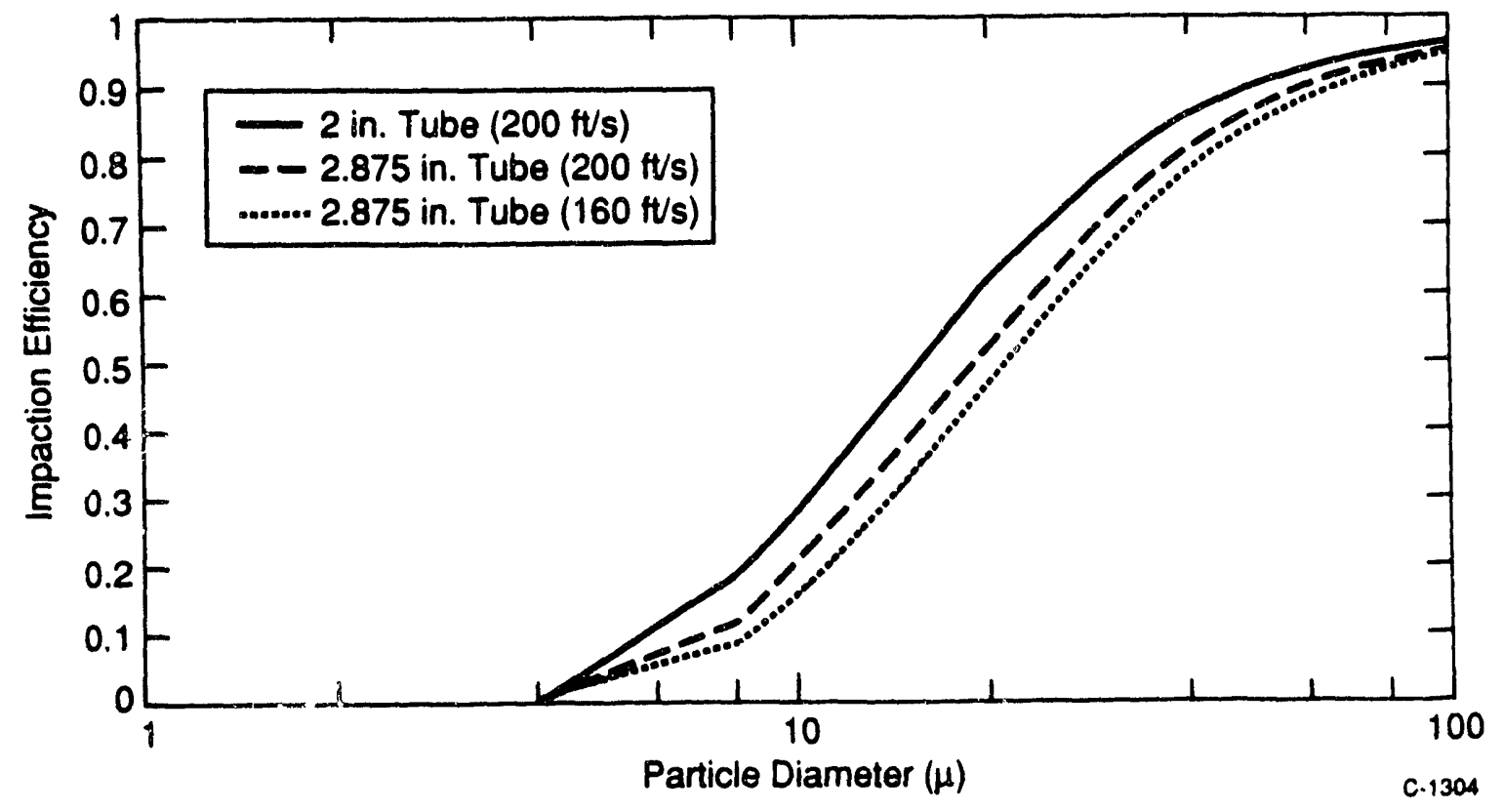

Figure 28. Impaction efficiency as a function of particle size

For a bank of tubes placed within the particle laden flow, the overall removal efficiency may be examined in two limits. The lower limit is one in which ash particles are redispersed uniformly throughout the flow between any two rows of tubes. If $n$ is the impaction efficiency for one tube, collection efficiency for a row is given by

$$
\eta_{\text {row }}=\eta \frac{A_{r}}{A_{f}}
$$

where $A_{r}$ is the projected tube area per row and $A_{f}$ is the tube flow area. Efficiency of the tube bank is then given by

$$
\eta_{\text {tot }}=1-\left(1-\eta_{\text {row }}\right)^{n}
$$


where $\mathrm{n}$ is the number of rows. While this limit is approached as the rows are spaced apart significantly, a more realistic situation is that particles are going to be concentrated in the wake region behind each tube. If tubes in the succeeding rows are staggered appropriately, we can take advantage of this concentration of ash particles in the wake. In this limit

$$
\eta_{\text {tot }}=\eta \frac{A_{\text {tube }}}{A_{\mathrm{f}}} ; \eta_{\text {tot }} \leq 1
$$

The collection of particles from gas streams by impaction on multiple spherical targets has been examined by Jacober and Matteson (1985) in a experimental study of impaction 10 droplets of dioctylphthalate (DOP) and isoproponol onto $6 \mathrm{~mm}$ targets. A numerical study of particle laden gas flow past tubes was conducted by Schuh et al., (1989). Experiment particle tracking and visualization work has also been performed by Shaffer et al., (1989). A review of tubular separation performance was provided by Calvert et al., (1975). From all of these studies, it becomes clear that the collection efficiency for single collectors cannot be directly applied to a collector array since the wakes of the leading spheres strongly influence both the particle concentration and velocity before the trailing spheres on the array.

In particular, the work by Jacober and Matteson (1985) demonstrated that the target collection efficiencies may be enhanced or reduced depending on inter-collector spacing and alignment. With an in-line arrangement of target tubes, a marked shielding effect created by the lead target reduced the efficiencies of subsequent targets. The multiple tube collection efficiency did not equal the isolated, single tube value until 20 target diameters downstream at low gas velocities. At higher gas velocities, the collection efficiencies of downstream targets were always lower than that of the lead target.

A staggered tube arrangement, on the other hand, exhibited a higher collection efficiency for downstream tubes compared to the leading tube for certain arrangements. Analysis of the experimental data indicated the formation of a wake behind the leading target containing relatively high concentrations of ash particles. If downstream targets are aligned such that they intersect this wake boundary, high collection efficiencies may be achieved.

In a study of wakes behind spherical targets, Swain (1929) expressed wake width and centerline velocity as a function of downstream distance (see Figure 10)

$$
\begin{aligned}
b & =\sqrt{10}\left(B C_{D A} x\right)^{1 / 3} \\
1-\frac{u}{u_{\infty}} & =R\left(\frac{\chi^{2}}{C_{D} A}\right)^{-1 / 3}
\end{aligned}
$$


where

$\begin{aligned} \mathrm{b} & =\text { wake width at downstream distance } \eta \\ \mathrm{A} & =\text { projected target area } \\ \mathrm{u} & =\text { centerline velocity } \\ \mathrm{u}^{\infty} & =\text { free sł5em velocity } 3 \\ \mathrm{R} & =2 / 3 B^{-152}-1 / 2 B^{-1} 3 \\ B & =\text { constant derived from ratio of Prandtl } \\ C_{D} & =0.44 .\end{aligned}$

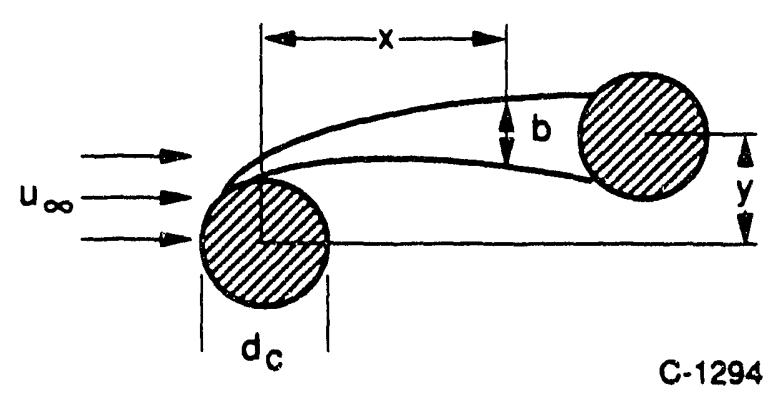

Figure 29. Growth of wake downstream of cylinder in crossflow

The angle formed by the wake boundary may be expressed as

$$
\theta=\tan ^{-1}[b / 2 \chi]=\tan ^{-1}\left[0.57\left(\frac{d_{c}}{\chi}\right)^{2 / 3}\right]
$$

and can be used to estimate the distance between rows. A value of $\theta=11^{\circ}$ corresponds to maximum deposition in the data presented by Jacober and Matteson (1985). An initial design using the above specifications is provided in Figure 30 . 


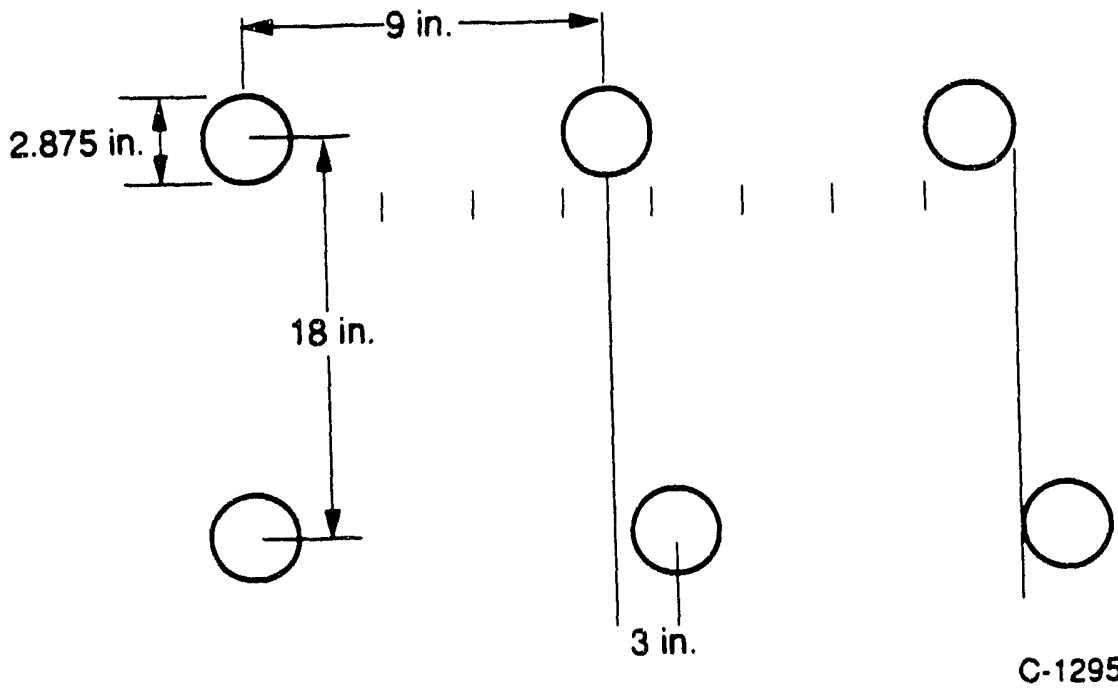

Figure 30. Preliminary slag screen design

The slag screen will consist of $2-1 / 2$ in. Schedule 160 tubes with an $0 . D$. $=2.875 \mathrm{in}$. and an I.D. $=2.125 \mathrm{in}$. The spacing within a row will be 9 in. on centerline and between rows will be $18 \mathrm{in.}$ on centerline. Staggering between two rows will be $3 \mathrm{in.}$ on centerline. Given the above design, an opacity (A $A$ fube $/ A_{\text {flow }}$ ) close to 1 can be obtained with three rows of tubes. A six-row tube bank is recommended for efficient removal of large particles. Table 4 provides the minimum and maximum (likely close to actual) efficiency of the slag screen for three particle sizes.

Table 7. Overall Collection Efficiency of Six-Row Slag Screen (200 ft/s, 2,875 diameter tubes)

\begin{tabular}{|l|c|c|c|}
\hline \multicolumn{1}{|c|}{ Particle Size } & $8 \mu \mathrm{m}$ & $10 \mu \mathrm{m}$ & $20 \mu \mathrm{m}$ \\
\hline$\eta_{\min }$ & 0.20 & 0.325 & 0.68 \\
\hline \begin{tabular}{l}
$\eta_{\max }\left(\approx \eta_{\text {actual }}\right)$ \\
\hline
\end{tabular} & 0.23 & 0.4 & 1.0 \\
\hline
\end{tabular}


Pressure Drop Calculations

The pressure drop of the gas through the tube bank may be calculated from the following expression

$$
\Delta p=N f\left[\rho u_{a v}^{2} / 2 g_{c}\right]
$$

where $\mathrm{N}$ is the number of rows, $\mathrm{f}$ is the friction factor, $\rho$ the gas density and $u_{a y}$ the gas velocity through the tubes. For high Reynolds number flow $\left(\operatorname{Re}>\mathrm{I}^{4}\right) \mathrm{f} 0.18$. Using values of $\rho=0.2 \mathrm{~kg} / \mathrm{m}^{3}$ and $u_{a v}=60 \mathrm{~m} / \mathrm{s}$ the pressure drop is calculated as

$$
\Delta p=N \cdot 67 \mathrm{~N} / \mathrm{m}^{2}=0.3 \mathrm{~N} \text { in. of water }
$$

For $\mathrm{N}=6$, a correction factor of 1.05 in the pressure drop correlation is recommended. The expected pressure drop through six rows is therefore 1.89 in. of water, well within the acceptable design constraints for the system.

\section{Heat Loss Calculation}

The heat loss through the water-cooled slag screen tube bank is estimated for the case where the gas temperature is $2700^{\circ} \mathrm{F}(1755 \mathrm{~K})$ and tube surface is at $40^{\circ} \mathrm{C}$ (Figure 12). The correlations developed by Grimson (1937) are used here. The spacing parallel to the flow, $S$ is 9 in., while the outer tube diameter (D) is $2.875 \mathrm{in}$. The film properties, an average of the gas and tube values are given below

$$
\begin{aligned}
& \text { Gas film temperature, } T_{f}=1034 \mathrm{~K} \\
& \text { Gas film viscosity, } \mu \mathrm{f}=0.34 \mathrm{~kg} / \mathrm{m}^{3} \\
& \text { Gas film viscosity, } \mu \mathrm{f}=4.3 \times 10-5 \mathrm{~kg} /(\text { mùs) } \\
& \text { Gas film conductivity, } \mathrm{k}_{\mathrm{f}}=1.15 \times 0.069 \mathrm{~W} / \text { (mùK) } \\
& \text { Gas heat capacity C } \mathrm{pf}=103 \mathrm{~J} /(\mathrm{kgsK}) \\
& \text { Prandtl number, } \mathrm{Pr} \mathrm{pf}=0.703 .
\end{aligned}
$$

The velocity through the tubes, assuming $160 \mathrm{ft} / \mathrm{s}$ at the entrance is

$$
u=u_{\infty} S n /\left(S_{n}-D\right)=72 \mathrm{~m} / \mathrm{s}
$$

The corresponding Reynolds number is 42,000. The heat transfer coefficient, $h$, is given by 


$$
\frac{h d}{k_{f}}=C\left(\frac{u_{\infty} d \rho_{f}}{\mu_{f}}\right)^{n} P_{r}^{1 / 3} .
$$

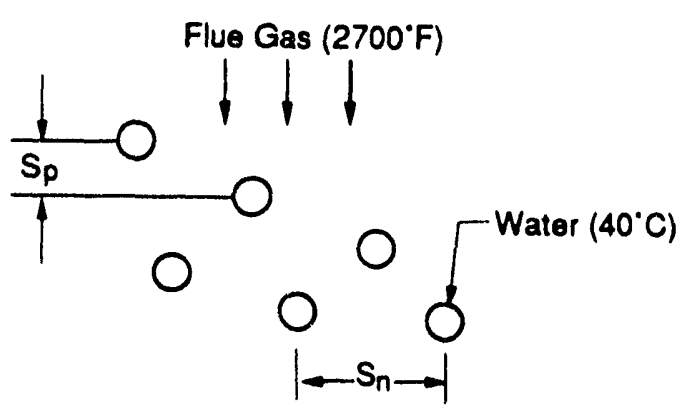

Figure 31. Parameters for heat loss calculations

The constants $C$ and $n$ assume the value of 0.467 and 0.574 respectively for the case $S_{p / D}=3$ and $S_{n / D}=3$. No data are provided for our case of $S_{p / D}$ 6. The heat transfer coefficient, $h$ is calculated as $164 \mathrm{~W} /\left(\mathrm{m}^{2} \mathrm{~K}\right)$, without applying the correction for the number of rows being less than 10 . For a conservative heat loss estimate, we will use the above value. The total heat transfer is calculated for a tube bank consisting of 114 tybes, $2.875 \mathrm{in}$. in diameter and $14 \mathrm{in}$. long, which is approximately $110 \mathrm{~m}^{2}$ in area. The heat balance equation may be solved to calculate the temperature of the gas leaving the slag screen region. A temperature drop of $80 \mathrm{~K}$ $\left(145^{\circ} \mathrm{F}\right)$ is obtained from the above calculations.

$$
\begin{aligned}
q & =h A\left(\frac{T_{g}, \text { in }+T_{g}, \text { out }}{2}-T_{W}\right] . \\
& =\text { m } C_{p}\left(T_{g}, \text { in }-T_{g}, \text { out }\right)
\end{aligned}
$$




\section{Slag Screen Location}

The location of the slag screen is most appropriate at the wet-dry ash interface. By providing various mechanisms for dry ash removal (soot-blowing) and wet ash removal (gas lancing) in this region and designing for easy ash removal to the hoppers, one can most affectively control the ash deposit growth on the slag screen and not on other more sensitive heat transfer surfaces. Clearly for effective particle capture on the slag screen tubes, the ash particles and the deposit should be relatively molten (low viscosity). Addition of a part of the dilution air should be postponed to the region after the slag screen as the colder dilution air will lower gas and ash particle temperatures and hence make the ash less prone to stick in the convective air heater that is downstream of the slag screen. A portion of the dilution air may be added before the slag screen to increase gas velocities hence impaction efficiencies and particle removal by the slag screen.

\section{Ash Deposition in the Convect:ve Air Heater}

The following discussion provides estimates of deposition rates expected in the convective air heater section.

A channel of the air heater is characterized by:

$$
\begin{aligned}
& \ell \text { : channel height: } \\
& \text { L: channel length: } \quad 150 \mathrm{~cm} \\
& \text { u: approach velocity: } 3000 \mathrm{~cm} / \mathrm{s} \\
& \text { p: gas density: } 2 \times 10^{-4} \mathrm{~g} / \mathrm{cc} \\
& \mu \text { : gas viscosity: } \quad 4 \times 10^{-4} \mathrm{~g} / \mathrm{cm} \mathrm{s}
\end{aligned}
$$

for which the two characteristic Reynolds numbers are:

$$
\operatorname{Re}_{\ell}=\frac{\rho u \ell}{\mu}=7500
$$

and

$$
\operatorname{Re}_{\mathrm{L}}=\frac{\rho \mathrm{uL}}{\mu}=2 \times 10^{5}
$$

The value of $\operatorname{Re}$ suggests that the channel would be turbulent but the length $L$ is not long enough for the wall boundary layer to be turbulent. Hence, we are operating with a laminar entrance length wherein some additional effect is required to trip the turbulent flow. The flow over the fin-tube may be sufficient to sustain some vortex shedding and marginally turbulent flow. Air heaters are most likely to be operated in the transition zone so as to avoid the large drag of fully developed turbulent "low but still generate some mixing. This "low grade" of turbulenc ay minimize the particle deposition since turbulence will not 
be fully developed at the wall. However, the following analysis will explore the worst case for particle deposition, i.e. that of fully developed flow.

If the flow is turbulent and the particles follow the turbulent fluctuations, the mass flux of ash to the wall is

$$
\dot{\mathrm{m}}_{\mathrm{A}}=\rho^{\prime} \mathrm{u}^{\prime} \mathrm{f}_{\mathrm{A}}
$$

where $\rho^{\prime}$ and $u^{\prime}$ are the turbulent fluctuations in the gas density and velocity respectively, and $E_{A}$ is the mass fraction of ash in the flow. Since

$$
\rho^{\prime}=\varepsilon_{0} \rho
$$

and

$$
u^{\prime}=\varepsilon_{0} u
$$

where $\varepsilon$ represents an average turbulent fluctuation intensity in the wall boundary layer normalized to the nearflow value.

$$
\begin{aligned}
& \text { We then rewrite } m_{A} \\
& \qquad m_{A}=\epsilon_{0}^{2}\left(\operatorname{ou} f_{A}\right) .
\end{aligned}
$$

As ash deposits on the wall, the flux of ash along the channel (positive $x$ direction) decreases as

$$
\frac{d}{d x}\left(\operatorname{ouf}_{A} l\right)=-2 \epsilon_{0}^{2}\left(\text { ouf }_{A}\right) S
$$

where there are two walls for each channel with sticking coefficient $S$. Integration, assuming a constant value for the sticking coefficients, yields

$$
\operatorname{\rho uf}_{A}=\left(\operatorname{puf}_{A}\right)_{0} \exp \left(-2 S \epsilon_{0}^{2} x / l\right)
$$

which, at $\mathrm{x}=\mathrm{L}$, and assuming a value of $\varepsilon 0=0.04$ yields

$$
\operatorname{\rho uf}_{A}=\left(\operatorname{\rho uf}_{A}\right)_{0} \exp (-0.1 \mathrm{~s})
$$

The sticking coefficient of ash particles on the walls of the air heater is a function of the ash composition and the gas temperature profile in the air heater. Fractional adhesion as a function of temperature for various eastern bituminous coals is shown in Figure 32. entrance gas temperatures 
to the convective air heater section are expected to range from $2100^{\circ} \mathrm{F}$ to $2400^{\circ} \mathrm{F}(1422$ to $1588 \mathrm{~K})$. Corresponding adhesion efficiencies range from 0.25 to 0.65 for the coals presented in Figure 32. Exit temperatures are expected to be around

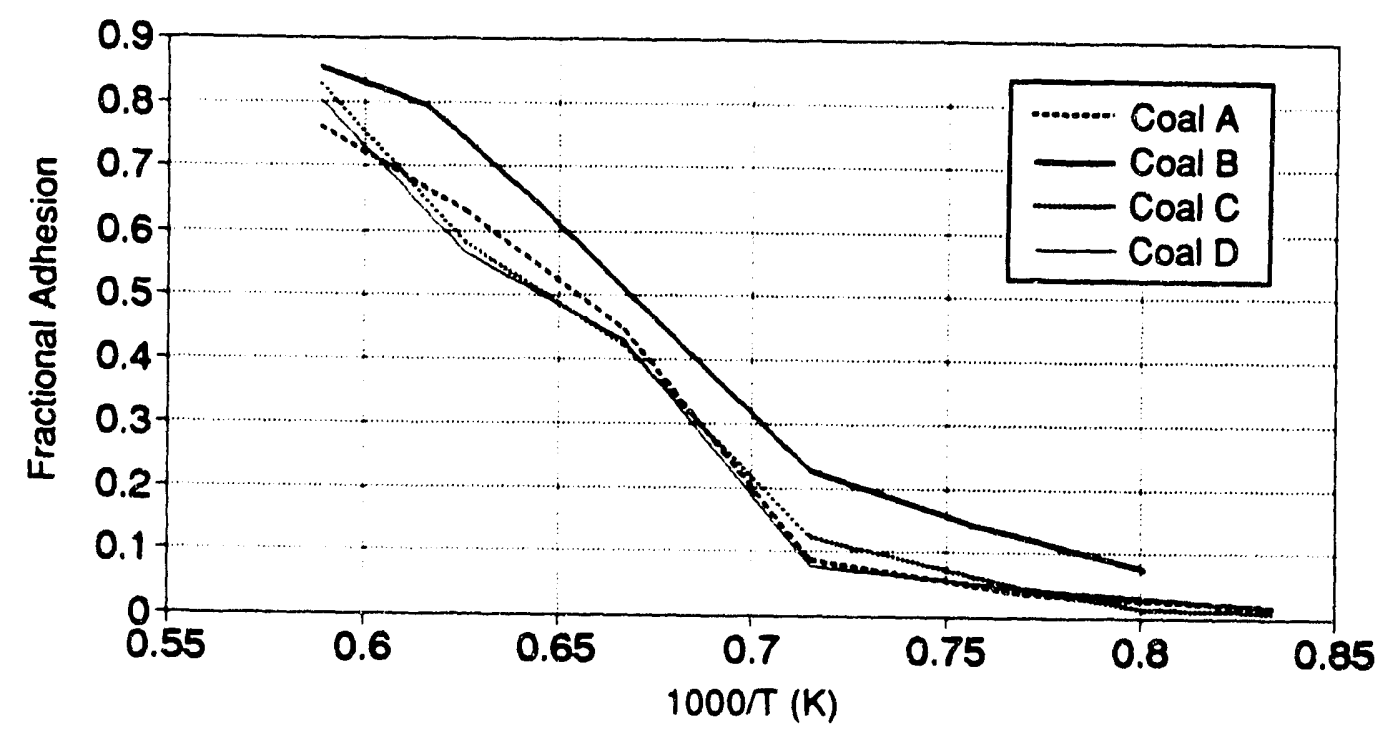

Figure 32. Calculated ash adhesion efficiencies for four Eastern bituminous coals under oxidizing conditions (ucrit $=106$ poise)

$1800^{\circ} \mathrm{F}(1260 \mathrm{~K})$. Corresponding adhesion fractions are about 0.05 . Assuming a linear profile for sticking efficiency

$$
\mathrm{S}=\mathrm{S}_{\mathrm{o}}-\mathrm{bx}
$$

and integration Eq. (25) yields

$$
\operatorname{\rho uf}_{A}=\left(\operatorname{puf}_{A}\right)_{0} \exp \left\{-2 \frac{\epsilon_{0}^{2}}{l}\left[S_{0} x-\frac{b x^{2}}{2}\right]\right\}
$$

which at $x=L$, and assuming a value of $\varepsilon_{0}=0.04$ results in

$$
\operatorname{\rho uf}_{A}=(\operatorname{\rho uf})_{0} \exp \left\{-0.1\left(s_{0}-\frac{b}{2} \cdot L\right)\right\}
$$


For values of $\mathrm{S}_{0}=0.25$ and $\mathrm{b}=0.2 / 150 \mathrm{~cm}^{-1}$

$$
\frac{\operatorname{\rho uf}_{A}}{\left(\operatorname{\rho uf}_{A}\right)_{0}}=0.985 \text {. }
$$

For values of $S_{0}=0.65$ and $b=0.6 / 150 \mathrm{~cm}^{-1}$

$$
\frac{\operatorname{\rho uf}_{A}}{\left(\operatorname{\rho uf}_{A}\right)_{0}}=0.965 .
$$

This implies that 1.5 to $3.5 \%$ of the ash entering the convective air heater section will deposit on the walls.

This is, however, an overestimate as large particles cannot follow the turbulent fluctuations and small particles will not penetrate the laminar sublayer of the turbulent flow. The range of particle sizes that can keep up with the turbulence and will penetrate the laminar sublayer is estimated next .

To determine the dynamic response of an ash particle to the gas, consider a particle at rest and subjected to a gas velocity $U_{G}$. The particle velocity $U_{P}$ is normalized to $U_{G}$.

$$
\mathrm{R}=\mathrm{U}_{\mathrm{P}} / \mathrm{U}_{\mathrm{G}}
$$

such that $R=0$ at $y=0\left(y=\right.$ coordinate in direction of $\left.U_{G}\right)$ and, for stokes flow

$$
R+\ln (1-R)=\frac{-9 \mu y}{2 U_{G} \rho_{p} R_{p}^{2}}
$$

where $\rho_{p}$ and $R_{p}$ are the particle density and radius. If $U_{G}$ is the turbuleht fluctuation velocity

$$
U_{G}=u^{\prime}=\varepsilon_{0} u
$$

and $y$ is the turbulent length scale

$$
y=\ell^{\prime}=\epsilon_{0} l
$$

particles will not keep up with the turbulent fluctuations if $R<0.5$. This bound is illustrated in Figure 33 for $p p=2 \mathrm{~g} / \mathrm{cc}$. 


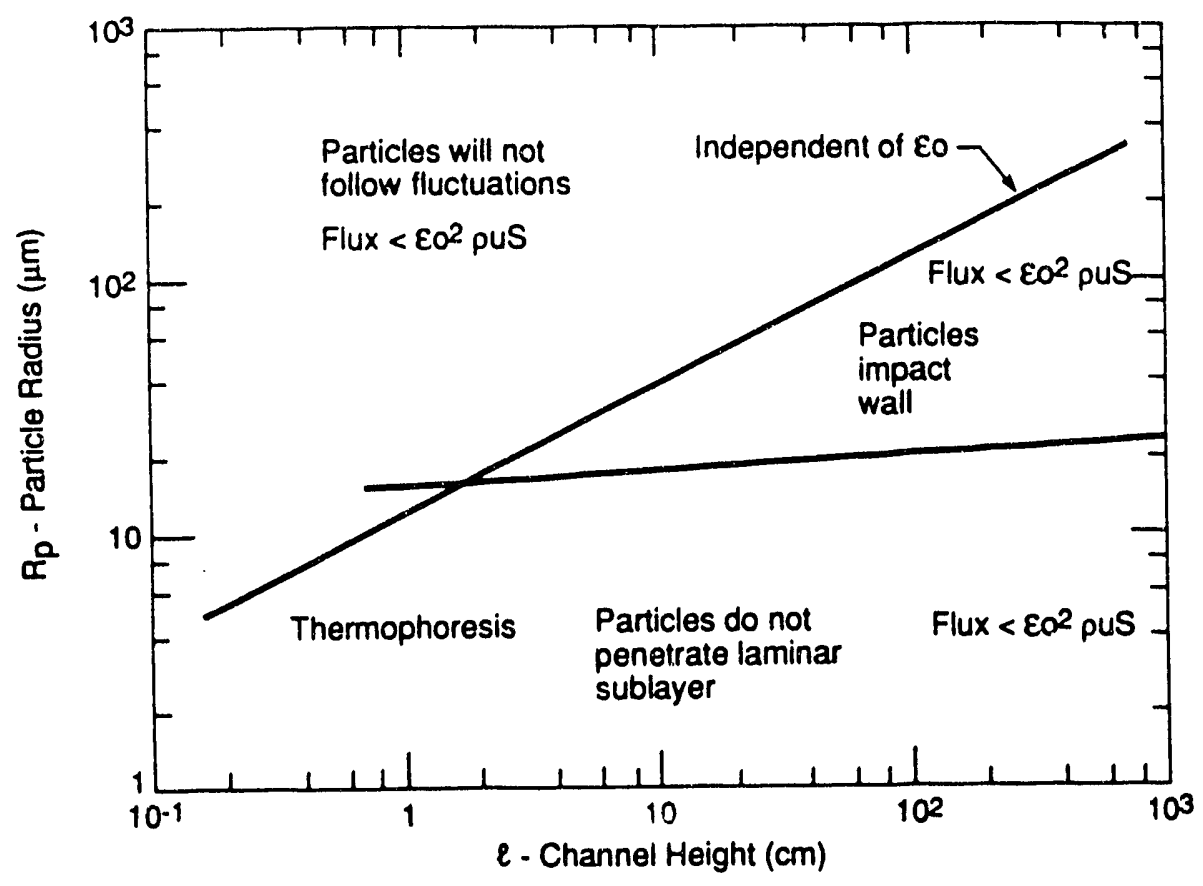

Figure 33. Size range of particles tha'i impact the channel wall

Smaller particles will not penetrate the laminar sublayer and impact the wall. The thickness of the laminar sublayer is $\delta$ where

$$
\begin{aligned}
& \delta=5 \frac{\nu}{v^{*}}, \\
& \nu=\mu / \rho=2 \mathrm{~cm}^{2} / \mathrm{s}
\end{aligned}
$$

and

$$
v^{*}=0.15(u)^{7 / 8}\left(\frac{v}{l}\right)^{1 / 8}
$$

If $y=\delta$ and $U_{G}=\mu^{\prime}, R=0.5$ will identiry the regions of parameter space where the particle will penetrate the sublayer. This is also illustrated in Figure 33. There is a range of particle sizes that will follow the turbulence, penetrate the laminar sublayer and impact the wall. This range of particle size is much greater for meter sized channels than for centimeter sized channels. For a $5 \mathrm{~cm}$ channel as projected for the air heater, our main concern is 10 to $20 \mu \mathrm{m}$ particles. 
One may summarize the deposition rates on the convective air heater for the various assumptions with respect to stickiness, level of turbulence, and particle response to turbulent fluctuations as shown in Figure 34.

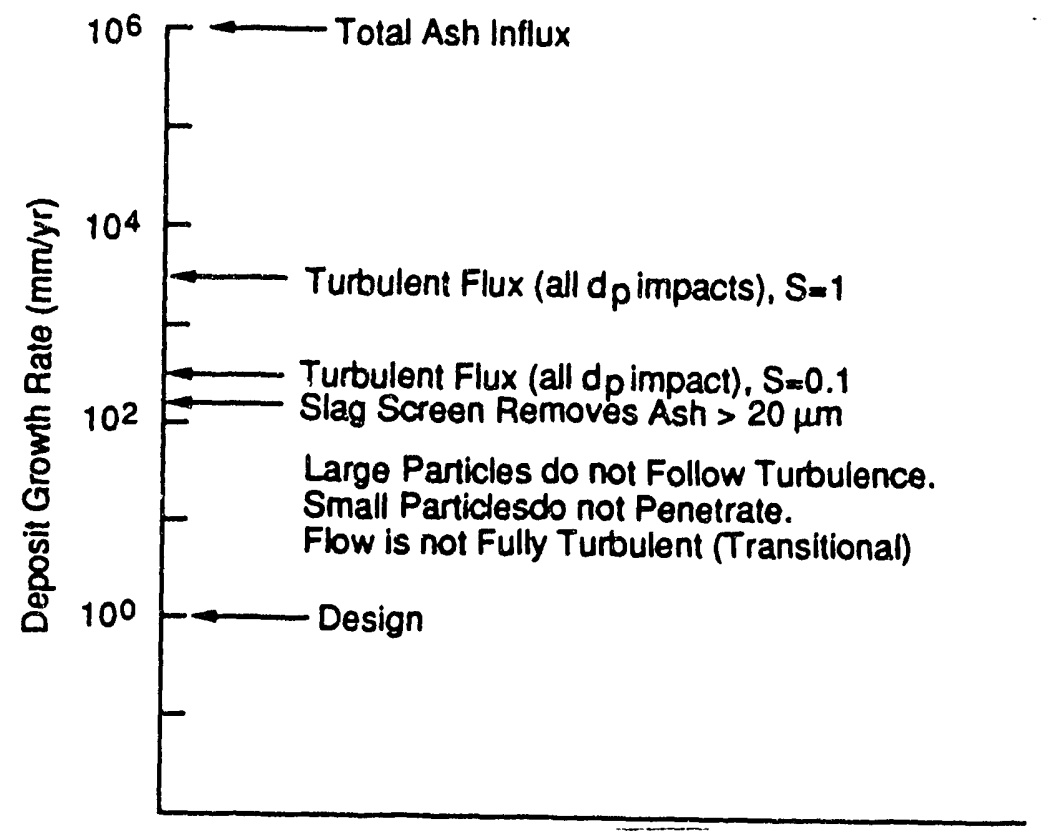

Figure 34 Approach to design deposition rate for convective air heater

Task 2.2.2.8 SO $_{\mathrm{x}}$ and Fly Ash Control

The objective of this task is to assure that the research team remains current in the fields of $\mathrm{SO}_{\mathrm{X}}$ and fly ash control in the emissions of coal burning power plants so that an efficient strategy for controlling these effluents can be proposed for the demonstration HITAF system that w1ll be proposed for Phase 2 of Combustion 2000. No experimental work will be performed in this task during Phase 1.

The environmental acceptability of any power generation facility is a critical question in its design. Public awareness as well as governmental regulations dictate that every effort be made to limit emissions to the lowest possible level. of critical concern with respect to the HITAF system are emission of $\mathrm{NO}_{x}$, $\mathrm{SO}_{x}$, and particulate material. In addition to low emissions, the system must minimize the capital and operating cost associated with emission control.

The philosophy behind the propsed HITAF is to minimize the need and therefore the expense associated with control of the three critical emissions. NO control will be achieved primarily by appropriate combustor design. However, SO and fly ash control will need to be provided by emission control systems. Since the control strategy varies depending on the type of emission, a short discussion of each category follows. 
Sulfur oxides

Control of sulfur in any coal combustion system may be accomplished by a variety of options. First, fuel selection should focus on trying to minimize the fuel sulfur input into the system. In addition to choosing low-sulfur coal, coal cleaning has the opportunity to reduce sulfur input to the system. Flue gas desulfurization (FGD) systems that will be considered for the proposed HITAF system include wet FGD, regenerative techniques that recover elemental sulfur or sulfuric acid, and dry injection techniques including spray dryers and duct injection. Some problems with these techniques are evident. Generally, technologies focused on regenerative systems have higher capital costs and higher energy consumption. Also, dry injection usually meets with less success than the other methods. However, second generation wet FGD, currently under development, promises greater than $95 \% \mathrm{SO}_{2}$ removal, reliability greater than $99 \%$, and energy consumption of less than $2 \%$ of station energy input. For these reasons we expect to use 2nd generation wet FGD to minimize risk, capital and $0 \& M$ costs while still meeting or exceeding the $\mathrm{SO}_{2}$ removal levels required for the HITAF systen.

\section{Particulate Control}

Entrained ash material generated during coal combustion is generally controlled using either electrostatic precipitation or fabric filtration. The goal of the proposed HITAF system is to achieve control of particulate to a level of at least $0.0075 \mathrm{lbs} / 10^{6}$ BTU. This translates to approximately $99.9 \%$ collection efficiency for a coal with $10 \%$ ash and $12,000 \mathrm{BTU} / \mathrm{lb}$.

We feel the technology of choice will be fabric filtration. This selection was made using information available now and will be readdressed as more definition of the size distribution, composition, and flux of fly ash is in the HITAF system is obtained. Additionally, the EERC is currently aware of and will continue to follow the efforts of a number of researchers as they investigate the potential of new techniques for particulate control. Fabric filtration was chosen for the following reasons:

a) Although either a well operated ESP or fabric filter could meet the proposed removal goal, the ESP would more than likely need to be oversized to assure compliance.

b) Since fabric filtration offers better performance than ESPs for submicron particulates, the probability of a relatively high fine particulate flux in HITAF flue gas indicates that fabric filtration will offer better overall control of particulate emissions as compared to ESPs.

c) It appears that the use of conditioning agents may allow for a significant reduction in baghouse size while maintaining high performance. 
No experimental research will be performed in this task in Phase 1 of Combustion 2000. Instead, literature review and discussions with researchers studying the control of $\mathrm{SO}_{x}$ and fly ash from coal burning power plants, as well as experience gained from concurrent research being performed at UNDEERC and PSIT, will be used to keep the researchers abreast of the latest developments in the control of these effluents.

No report will be prepared as a part of this task. Instead, the knowledge gained will be used to prepare a proposal for control of So and fly ash emissions from a demonstration HITAF that will be proposed for Phase 2 of Combustion 2000.

\section{Task 2.2.2.9 Controls}

The purpose of this subtask is not to evaluate the control systems that are required for the entire advanced power system but only those concerned with combustion controls, including:

- coal quality monitoring;

- coal flow rate;

- oxygen addition if appropriate;

- HITAF furnace temperatures, and

- wall/tube conditions.

The effort in this task was reprogrammed after contract negotiation to account for the reduction in contract cost. The combustion control system will be considered in Task 3.1.7. 
Task 2.3 Preliminary Bconomic Analysis

At this point, only the gas turbine and steam power equipment are defined well enough to perform preliminary economic analysis. Since alternative cycles would only involve changes in steam conditions, economic analysis was limited to evaluating the cost effects of changing steam conditions and estimating the effect that advanced steam systems would have on life-cycle costs. The approach was based on the EPRI Levelized Cost procedures detailed in the 1979 EPRI Report (Technical Assessment Guide - PS-1201-SR, July 1979, Electric Power Research Institute).

\section{Levelized Costs}

The utility industry makes decisions on equipment purchases based on the concept of life cycle costs. This means that the owning and operating expenses of equipment alternatives are compared on the basis of their costs over the life time of the alternative. One method of doing this that allows comparison of a variety of alternatives on an equal basis is the use of the levelized cost.

The revenue requirements for an alternative will involve a series of annual fixed and variable charges arrayed over the life of the equipment. This series of numbers is often difficult to compare with other alternatives, hence the use of the present value analysis to develop the present value of the annual revenue requirements. For convenience, the single present value number may be levelized over a given period of time, usually the equipment useful lifetime (book life). The revenue requirements in terms of the annualized present value and levelized cost are shown in Fig. 35.

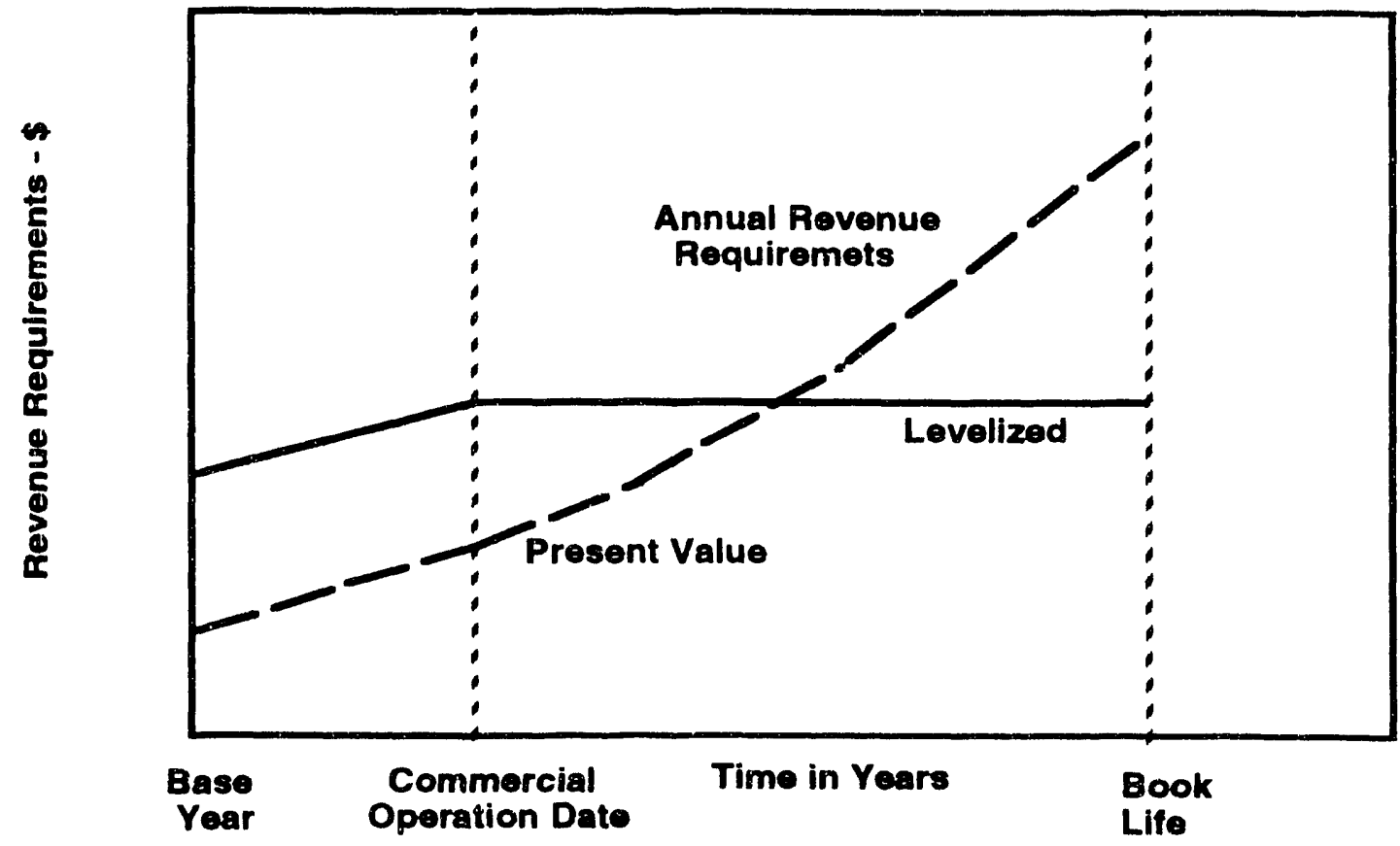

Fig. 35 - Levelized Costs 


\section{Equipment Costs}

Incremental costs of equipment, i.e., the cost of additional kWUs over and above the baseline system design, were obtained as a function of pressure and temperature. These data were normalized to the baseline (cost at 1800 psi $1000 \mathrm{~F} / 1000 \mathrm{~F}$ is 1 ) and determined for a range of pressures and temperatures. The relationship for steam turbines is shown in Fig. 36 and for heat recovery steam generators in Fig. 37.

Using these cost relationships, an incremental levelized cost of power was determined to identify the benefits of using advanced steam conditions. The methods used to annualize the costs are those used by EPRI. The results are shown in Figs. 38 through 40 for fuel costs of $\$ 1, \$ 4$, and $\$ 10 / \mathrm{milli}$ ion $B$ tu. It is only at very high fuel costs that the increased performance of the advanced steam systems offsets the increased capital cost of the turbine and HRSG. Costs for the low-temperature air heater (from compressor discharge at $732 \mathrm{~F}$ to radiant section inlet) could not be evaluated because the furnace design variables have not been well enough defined.

\section{HRSG Incremental Cost}

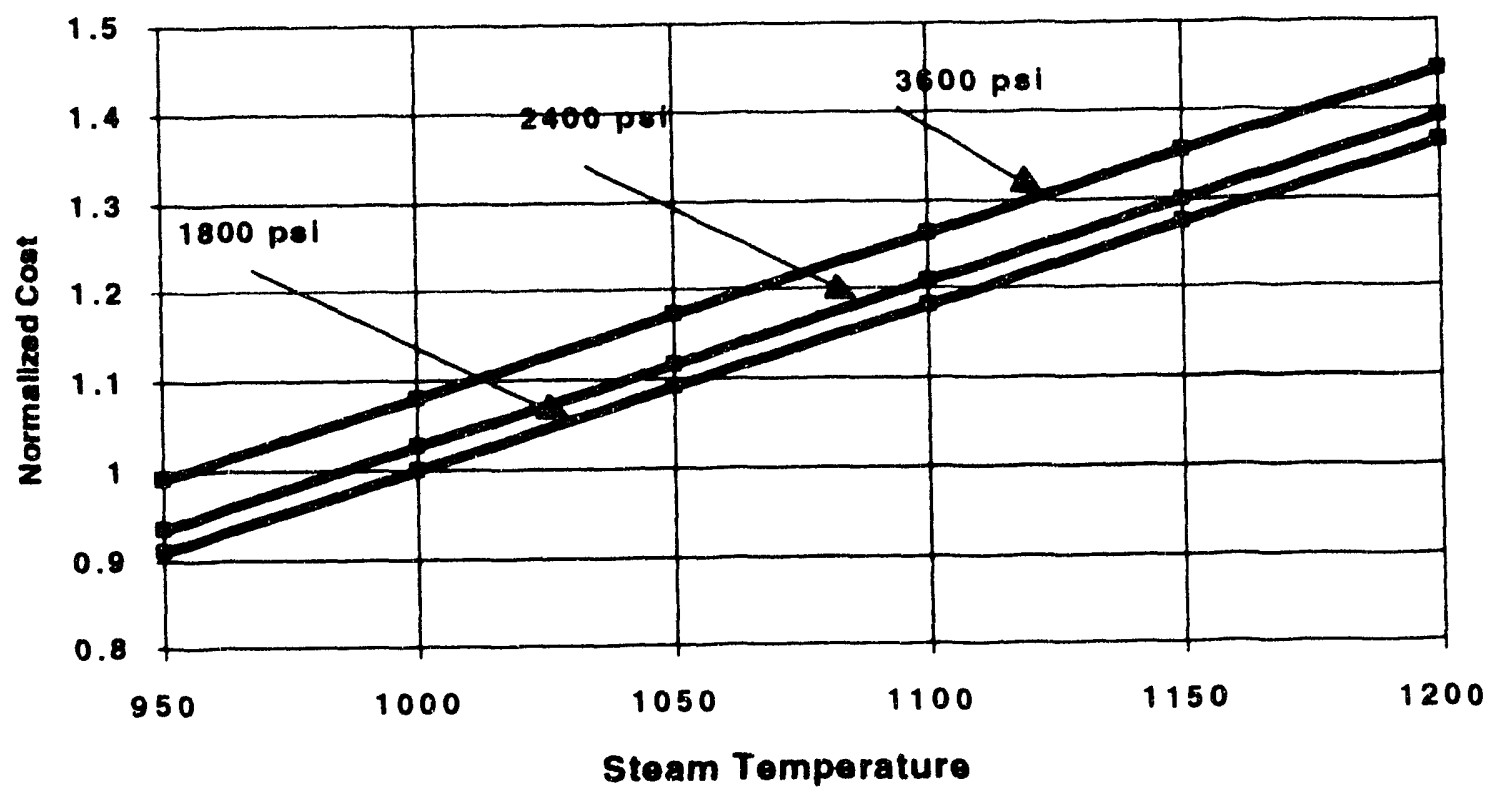

Fig. 36 - Incremental costs of steam turbines 
Steam Turbine Incremental Cost

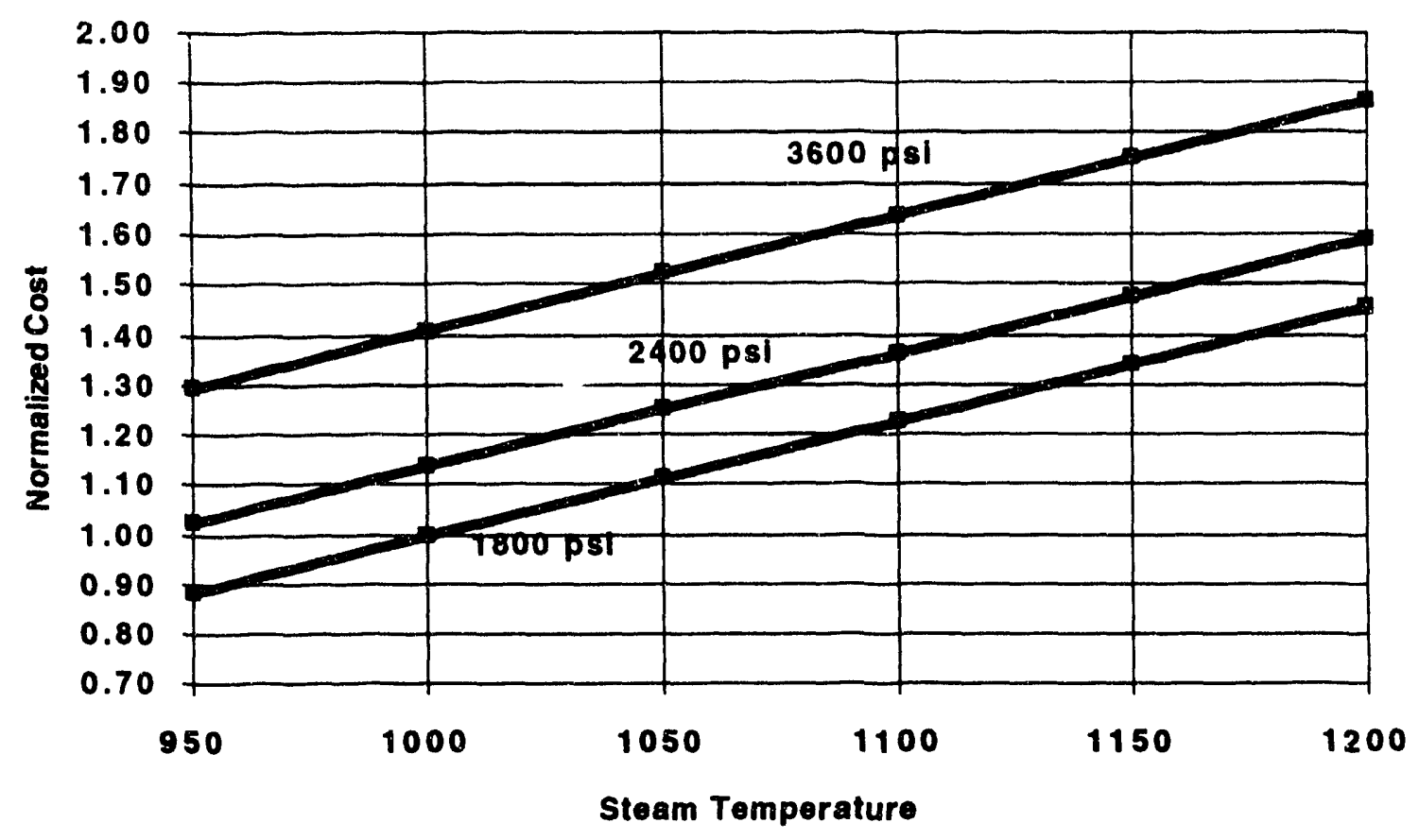

Fig. 37 - Incremental cost ratio for HRSG

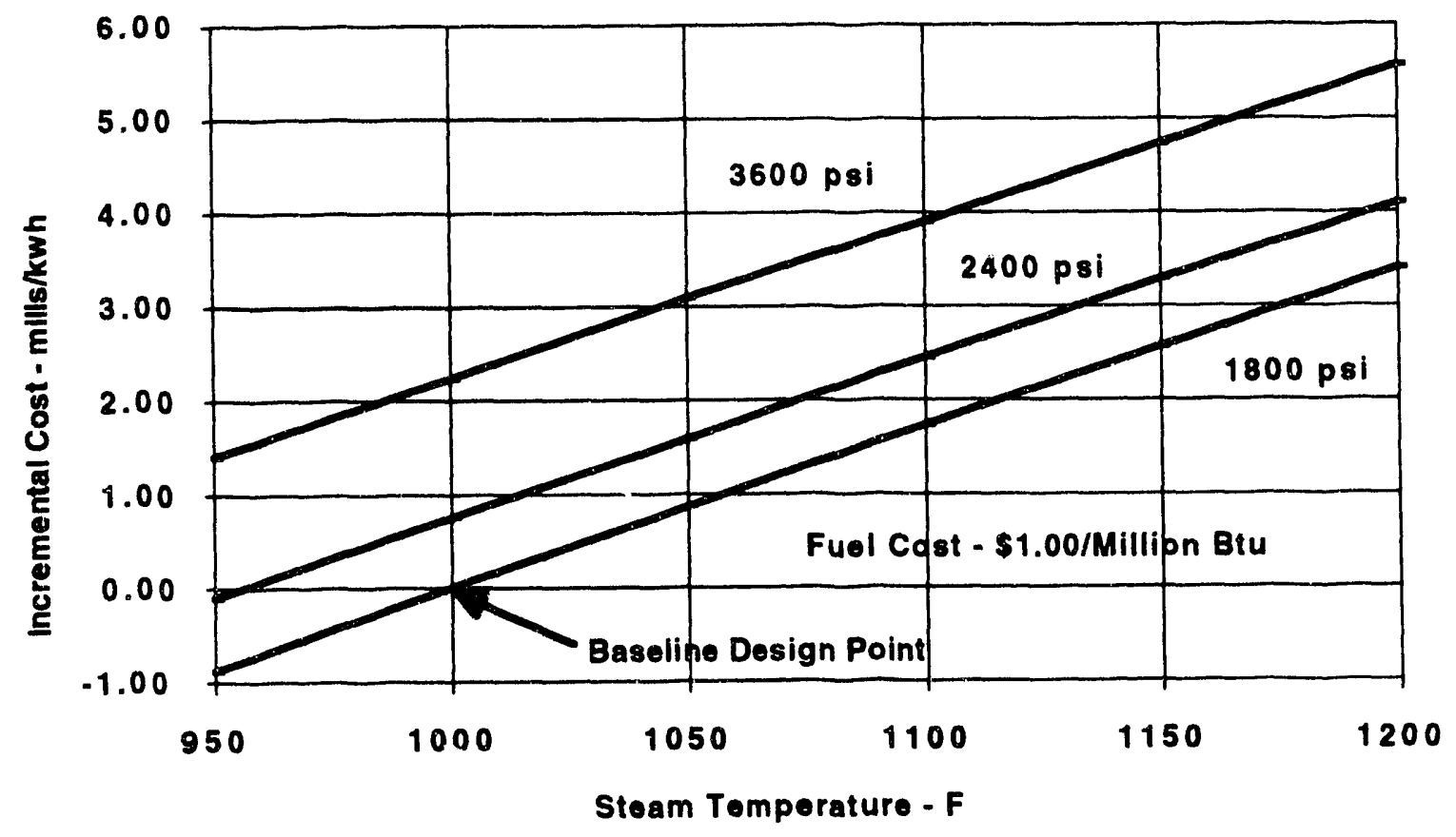

Fig. 38 - Incremental levelized cost 


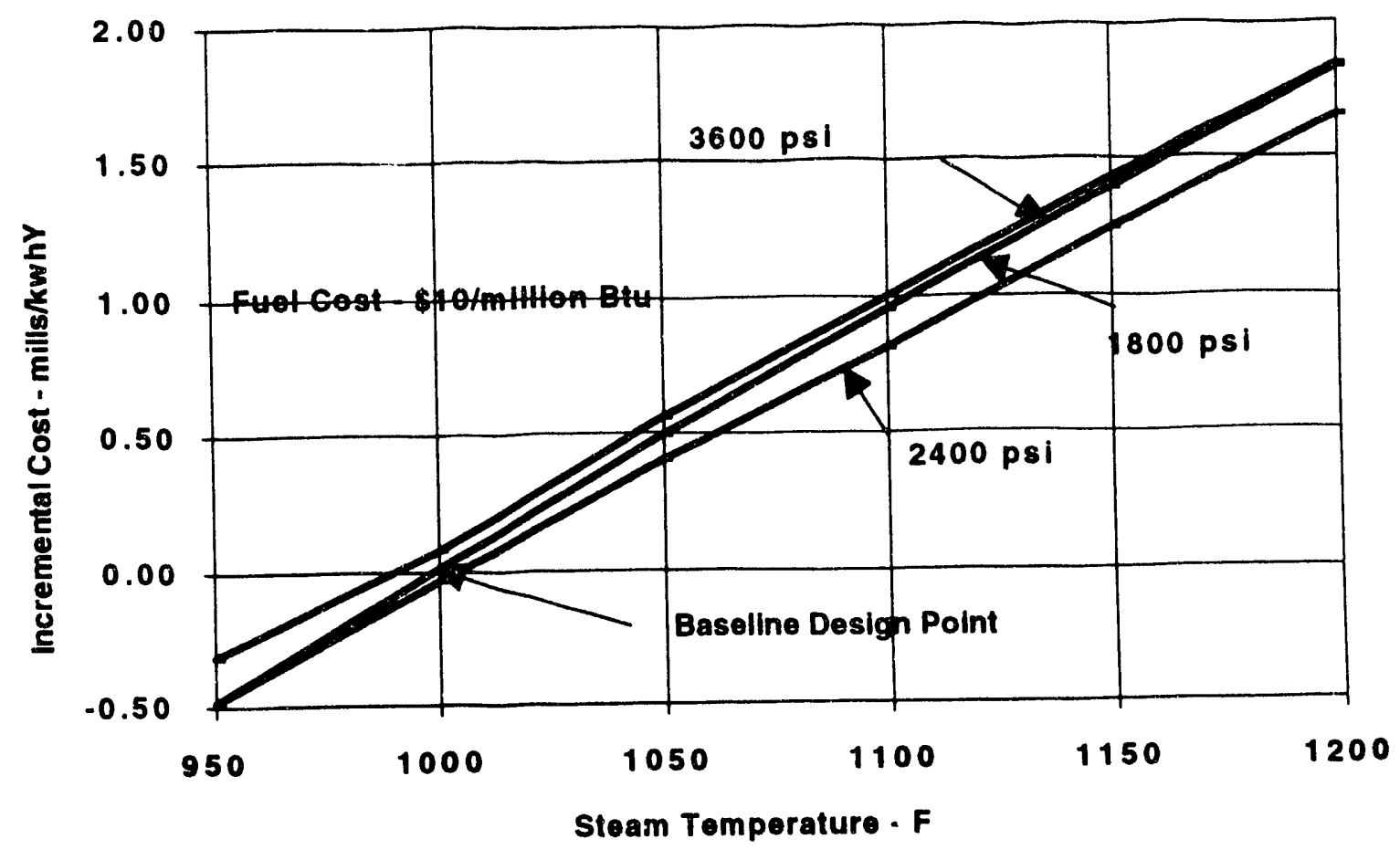

Fig. 39. Incremental levelized cost

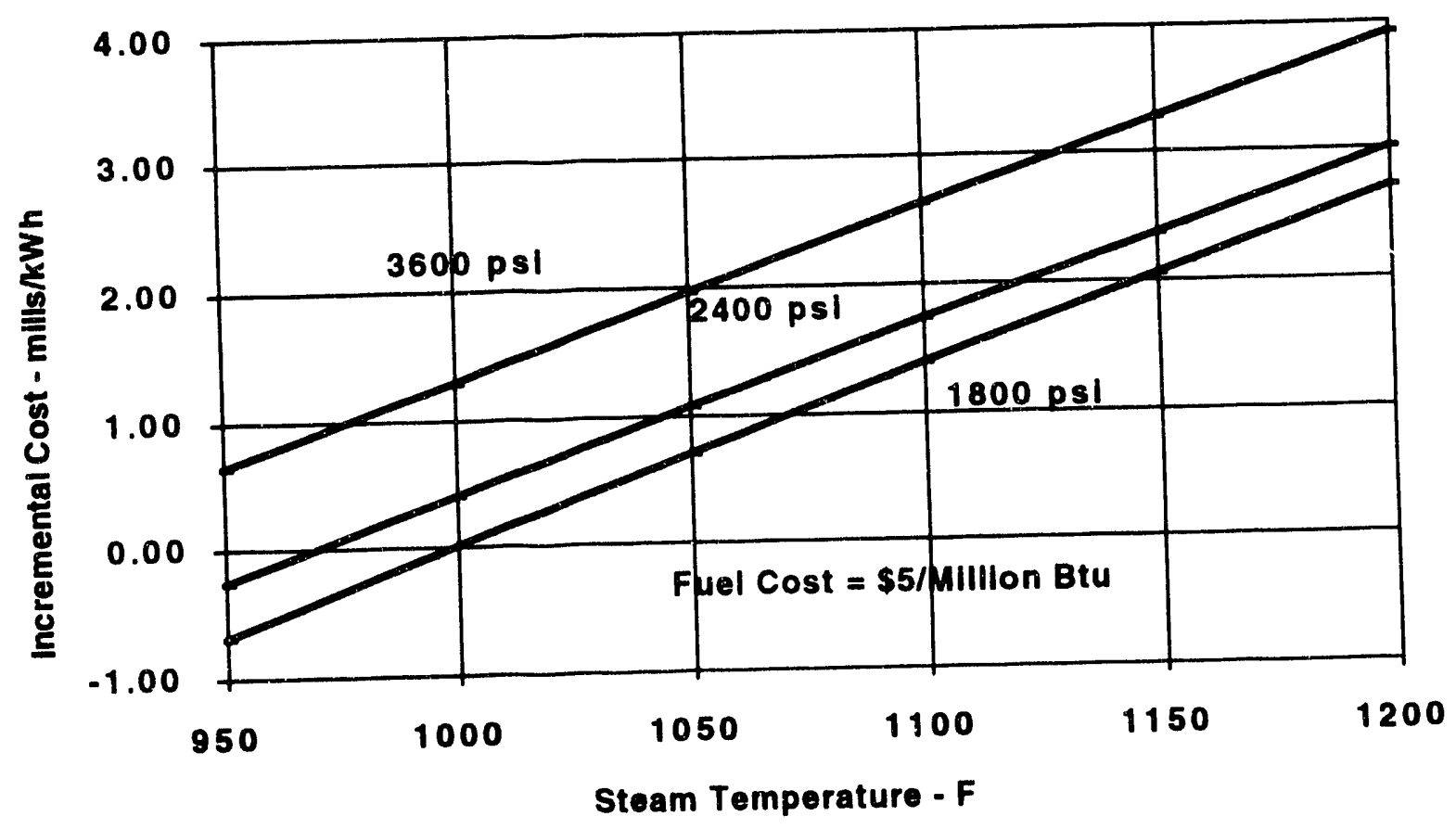

F1g. 40. Incremental levelized cost 
Task 2.4 Preliminary R\&D Program for Task 3

This task outlines the work to be carried on in Task 3 Preliminary R\&D. It also constitutes a necessary addition to the Project Plan.

Task 3,1.1 Chemical Reactor Modeling

Task 3.1.1 Chemical Reactor Modeling includes two subtasks: 3.1.1.1 Engineering Analysis (see Table 4) and 3.1.1.2 Parametric Studies (see Table 5). These tasks will provide information on the design constraints that control primary No formation. Particularly the volume and the furnace aspect ratio as a function of the final No level. The requirements for optimized tertiary No control will be considered also. It should be noted that the deadline for preparation of the topical report has been delayed to reflect the current estimate of time that will be required to complete this task. The control systems for the HITAF will be considered in subtask 3.1 .7

The HITAF performance modeling will be completed under subtask 3.3.1. First, it will be necessary to improve certain submodels in subtask 3.3.1.1 that are included in the current combustion code. These are:

$$
\begin{aligned}
& \text { - the }{ }^{N O}{ }_{x} \text { submodel; } \\
& \text { - the carbon conversion submodel, and } \\
& \text { - the wall deposition model. }
\end{aligned}
$$

The full scale combustor simulations will be carried out in subtasks 3.3.1.2 and a test will be carried out at small pilot scale to verify the design concepts 
Task 3.1.1.1 Engineering Analysis

\section{Objective}

To establish the design requirements for two combustor types: a delayed controlled mixing system, and well mixed rich system for primary N0 formation assuming a given wall temperature. Tertiary ${ }^{\mathrm{N} O} \mathrm{x}$ control design requirements will be considered also.

\section{Background}

Previous work has demonstrated that two combustor types could satisfy the No emission requirements l:or the HITAF, but the well mixed rich system requires a high temperature environment that will probably produce liquid ash deposits for most coals. The alternative design could be less expensive but less flexible with regard to coal capability.

\section{Technical Approach}

Two engineering analysis tools will be used to evaluate the design requirements for the two combustor types; a comprehensive combustion code and a well mixed gas phase kinetics code. The kinetics code will be used to evaluate recently published data on selective NO reduction processes to gain confidence in the kinetic reaction set before conducting a study to evaluate the influence of HITAF conditions on the effectiveness of the tertiary reduction process. The primary output will be reduction efficiency as a function of residence time for a temperature range that could be applicable to a hold-up zone in the convective air heater. The kinetic code will be used to establish XN species concentration at the exit of a well mixed hot combustor as a function of: residence time; temperature and stoichiometry. The comprehensive code will be used primarily to evaluate the delayed controlled mixing concept in order to optimize combustor size, aspect ratio, flame energy release, pilot gas ignition, coal type and coal size distribution for primary No control, carbon burnout with wall temperatures required to satisfy the need of the radiant air heater.

\section{Deliverables}

Preliminary design specifications for the two combustor types for varying degrees of primary and tertiary No control. 
Task 3.1.1.2 Parametric Studies

Objective

Provide experimental information on the impact of HITAF design variables on No formation in pulverized coal flames.

\section{Background}

Data is not available on No formation under the specific (somewhat unusual) conditions proposed for the primary zone of the HITAF: vitiated oxidant with reduced initial $0_{2}$ concentration (17\%); small coal particles $(90 \%-200$ mesh, reduced top size); possibility of limited (and non-uniform) $\mathrm{O}_{2}$ enrichment, auxiliary gas piloting; $1050 \mathrm{~F}$ preheat, and minimally cooled walls. Data are needed to verify the influence of these variables on $\mathrm{NO}_{\mathrm{x}}$.

Technical Approach

This testing will be conducted in the $100,000 \mathrm{Btu} / \mathrm{hr}$ pulverized coal facility in the University of Utah combustion laboratory (the "Tower Furnace") which is currently being modified to produce the required combustion environment. This downfired, refractory-walled combustor is 6" in inside diameter and has multiple ports for downstream air or gas addition, flame observation and sampling as illustrated in the following figure. The variable swirl burner will be fitted with a special axial injector for this testing. NO, $\mathrm{CO}, \mathrm{CO}_{2}, \mathrm{O}_{2}$ and THC emissions are continuously monitored in the exhaust.

The parameters to be tested will include:

- Inlet oxygen concentration (17 to 20\%)

- Primary air percentage ( 5 to $25 \%$ )

- Oxygen enrichment $(21-30 \%)$

- SR primary zone $(1.25-0.7)$

- Use of segmented air

- Particle size distribution

- Gas piloting

- Coal type

- Wall temperature (cooled uncooled)

\section{Deliverables}

Data identifying parameters most critical to primary No formation under HITAF conditions. 
Task 3.1.2 Air Heater Design

OBJECTIVE

The performance of radiant and convective air heater designs shall be evaluated using state-of-the-art fluid dynamics and heat transfer models. Physical configurations for the air heaters will be determined and the designs will be optimized for size, weight, heat transfer, survivability, and fabrication.

\section{BACKGROUND}

Before the various performance capabilities of the radiant and convective air heaters can be established, the following key technical issues related to air heater performance will be studied:

(1) What is the correct or optimum distribution of heat loads between the radiant and convective air heaters in relation to coal type and ash management considerations?

(2) What design features will serve to minimize thermal stresses in the radiant and convective air heaters?

(3) What refractory materials offer the best combination of properties for minimum thermal resistance, maximum service life, and ease of application?

(4) What is the optimum shape for the hot gas side surface of the convective air heater to maximize heat convection and minimize deposition of ash particles?

(5) What are the specific design features of the air heaters which will ensure acceptable levels of thermal and mechanical functions, fabrication, survivability, and cost?

(6) How will the radiant and convective air heaters be integrated in the HITAF system in relation to other major equipment for coal combustion, ash and slag removal, and pollution control?

\section{TECHNICAL A.PPROACH}

This task will involve the use of state-of-the-art fluid dynamic and heat transfer models to evaluate the performance capabilities of potential radiant and convective air heater concepts in the HITAF environment. Since design concepts and requirements of the air heaters are interrelated with other major components of the HITAF, this activity will be coordinated with other program technical issues regarding coal combustion, cycle performance, ash management, pollution control, materials, structural design, component integration and econouics. While existing computer codes will be used in some instances, new mode:s will be developed whenever existing models are inadequate. 


\section{DELIVERABLES}

A report will be prepared documenting the results of this task with regard to the technical issues for the air heaters listed above. This report will include an assessment of the performance capabilities of radiant and convective air heaters in the HITAF environment ano recommendations regarding the best methods of integrating air heaters in HITAF system. 


\section{Task 3.1 .3 Air Heater Materials}

\section{OBJECTIVE}

Identify a minimum of four candidate structural ceramic materials as suitable candidates for the air heater. Estimate slag corrosion effects based on vendor supplied and open technical literature.

\section{BACKGROUND}

Several state-of-the-art commercially available structural ceramic materials are under consideration for use in the HITAF air heater. Consideration must be given both to the high temperatures that must be endured for extended periods of time, as well as the corrosive effects of various coal ash deposition products on long term materials behavior.

\section{TECHNICAL APPROACH}

This Task will consist of selecting four prime ceramic material candidates for more detailed investigation. Ceramic material high temperature strength, high temperature durability (e.g., slow crack growth resistance), fracture toughness, Weibull modulus and thermal conductivity will be correlated from vendor supplied and open technical literature. Wherever possible, estimates of the materials performance in both static and dynamic coal combustion environments will be obtained (again through vendor supplied or open technical literature). Some consideration will also be given to vendor capability with respect to potentially processing the comparatively large air heater panels under design for the HITAF.

Specifically, a minimum of seven materials/vendors will be determined which have potential capability for functioning in the HITAF air heater for extended periods of time. Based on the criterion described above, the primary goal of this task will be to downselect to four materials/vendors whose materials systems are found to warrant further testing and evaluation.

\section{MILESTONES/DELIVERABLES}

For this Task the deliverable will be the four downselected candidate materials along with a report of their physical, chemical and mechanical properties. Wherever possible, information will be provided as to a given materials performance in a coal combustion environment. Also, some note will be made with regard to the vendor's experience in fabricating large/complex shapes. 
Task 3.1 .4 Air Heater Structural Analysis

\section{OBJECTIVE}

The performance of radiant and convective air heater designs shall be evaluated lising state-of-the-art fluid dynamics and heat transfer models. Physical configurations for the air heaters will be determined and the designs will be optimized for size, weight, heat transfer, survivability, and fabrication.

\section{BACKGROUND}

Before the various performance capabilities of the radiant and convective air heaters can be established, the following key technical issues related to air heater performance will be studied:

(1) What is the correct or optimum distribution of heat loads between the radiant and convective air heaters in relation to coal type and ash management considerations?

(2) What design features will serve to minimize thermal stresses in the radiant and convective air heaters?

(3) What refractory materials offer the best combination of properties for minimum thermal resistance, maximum service life, and ease of application?

(4) What is the optimum shape for the hot gas side surface of the convective air heater to maximize heat convection and minimize deposition of ash particles?

(5) What are the specific design features of the air heaters which will ensure acceptable levels of thermal and mechanical functions, fabrication, survivability, and cost?

(6) How will the radiant and convective air heaters be integrated in the HITAF system in relation to other major equipment for coal combustion, ash and slag removal, and pollution control?

\section{TECHNICAL APPROACH}

This task will involve the use of state-of-the-art fluid dynamic and heat transfer models to evaluate the performance capabilities of potential radiant and convective air heater concepts in the HITAF environment. Since design concepts and requirements of the air heaters are interrelated with other major components of the HITAF, this activity will be coordinated with other program technical issues regarding coal combustion, cycle performance, ash management, pollution control, materials, structural design, component integration and economics. While existing computer codes 
will be used in some instances, new models will be developed whenever existing models are inadequate.

A report will be prepared documenting the results of this task with regard to the technical issues for the air heaters listed above. This report will include an assessment of the performance capabilities of radiant and convective air heaters in the HITAF environment and recommendations regarding the best methods of integrating air heaters in HITAF system.

Structural analyses at a general or preliminary level will be performed on the air heater designs in support of activities under Task 3.1 .2 and related tasks. Using finite element modeling based on steady state conditions, estimates will be made of maximum displacements and stresses for differing heater orientations, supporting boundary conditions, weights, and thermal loadings under expected HITAF operating conditions.

Inasmuch as the components of the HITAF system will be expected to endure severe mechanical and thermal conditions for a long period of time, structural analyses of these components, particularly the air heaters, is an important activity to the development of the HITAF system.

In coordination with the activities of Task 3.1.2, finite element modeling will be used to evaluate the structural capabilities of radiant and convective air heater designs. These analyses will consider the effects of mechanical and thermal loads on the integrity of key structural members of the air heaters. Estimites will be made of displacements and stresses in air passage walls, ai. seals, headers, refractory, and other structures which are expecteu to be exposed to such severe loads. Because ceramic materials are expected to be used for fabrication of many of the structural components for high temperature sections of the air heaters, design features which would minimize stresses in these components will be investigated.

\section{DELIVERABLES}

A report on the displacements and stresses expected in the key structural components of the radiant and convective air heaters will be prepared. This report will include the results of an investigation of design features which would serve to minimize thermal stresses in air passage walls, air seals, headers, refractory and other key structural components. 
Task 3.1 .5 - Definition/Evaluation of Slag Impacts

\section{OBJECTIVE}

Evaluate the implications of the following ash properties on the HITAF design:

Partitioning based on thermodynamic equilibrium

Ash particle composition, particle size, ash viscosity

Deposition mechanisms for ash in the air heater

Alkali-ceramic interactions

Slag-ceramic interactions.

\section{BACKGROUND}

One of the most serious and costly problems associated with the combustion of pulverized coal is the deposition of ash on heat transfer surfaces. In traditional p.c. combustion systems, slagging of water wall furnaces, caused by low viscosity ash, and fouling of convective surfaces, frequently caused by condensing volatile species, contribute to increased heat rate and decreased process availability. Both deposition mechanisms may also create conditions which foster corrosion, leading ultimately to tube failure. During the combustion of pulverized coal, the inorganic species contained in coal interact to form glassy melts, crystalline particles, vapors, and submicron fumes. Although the majority of the resulting ash particles will be removed in scrubbers or electrostatic precipitators in p.c. systems, a small portion may deposit on heat transfer surfaces during its passage through the boiler.

A relatively small number of particles initiate a deposit. However, as the deposit begins to grow, heat transfer is impacted, its surface temperature increases, and more particles are likely to become incorporated. Deposit growth can be rapid. Once the deposit begins to grow, it must be mechanically or thermally removed before it sinters inco a strongly bonded mass that may be impossible to remove without shutting down the unit. Even if the deposit is removed, a residue usually remains to form the basis of the next growth cycle. To control ash deposition, the furnace designer must either prevent the deposit from initiating (via coal

seleciion/beneficiation or furnace sizing to eliminate transport mechanisms) or provide the means to remove troublesome deposits before they sinter. Realistically, both will be needed.

In addition to deposition and corrosion, erosion of heat transfer surfaces can significantly degrade equipment integrity. Erosion is caused by fly ash particles that impact and mechanically remove portions of the tube metal surface. Erosion rate is related to the size of the particles, their composition (relative to hardness), and the velocity of the gas stream propelling them onto a surface. In conventional boiler systems, convective pass tubes and their supporting hangers are most prone to erosion. These surfaces are tube bundles located in crossflow, subjecting them to inertial impaction. Normally, the gas velocity between the tubes is limited to 60 $\mathrm{ft} / \mathrm{s}$ in order to minimize erosion. 
Erosion potential of a certain coal has been related to the amount of free quartz and pyrite that it contains. The quartz passes through the high-temperature regions unreacted, and the pyrite is converted to crystalline magnetite $\left(\mathrm{Fe}_{3} \mathrm{O}_{4}\right)$ or hematite $\left(\mathrm{Fe}_{2} \mathrm{O}_{3}\right)$. The resulting particles are of ten harder than the tubes and can slowly wear them away.

A wealth of information on the deposition, corrosion, and erosion of ash in conventional p.c. systems exists in the literature. However, the corresponding information applicable to the operation of high temperature, ceramic heat exchangers is scant. Previous work sponsored by DOE and EPRI (Pietsch, 1978; Ward and Kubasco, 1983) demonstrated the ability to fabricate large and complex silicon carbide air heaters for use in combustion systems. Unfortunateiy, the running time with coal ash was limited to a few tens of hours. Ferker and Tennery $(1981,1982)$ exposed single air-cooled silicon carbide tubes to the ash from an oil-coal combustion furnace for 200 to $500 \mathrm{hr}$. The latter work represents the longest exposure, but features relatively simple geometry. This leaves us with unanswered questions about the interactions of ash with ceramic components.

The research areas for controlling deposition, corrosion, and erosion can be summarized as follows:

- Ash particle viscosity and aerodynamics: ash composition versus particle size; deposition of sticky ash particles, thermophoretic deposition of submicron fume.

- Slag-ceramic interactions: sintering and deposit strength, corrosion as a function of temperature and composition

- Alkali release: enhanced vaporization of alkali, form of vapor-phase alkali

- Alkali-ceramic interactions: corrosion reactions as function of temperature, composition.

\section{TECHNICAL APPROACH}

This task is related to experimental and modeling tasks in that it will define measurements and/or modeling and analysis that are needed as outlined in Table 5. Beyond definition of experiments and modeling, this task will provide a framework of ash management in the combustion system. 
Critical Issues for Preliminary R\&D in Ash Management

Ash Particle Viscosity and Aerodynamics

Slag-Ceramic Interactions

Alkali Release

Alkali-Ceramic Interactions
Mineral transformation Composition and size distribution of ash

Pyrite transformation model

Viscosity model

Deposition Aerodynamirs

Equilibrium thermochemistry with non-ideal solution theory

Viscosity model

Mineral matter transformation model

Vapor-phase alkali kinetics

Silicate-alkali interactions

Equilibrium thermochemistry model with non-ideal solution theory, vapor-phase alkali kinetics
Ceramic corrosion by ash deposits

\author{
Alkali release at \\ representative \\ cond 1 tions
}

\section{DELIVERABLES}

A literature evaluation and technical assessment will be completed in the areas of oxidation and corrosion of materials, particularly ceramics, under expected HITAF conditions. The other deliverable from this task will be a structure for performing a complete ash mass balance, coal pile to disposal/emission. The ash mass balance will be continuously refined as the work in Task 3 proceeds. 
Task 3.1 .6 Waste Processing

\section{OBJECTIVE}

The objective of this task is to assure that the research team remains current in the field of ash utilization so that an efficient strategy for determining economical use of the ash produced in a HITAF system can be developed. No experimental work will be performed in this task during Phase I.

\section{BACKGROUND}

The potential of ash produced in a coal-fired utility boiler as an engineering material has not been fully realized and may only be limited by available technology and scientific and engineering innovation. Several documents describe the history of coal ash utilization (Torrey, 1978; Manz, 1989a,; Faber and Babcock, 1987), and many are high volume applications. Primary among these are the low and medium technological level applications such as cement replacement in concrete (Manz et al., 1989), mineral filler in asphalt (Weishan, 1990), for soil stabilization including road bed stabilization (Manz and Manz, 1989), structural fill applications (Brendel et al., 1987; Buss, 1987; Weber, 1987; Pintcke, 1987), and in bricks and ceramic materials (Faber and Slonaker, 1989; Hay and Rademaker, 1987). These applications can readily be subdivided into more specific applications.

The use of fly ash as a cement replacement in concrete includes use in paving concrete, manufacture of concrete block and pre-cast concrete building forms, roller compacted concrete, and concrete with specific requirements for strengths and resistance to chemicals. Additionally, fly ash may be used to produce a light weight aggregate (Hay and Rademaker, 1987; Styron, 1987) which can also be used in concrete mixes and is especially desirable in concrete block manufacturing. Bottom ash can also be used as a replacement for standard aggregate in concrete mixes, and combinations of concrete containing fly ash as cement replacement and bottom ash as aggregate is a good option for utilization applications. The specific applications of fly ash in bricks and ceramics as well as in structural fills are equally varied and constantly being expanded.

other low and medium technological utilization application that have been developed more recently include the production of mineral fibers from either fly or bottom ash. These fibers are most frequently used as mineral wool for insulation purposes, but other applications are being investigated. These applications will rely on the strength and chemical nature of the mineral fibers. Bottom ash is an excellent abrasive material which can be used in sandblasting and other similar applications. The production of light weight aggregate, mentioned above, is also a relatively new process meeting with success in the construction industry. 
Recent developments have also been made in higher technological

applications of coal ash. Fly ash has been used as an extender in plastics and paints (Manz, 1989b). Coal ash is also being used for solidification of hazardous wastes (Jablonski, 1987; Smith, 1990; Lahrs, 1990) and investigation of this application continues. The use of coal ash to stabilize hazardous wastes is being researched extensively at UNDEERC (Hassett et al., 1989). Work at PSIT also provides evidence to show that chemical reactions between the ash and hazardous wastes may chemically stabilize potentially hazardous inorganic elements.

The North Dakota Mining and Mineral Resources Research Institute at the UNDEERC has extensive experience in the utilization of this high quality engineering material. Many of the applications listed have been investigated in research projects conducted by the group from both the scientific and engineering standpoints. Coal ash utilization research continues at UNDEERC working toward innovative applications and scientific understanding of the behavior of the coal combustion ash in those applications.

\section{DELIVERABLES}

No experimental research will be performed under this task. Instead, literature review and discussions with researchers studying coal ash utilization will be used to prepare a report describing the state of ash utilization at the end of Phase $I$. It will also include recommendations for an experimental matrix to determine a suite of beneficial uses of the coal ash produced in a HITAF system that will be built in Phase II. The report will be prepared for inclusion in the Phase $I$ report and as part of the Phase II research proposal. 


\section{Task 3.1 .7 Combustion Controls}

Objective

Identify combustion system control options that will: 1) maintain uperation of the HITAF at optimum conditions, and 2) identify potential problem areas that will affect system availability.

\section{Background}

Current combustion control systems may be insufficient for the selected HITAF design. Precise control of certain variables may be necessary to ensure minimum NO emissions and optimum performance over extended time periods.

\section{Technical Approach}

This task will evaluate controls to maintain long term operation at the design point. The systems that will be considered include:

- Coal input monitoring including coal flow to each burner and on-line coal quality monitoring to identify potential future deposition problems.

- Direct flame imaging to monitor ignition distance and perhaps flame configuration in multiple burner systems.

- Optical diagnostics to maintain appropriate stoichiometry in the primary zone of the well mixed rich combustion system.

- Diagnostics to monitor surface deposit temperature.

- Diagnostics to monitor spatial distribution of gas/particle temperatures at strategic locations.

Consideration will be given to linking all of this information to a central model based control system.

\section{Deliverables}

Suggested sensors and control schemes for the HITAF and for the entire power plant system. 
Task 3.2 Experimental Research

Task 3.2.1 Coal and Ash Preparation

\section{OBJECTIVE}

The objective of this task is to obtain, characterize, and distribute (as required) coals for use in combustion and deposition/corrosion experiments. The coals acquired shall be those identified in an earlier task.

\section{BACKGROUND}

As part of Tasks 2.2.2.4 (Coal Selection) and 2.2.2.6 (Coal Cleaning Evaluation), four coals shall be selected for further study. Although some or all of these coals may have been previously studied by PSIT and UNDEERC in other programs, additional combustion testing will be required. At a minimum it will be necessary to generate ash samples for ash-ceramic materials interaction testing; it may also be necessary to conduct baseline combustion experiments to identify the size and composition of ash particles generated under HITAF combustor conditions.

Approximately $75 \mathrm{~kg}$ ( 40 gallons) of each coal are required to generate ash for all corrosion experiments. Including $5 \mathrm{~kg}$ each for possible combustion transformation experiments and an estimated $5 \mathrm{~kg}$ for any oxygen-enriched combustion experiments at UTRC (Task 3.2 .7 ), $85 \mathrm{~kg}$ of each coal will be required.

\section{TECHNICAL APPROACH}

The technical approach for this task is as follows:

1. Contact the suppliers of the four coals identified in earlier tasks. Determine availability of $85 \mathrm{~kg}$ quantities of each.

2. Identify slitable location for pulverization of coal samples to the particle size identified by REI in the combustor design subtask. Coals may be pulverized either by the supplier, by UNDEERC, or perhaps on a purchase order basis through an independent laboratory. The possibility of pulverizing the coals at DoE/PETC may also be explored. While most of this coal will be finely pulverized to a size identified by the PTI combustor design team, a portion of the coal ( 2 to $3 \mathrm{~kg}$ ) should be pulverized to standard utility grind and retained for comparative purposes.

3. Arrange to have the pulverized coals transported to PSIT.

4. Provide samples of each coal to either an independent laboratory or UNDEERC for analysis. Coal analyses shall include: 
a. ASTM analyses:

Proximate, D-3172

Ul timate, $D-3176$

Ash chemistry, D-3682

Coal moisture, D- 3173

Coal size distribution, D-410

HGI, D-409

Chlorine, D-4208

HHV, D-3286

b. Chemical fractionation for organically bound species

c. Computer controlled SEM (CCSEM) for coal mineralogy analysis to determine size and composition of minerals that are $>1 \mathrm{~mm}$ in size.

d. (optional) XRD for overall mineralogy

e. (optional) trace element analysis by neutron activation analysis if it is determined that this information is required in Phase $I$ and that literature values for identical or similar coals are unavallable or unreliable.

f. (optional) CCSEM analysis of the mineralogy for the standard pc grind sub-sample of two of the coals.

5. Provide small samples of coal to other team members as required.

\section{DELIVERABLES}

Pulverized samples of each of the four coals, stored at PSIT and available to other teams members as required, and complete ultimate, proximate, and inorganic analyses for each of the coals shall be the PSIT deliverables for this task.

\section{Task 3.2.2 Mineral/Inorganic Transformations}

Combustion experiments will be conducted in the Entrained Flow Reactor Facility (ERF) at PSIT (Figure 16). The entrained flow reactor is designed to simulate heterogeneous combustion and mineral matter transformation processes under well-characterized laminar flow conditions. This furnace is capable of handling 1 to $10 \mathrm{lb} / \mathrm{hr}$ of solids feed $(10,000$ to 100,000 $\mathrm{Btu} / \mathrm{hr}$ heat input). The flame zone is swirl-stabilized in order to simulate the high intensity, near-burner region of an industrial furnace flame, followed by a plug flow burnout region. The flame may be fueled by coal and/or natural gas. Coal particles are introduced 


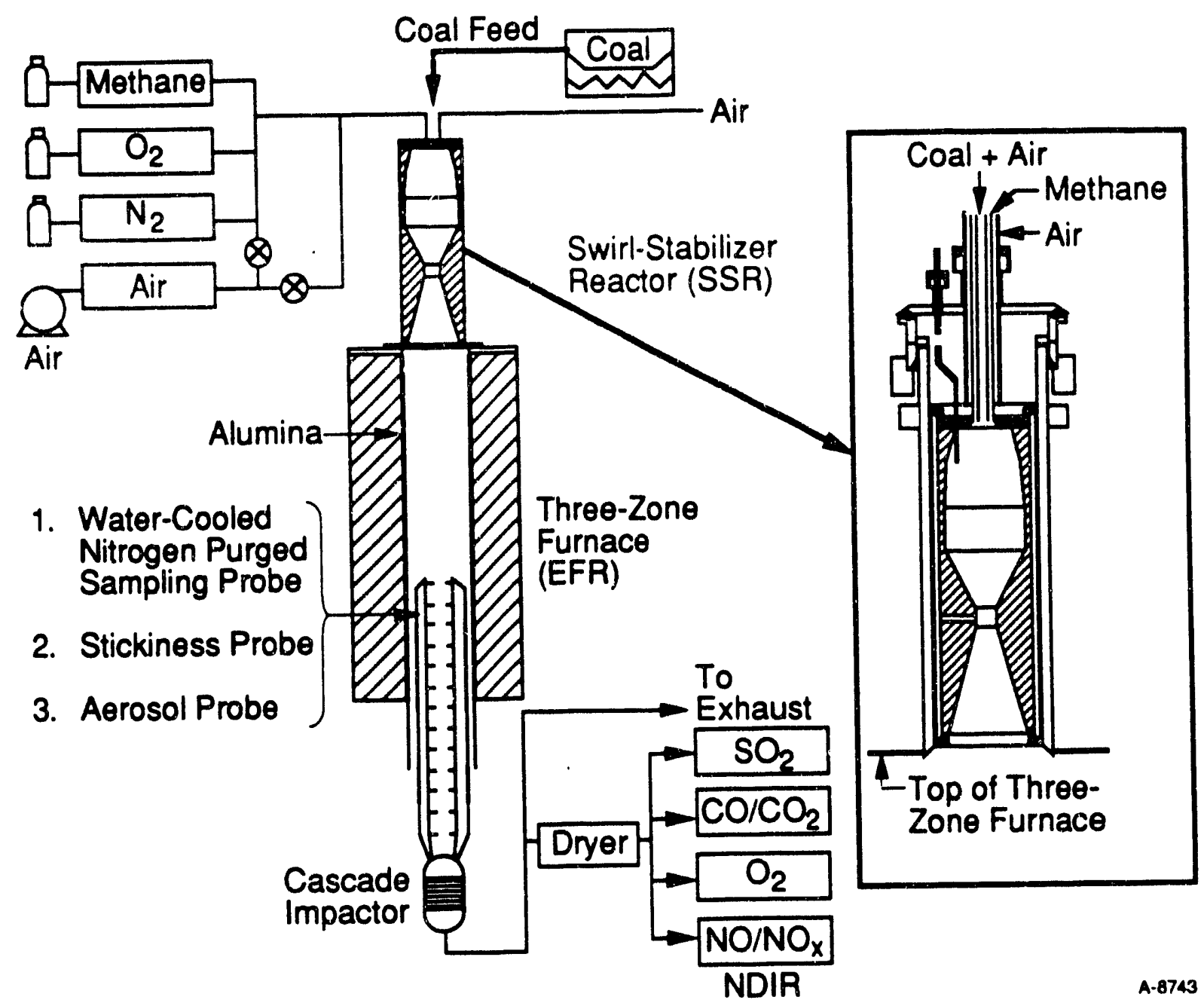

Figure 41. Entrained Flow Reactor

into the vertical tube furnace via a water-cooled injector. The primary gas is typically air supplied by a regenerative blower at a nominal rate of 2 scfm. Various gases (e.g., oxygen, sulfur dioxide) can be added to the primary air as required. The particle laden gases flow through a $3-3 / 8$ in. ID alumina tube furnace, 51 in. length, allowing residence times of up to $5 s$ at temperatures up to $1540^{\circ} \mathrm{C}\left(2800^{\circ} \mathrm{F}\right)$. Three zone, electrical temperature control of the furnace is included, providing uniform or variable temperature profile profiles. Water-cooled sampling probes are used to isokinetically sample and rapidly quench the ash particles from the furnace. A Pollution Control Systems cascade impactor and/or cyclone are used to size-segregate the ash particles. The combustion gases are cooled and dried, and analyzed continuously for $\mathrm{CO}, \mathrm{CO}_{2}, \mathrm{O}_{2}, \mathrm{NO}_{2}$, and $\mathrm{SO}_{2} . \mathrm{A}$ special deposition test section is used in the test factility to study ash deposit initiation and growth. 
Limited combustion experiments will be conducted with the four coals selected for further study under conditions representative of the HITAF combustor. The gas temperature oxygen partial pressure, and coal particle feed rate will be adjusted to achieve coal particle temperatures equal to the flame temperature expected in the HITAF. The coal particle size will be a fine grind (finer than standard pc grind) comparable to that anticipated for the HITAF system, as defined in a separate task by the REI combustor design team. Alkali vaporization and inorganic transformations will then be determined as follows:

1. Collect "total filter" ash samples by extracting ash particles from the post-combustion gases in the PSIT laboratory reactor with an isokinetic sampling probe, quenching them within the probe, and depositing them on - Olycarbonate filters.

2. Analyze the ash particles by CCSEM (2.000 to 3000 particles per sample) to obtain particle size and sizeresolved chemical composition distributions.

3. Collect size segregated ash particle samples using a PSIT-owned PCSC Mark III Cascade Impactor and cyclone precutter. Determine the amount of submicron fume by identifying the ash mass fraction $<1 \mathrm{~m}$ in size collected with this device.

4. Analyze selected cascade impactor stages for sodium content and (optional) potassium content by atomic absorption spectroscopy at an independent testing laboratory.

5. For two of the coals, collect "total filter" ash samples at standard pc combustion conditions. If avallable, a standard pc grind should be used for these experiments.

6. For two of the coals, collect size segregated ash particle samples from combustion of the standard pc grind coal sub-sample using a PSIT-owned PCSC Mark III Cascade Impactor and cyclone precutter. Determine the amount of submicron fume by identifying the ash mass fraction $<1 \mu \mathrm{m}$ in size collected with this device.

7. If significant differences in ash vaporization and ash chemical composition distribution are observed between fine grind coals at HITAF conditions and standard pc grind coals at typical utility combustion conditions are observed, analyze the submicron fume and selected impactor stages for sodium content. 
8. Analyze data to determine differences in ash formation behavior at HITAF conditions for a finely pulverized coal compared with that observed for a standard pc grind coal under typical utility combustion conditions.

\section{DELIVERABLES}

Ash particle size distributions, ash particle chemical composition distributions, measurements of the amount of submicron ash, and measurements of the amount of sodium vaporized (and residing in the submicron fume) will be identified and reported to DoE and other team members. Any differences in ash characteristics between standard pc conditions and HITAF conditions shall be identified. Differences resulting simply from the finer pc grind shall be separated from those resulting from the higher temperature combustion condition employed. 
Task 3.2.3 Deposit Initiation

Task 3.2.3.1 - Alkali Vapor Corrosion of Ceramic Air Heater Coupons

\section{OBJECTIVE}

In this experiment we will perform initial screening tests of candidate ceramic coupons. These tests provide a means to quickly measure relative reactivities at simulated process conditions. They also allow simple determination of qualitative effects of varying parameters such as temperature $(1000 \mathrm{C}$ or $1300 \mathrm{C})$, gas composition $\left(\mathrm{Na} / \mathrm{SO}_{z} / \mathrm{SO}_{3}\right)$ and space velocity $\left(1 \mathrm{~cm}^{3} / \mathrm{s}\right)$.

\section{BACKGROUND}

There is a fairly extensive description of alkali-ceramic interactions in the technical literature. There is also a great deal of continuing work at Westinghouse, Acurex, VPI, and others, primarily under DoE sponsorship, in assessing alkali. ceramic interactions for ceramic filter applications. Most of this work has been conducted at temperatures below the dew point of sodium molecular species (sulfate, hydroxide, chloride); little high temperature data us available. Because the radiant portion of the HITAF system may be exposed to alkali vapor in a small region (either before molten slag deposition becomes significant near the burner, or after the slag "freezes" and sporadic dry deposits begin), assessing alkali vapor ceramic interactions is an important step in ensuring system survival.

\section{TECHNICAL APPROACH}

\section{Experimental Apparatus}

A schematic diagram of the test facility is presented in Figure 17. A Lindberg horizontal tube furnace will be located in an available exhausted fume hood. The Lindberg furnace is approximately $24 \mathrm{in}$. in length with a 12-in. hot zone capable of a maximum operating temperature of $2700^{\circ} \mathrm{F} / 1482^{\circ} \mathrm{C}$. A process tube of high purity alumina (Coors AD998) was selected for its chemical stability in high temperature oxidizing and reducing environments. Fifty inches in length, the process tube will be open at one end, 2 in. $O D$ and $1-3 / 4 \mathrm{in}$. ID and reduce at the other, $1 / 2$ in. $O D 1 / 4$ in. ID. A 50-in. tube will provide a 12- in. high temperature region which will accommodate the candidate ceramic coupons. This provides $19 \mathrm{in.}$ of reactor, upstream of the ceramic coupons, in which to situate a crucible of $\mathrm{NaOH}$. Sodium will be introduced into the gas stream by vaporizing $\mathrm{NaOH}$. The majority of heat required to vaporize $\mathrm{NaOH}$ will be conductive heat from the furnace hot zone, any additional heat will be provided by heat tapes. A NaOH vapor pressure curve (CC Handbook) indicates a temperature between $500^{\circ}$ to $700^{\circ} \mathrm{C}$ will place 10 to $100 \mathrm{ppm} \mathrm{Na}$ into the gas stream. NaOH temperature will be monitored by a $1 / 8$ in. OD ceramic shielded $R$ type thermocouple. Table 6 presents the target gas $\mathrm{mix}$ to be used through this experiment. 


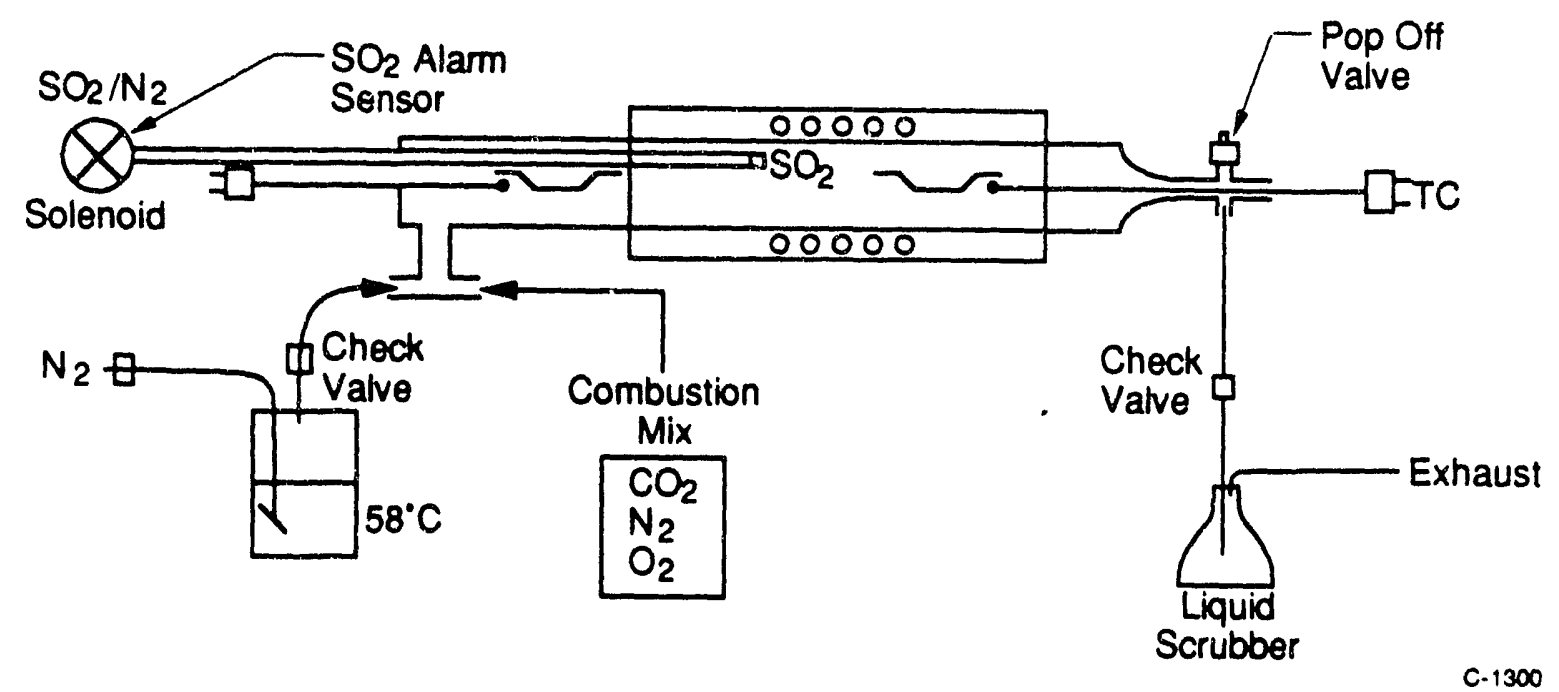

Figure 42. Experimental Apparatus for Alkali Exposure Tests Gas Composition for Alkali Exposure Tests

\begin{tabular}{|l|l|}
\hline $\mathrm{N}_{2}$ & Balance (approximately 77\%) \\
\hline $\mathrm{CO}_{2}$ & $14 \%$ \\
\hline $\mathrm{H}_{2} \mathrm{O}$ & $6 \%$ \\
\hline $\mathrm{O}_{2}$ & $3 \%$ \\
\hline $\mathrm{SO}_{2}$ & 0.1 to $0.3 \%$ \\
\hline $\mathrm{Na}$ & 0.001 to $0.01 \%$ \\
\hline
\end{tabular}

Simulated exhaust gas will be prepared by combining two compressed gas mixtures, $\mathrm{SO}_{2}$ in $\mathrm{N}_{2}$, a $\mathrm{N}_{2} / \mathrm{CO}_{2} / \mathrm{O}_{2}$ mix and $\mathrm{N}_{2}$, each at a delivery pressure of 20 psig. The flow rates of these three gas streams will be monitored by three Matheson Gas Products flowmeters (Model FM-1050) with operating ranges between 10 to $350 \mathrm{sccm}$ with ñ5\% absolute accuracy. For flow control high accuracy needle valves will be used. The $\mathrm{N} 2$ gas stream will pass through a heated water saturator to formed a humidified gas. A water vapor pressure curve will provide the exact water temperature necessary to achieve humidification. The humidified $\mathrm{N}_{2}$ mixes with the $\mathrm{N}_{2} / \mathrm{O}_{2} / \mathrm{CO}_{2}$ gas stream at the open end of the process tube. Note that all Iines (stainless steel or teflon) conducting wet gas are heated to prevent condensation. 
To eliminate formation of sodium sulfate $\left(\mathrm{Na}_{2} \mathrm{SO}_{4}\right)$, $\mathrm{SO}_{2}$ will be introduced through a $1 / 4$ in. OD ceramic tube which will run past the $\mathrm{NaOH}$ crucible and deposit S02 vapor into the furnace hot zone $\left(1300^{\circ} \mathrm{C}\right)$, well above the dewpoint of $\mathrm{Na2S02}$. The exhausted gases will past through a liquid scrubber. Coupon temperature will be monitored by an ceramic shielded $R$ type thermocouple feed through the process tube's reduced end.

Gas mixing and heating should not present a problem as total flow is expected to be between 1 to $1.6 \mathrm{~cm} / \mathrm{s}\left(60\right.$ to $\left.100 \mathrm{~cm}^{3} / \mathrm{min}\right)$. Check valves will ensure one directional flow and a pressure relief valve will minimize the effects of over pressurization. 
Task 3.2.3.2 - Corrosion of Ceramic Surfaces by Ash Deposits

\section{OBJECTIVE}

The objective of this task is to determine the relative corrosion resistance of structural ceramic materials by ash deposits that are candidates for air heater construction.

\section{BACKGROUND}

A 1981 study of the economics of the use of ceramic heat recuperators concluded that $\$ 228$ million could be saved annually if the recuperators were used extensively in the steel, glass, and aluminum remelting industries to preheat combustion air used in the industries furr. ces (Tennery, 1981). The study concluded that silicon carbide (SiC) was the lowest cost ceramic material available at the time that had satisfactory creep resistance, corrosion resistance, and strength at the temperatures at which these recuperators would work. However, the study included only uses of the heat exchangers to a maximum of temperature of $1400^{\circ} \mathrm{C}$, and concluded that more work should be done to find the best ceramic candidate for these or higher temperature heat exchangers.

Studies made at Oak Ridge National Laboratories (ORNL) on the long-term chemical and structural stability of ceramic materials used in heat exchangers designed to be placed in slagging conditions in coal and oil fired bollers showed that the fate of the different materials depenced very much on the nature of the slag that deposited on the heat exchanger. The studies involved long duration ( 250 to $500 \mathrm{hr}$ ) tests of ten different heat exchanger candidate materials at temperatures of up to $1240^{\circ} \mathrm{C}$ in the Ceramic Recuperator Analysis Facility (CRAF). Two different coal-oil-mixtures were used, one involving a coal producing a high silica ("acidic") slag, and the other a coal producing a low silica ("basic") slag. The ceramic heat exchanger candidate materials included siliconized SiC, sintered a-SiC, chemically vapor deposited (CVD) SiC, high purity alumina, and sialon. When firing with a coal producing a dry acidic slag the SiC materials survived without degradation whereas the alumina and sialon tubes were cracked extensively (Ferber and Tennery, 1981). When firing with a coal producing a runny basic slag, tube degradation was much more pronounced for all materials (Ferber and Tennery, 1982). Greatest loss of ceramic material occurred in the upstream direction and varied from $7 \%$ to $78 \%$ reductions in wall thickness. Unlike the results of the acidic slag firing tests, the SiC materials were more degraded than the high purity alumina when firing under acidic slag conditions. The principal corrosion mechanism of the SiC appeared to be the formation of iron silicides at the ceramic slag interface with subsequent transport of the silicides away from the ceramic material. This led to the creation of pits on the surface of the SiC. Similarly, the alumina tube was corroded due to the activity of iron in the slag. In that case, an iron aluminate spinel layer formed on the surface of the ceramic and then dissolved into the slag. 
The relatively higher degradation of alumina as compared to $\mathrm{SiC}$ in the acidic slag in the ORNL studies is in marked contrast to a study reported by Bonar et al. (1980) of the stability of ceramic materials in coal fired slagging gasifier conditions. They found that alumina was relatively stable in an acidic slag but corroded much more in basic slag. The differences in alumina corrosion between the Bonar et al. (1980) study and the 0ak Ridge study indicate that simple differentiations between the chemical nature of slags as basic or acidic does not provide adequate information about the corrosiveness of the slag. Instead, the reactor atmosphere, slag viscosity, and subtle differences in the composition of the slag may play important roles in determining slag corrosiveness toward specific ceramic materials. In addition, these variables are likely mutually dependent in determining the rate of ceramic corrosion because the extreme range of conditions in a HITAF system allow both chemical kinetics and mass transport to play important roles in reaction rates.

\section{TECHNICAL APPROACH}

A minimum of three candidate materials will be tested for corrosion resistance at UNDEERC. The tentative candidates are sintered silicon carbide (SIC), siliconized silicon carbide (SiSiC), and DuPont Lanxide which is a silicon carbide/alumina blend. The materials were chosen on the basis of known corrosion resistance as determined by literature review and personal conversations with researchers, strength, high temperature stability, and possibility of near term availability for construction of the air heater in the demonstration HITAF scheduled for construction in Phase II of Combustion 2000. Two inch square coupons of each material will be provided to UNDEERC by UTRC. UNDEERC will coat the coupons with fly ash size classified to less than approximately $10 \mathrm{microns}$ to a depth of $1 / 8$ in., and heat them in a muffle furnace for a period of several days. The exact time period will be determined in screening tests. Ash samples will be generated at PSIT in the Entrained Flow Reactor (ERF) facility shown in Figure 5. Ten grams of ash will be needed per coupon and six coupons will be tested for each coal. A cyclone will be used to remove the ash particles greater than $10 \mathrm{~cm}$. Using small ash particles will simulate more closely the deposition of ash particles in the convective air heater. Assuming that $30 \%$ of the ash is less than $10 \mathrm{~m}$ in diameter, and that we collect $10 \%$ of the ash that is produced in the drop tube furnace with the sample probe, sixty grams of ash less than $10 \mathrm{~m}$ will require $2 \mathrm{~kg}$ of ash to be generated. If the coal contains 5 to $10 \%$ ash, 20 to $40 \mathrm{~kg}$ of coal must be burned. A gallon of coal weighs about $2 \mathrm{~kg}$; ; therefore, 10 to 20 gallons of coal are required to generate enough ash for this task.

It may also be desirable to perform limited ash exposure testing at the conditions of the radiant section of the combustor. This may be required because (1) the higher temperatures in the radiant section will likely produce liquid ash deposits which will behave differently than dry deposics, and (2) different ceramic materials may be used in the radiant and convective sections. If ash exposure experiments are deemed necessary at these conditions, the same amount of ash as in the "dry" deposition tests will be required. All of the ash can be used, however (deposition is not limited to particles $<10 \mu \mathrm{m}$ because we are considering interactions 
before the slag screens), so only $1 / 3$ to $1 / 2$ as much coal is required. An additional 10 to $20 \mathrm{~kg}$ of coal (for each of the four coals selected) shall therefore be required. The total amount of coal required to complete these test, including an adequate allowance for additional testing, is $75 \mathrm{~kg}$ or approximately 40 gallons per coal. Ash from two coals, one producing acidic and the other basic ash, will be studied. Two temperatures for each coal ash will be used to determine the temperature dependence of corrosion rates. At the end of the test, the coupons will be cooled over a period of one day to prevent thermal shock. They will be sent to UTRC for sectioning into 4 strength testing bars per coupon. Room temperature four-point fast fracture tests will be performed at ORNL. An additional section for each coupon will be returned to UNDEERC for analysis in a scanning electron microscope to determine corrosion depth and corrosion mechanism.

\section{DELIVERABLES}

A report will be provided detailing the experimental procedures and rates of corrosion versus ceramic, temperature. The information will also be used to determine the type of material to use for the air heater in the demonstration HITAF to be built in Phase II of Combustion 2000. 
Task 3.2.4 Materials Testing

\section{OBJECTIVE}

This task involves the measurement of selected mechanical and physical properties of structural ceramics which are leading candidates for use in the construction of the HITAF air heater design being developed by the United Technology Research Center for PETC/DOE. The purpose of the research is to evaluate candidate structural ceramics for this potential application by studying the fast fracture and fatigue (both dynamic and interrupted static) properties at temperatures from 1100 to $1400^{\circ} \mathrm{C}$ in air, for promising materials, with the effects of coal ash slag considered.

\section{BACKGROUND}

Due to the temperatures and highly corrosive coal combustion products involved, structural ceramics are the only reasonable candidates for use in the construction of an advanced system like the HITAF. The research in this task is focused on providing information for the identification and selection of the candidate structural ceramics which could be used for the design and construction of the heat exchanger.

The mechanical properties of ceramics show a high degree of variability and need to be treated statistically. Work by Weibull provided the first framework for considering how the strength of brittle solids fracture under applied stresses. He showed that a new density function, now referred to as the Weibull distribution, could explain the fracture behavior of a number of brittle solids, including glasses and crystalline ceramics. This function is described by two adjustable parameters, which are referred to in the ceramic literature as $m$ and $\sigma$, and in the statistical literature as $\alpha$ and $\beta$. The first parameter is mos $f^{\prime}$ important in the design of components from these materials, because it is dominant in the expressions for lifetime predictions, for example. In the past three years, there has been a growing tendency in the $U$. S. structural ceramic community to use the terms $m$ and $B$, parameter density function has the form:

where

\footnotetext{
$X=$ the variable of interest, strength in this case.

$m=$ the Weibull "shape" variable

$\beta=$ the Weibull "scale" variable
}

The critical issue in design using structural ceramics and, therefore, using their Weibull parameters as a means to describe their tensile strength, is to obtain accurate and representative values for the two parameters, $m$ and $\beta$. 
The term "fatigue" as now used in the international structural ceramic community, and as it will be used here, is a process whereby the tensile strength of the material decreases with time as a function of the application of stress and exposure to temperature and other environmental variables. Most oxide ceramics exhibit severe fatigue when exposed to water vapor, even at temperatures as high as $1000^{\circ} \mathrm{C}$ due to the action of hydrogen and hydroxyl species weakening bonds in the oxide at the incipient crack tips present on the surface and within the microstructure of the material. There are two basic types of mechanical fatigue measurements made on structural ceramics. One is called static fatigue, and the other is dynamic fatigue. Under static fatigue conditions a flexural or other specimen is loaded to a selected stress, one waits for fracture while the specimen is exposed to the selected environmental condition, and the time to failure is measured. Another method for measuring and predicting fatigue in structural ceramics involves so called dynamic fatigue methods. These have a major advantage over static fatigue methods. They depend upon varying the loading rate on a specimen to deduce the susceptibility of the material to stress corrosion. They are therefore relatively fast, whereas static fatigue measurements may require use of a given load train for hundreds to thousands of hours.

\section{TECHNICAL APPROACH}

In this project, candidate structural ceramic materials are selected in consultation with researchers at UTRC. The mechanical and selected physical properties of candidate materials are measured both under conditions of fast fracture and under dynamic and long term static loading conditions in air over a temperature range up to $1400^{\circ} \mathrm{C}$. Initially one state of the art SiC material will be tested. It is imperative that the materials properties be determined on test bars from the exact same type of material as will be used in the final design. Therefore, it is necessary to consider only those materials which the vendors say they will be able to manufacture in large enough sizes.

The test matrix will be as follows. All tests will be done in four-point bending on $3 \times 4 \times 50 \mathrm{~mm}$ bars with chamfered edges. Test configuration is $20 \mathrm{~mm}$ inner span and $40 \mathrm{~mm}$ outer span according to ASTM. All tests will be done in ambient air.

\section{Fast fracture}

Room Temperature, $1100^{\circ} \mathrm{C}$ and $1400^{\circ} \mathrm{C}$ at $40 \mathrm{MPs} / \mathrm{s}$. ( 30 specimens at each condition)

\section{Dynamic fatigue}

Four stressing rates over approximately five orders of magnitude; $10 \mathrm{MPa} / \mathrm{s}, 1 \mathrm{MPa} / \mathrm{s}, 10^{-2} \mathrm{MPa} / \mathrm{s}$ and $10^{-4} \mathrm{MPa} / \mathrm{s}$ (testing times $10 \mathrm{~s}, 5 \mathrm{~min}^{\circ} 6 \mathrm{~h}$ and $300 \mathrm{~h}$ ). Two temperatures; $110 \mathrm{oC}$ and $140 \mathrm{oC}$ and 10 specimens at each condiition. 
Interrupted static fatigue

Two stress levels, one high $70-80 \%$ of fast

fracture load, and one low $20-30 \%$ of fast fracture

load, hold for $300 \mathrm{~h}$ and then fast fracture. Two

temperatures; $1100^{\circ} \mathrm{C}$ and $1400^{\circ} \mathrm{C}, 10$ specimens at

each condition.

The next step will be to evaluate the fast fracture strength of several candidate materials after their exposure to the corrosive environment. The purpose of this is to screen the materials as to the possibility of any of the candidates losing a significant portion of their strength during the exposure. Then the candidate material which looks most promising from a corrosion point of view will be subjected to the same test matrix as described above.

Extensive fractography using both optical and scanning electron microscopy will be conducted to determine the nature of the critical flaws resulting in fracture. Very limited transmission electron microscopy analyses may be conducted to determine fine scale microstructural details. Statistical analyses will be used to determine the nature of the distribution function for the strength and the optimum techniques for determining these parameters. Maximum likelihood estimators will be used for all Weibull analyses. Kolmogorov-Smirnov techniques are used to estimate the quality of the fit between strength data and the estimted cumulative strength distributions.

\section{DELIVERABLES}

Output data are fast fracture strength, Weibull parameters, slow crack growth parameter and static fatigue data. Results from this task will be critical to the completion of realistic designs for the structural ceramic heat exchanger in the UTRC air heater. Future work not covered in this task must be conducted to determine the effects of a variety of coal ash slags on the fast fracture strength and fatigue properties of the candidate structural ceramics. 
Tasis 3.2 .5 - Additives for Deposit Mitigation

The objective of this task is to keep abreast of advancements occurring in the areas of modification of slag viscosity and corrosivity through the use of coal additives during Phase I of Combustion 2000 work. No experimental work on additives will be performed in Phase I of Combustion 2000, but the authors are aware of and will be performing additive work at UNDEERC in other projects. By remaining current in the results of this type of research, it will be possible to apply state-of-the-art additive techniques in Phase II of Combustion 2000 in efforts to control the physical and chemical nature of the slag in the demonstration HITAF.

\section{BACKGROUND}

In one HITAF design, the high-temperature air heater system must be placed within the main furnace in a region that may have gas that is chemically reducing and at temperatures near $3000^{\circ} \mathrm{F}$. Under such conditions, the ash produced from the combistion of the coal can be sticky and even running. Ash of this nature causes a number of operational problems, including refractory and structural ceramic corrosion, fouling of heat exchange surfaces, and even plugging of gas passes. At lower temperatures, soot blowing can be used to keep the deposition problems to a minimum. However, soot blowing is not an effective means of controlling ash buildup on a ceramic high temperature air heater because it may cause catastrophic failure of the air heater due to thermal shock and high stress levels. Therefore, it is necessary to prevent ash from depositing on the high tem: a ure air heater, or force it to continually slough off.

Prevention of ash deposition is not possible in a coal combustion system, it can only be reduced. However, the ash deposit may be relatively dry and continually slough off under its own weight. Although a very few coals may be found that will produce dry ash under HITAF conditions, the HITAF would have to be designed specifically to burn one of those few coals. Instead, most coals will produce wetter, even running ash at $3000^{\circ} \mathrm{F}$ and in a reducing atmosphere. In order to have the operational freedom to run a variety of coals, procedures must be available for modifying the slag properties, either to make the slag non-wetting toward the ceramic in the air heater, or to make the slag viscosity so low that it runs off of the air heater as rapidly as it deposits. In addition, the ash must change viscosity over a narrow temperature range from wet and running to very dry so that the deposition problem is not pushed downstream but instead is pushed to a region in the HITAF where it can be dealt with by conventional sootblowing, i.e., away from ceramic materials. Also, methods must be developed to reduce the chemical reactivity of the slag toward the ceramic material in the heat exchanger.

One method to modify the viscosity and corrosiveness of slag at a given point in the HITAF is to change combustion conditions to change the local gas temperature. However, in order to maintain the performance of the high efficiency HITAF, there may be very limited leeway in operations to reduce 
slag-related problems. Therefore, the most flexible methods of modifying slag properties are through blending and the use of non-proprietary additives to the coal.

\section{Additive Use in the Modification of Corrosion Properties}

The interdependence of physical and chemical properties of slag on its corrosivity imply that there is no unique type of additive that could be used for reducing the rate of slag corrosion of ceramic materials in a HITAF system. In fact, several different additive types or methods of addition to the system may be employed. Guidelines as to the appropriate method to use under given conditions have not yet been developed. One way of reducing the rate of corrosion may be to assure that the viscosity of the slag next to the ceramic is relatively high thus reducing the rate of mass transport to the is ceramic and thereby reducing the rate of corrosion. The viscosity may be kept high by firing with a coal that has a high sintering temperature as suggested by Mazer and Seger (1990), or by including a network former in the surface of the ceramic as suggested by Wiederhorn and Krause (1988). This type of additive would probably be used in shot additions to provide a coating of high viscosity material next to the air heater. It would not be used continuously because it may lead to plugging of gas passages. The corrosion rate may also be slowed by modifying the chemistry of the slag. Bonar et al. (1980) found that the addition of magnesium to a model slag increased the corrosiveness of the slag toward alumina, which suggests that the opposite effect may also be possible. Finally, it may be possible to create a non-reactive protective layer next to the ceramic material. Such a protective layer has been shown by Bonar et al. (1980) to form next to chrome spinel refractory. The protective layer formed when in contact with both acidic and basic slags. However, not all reaction products are protective. That study also described the formation of a calcium aluminate layer next to alumina containing refractories in contact with basic slags. The calcium aluminate became detached and floated off into the slag allowing further corrosion to occur.

\section{Additive Use in the Modification of Slag Viscosity}

Examples of the benefits of additives can be portrayed using PHOEBE, a computer model developed at UNDEERC thai employs thermodynamic equilibrium calculations to determine the partitioning of ash among gas, liquid, and solid phases according to temperature and atmosphere. In addition, PHOEBE predicts the viscosity of the liquid phase from the composition of the liquid material. The liquid phase viscosities are calculated based on the equation developed by Urbain et al. (1980) for metallurgical silicate-based slags. The equation was modified for use in PHOEBE by Kalmanovitch and Frank (1988) based on data from coal ash melts.

Illinois No. 6 was chosen as a base coal for testing predictions of slag viscosity modification through the use of additives. Because it yields an acidic ash, modeling involved a scenario where a variety of naturally occurring, non-proprietary basic materials were added to the HITAF with the coal at rates of 5,10 , and $20 \%$ of the ASTM ash feed rate. By far the most 
successful additive modeled was calcined dolomite, defined to have the composition $\mathrm{MgCaO}_{2}$. Figure 18 shows the viscosities calculated by PHOEBE for the liquid phase present in the ash from each of the calcined dolomite and Illinois No. 6 mixtures over a range of interest in HITAF systems. The figure shows that with the addition of calcined dolomite at a rate of $5 \%$ of the coal ash feed rate, the viscosity of the ash at $2000^{\circ} \mathrm{F}$ was 1 ittle changed and remained dry. However, at $2400^{\circ} \mathrm{F}$, the approximate temperature of the primary air heater in a HITAF system, the ciolomite addition reduced the viscosity of the liquid material in the ash by nearly an order of magnitude. In addition, the PHOEBE calculations show that the calcined dolomite additive increased the concentration of liquid phase in the condensed species from $10 \%$ to $20 \%$. The higher liquid concentration and lower viscosity of the treated ash indicate that it may be considerably less viscous and may actually flow off of the heat exchanger at $2400 \mathrm{~F}$ whereas the parent coal ash would present a considerable slagging problem. The addition of higher levels of calcined dolomite are predicted to decrease viscosities even more. At 3000F the treated ashes are even less viscous and contain more liquid so the model indicates that they would be even more likely to run off of the secondary air heater and so prevent the buildup of a thick slag layer. However, the amount of calcined dolomite to add that will meet the needs of a HITAF system yet still be economical must be found by experimentation. In addition, the database

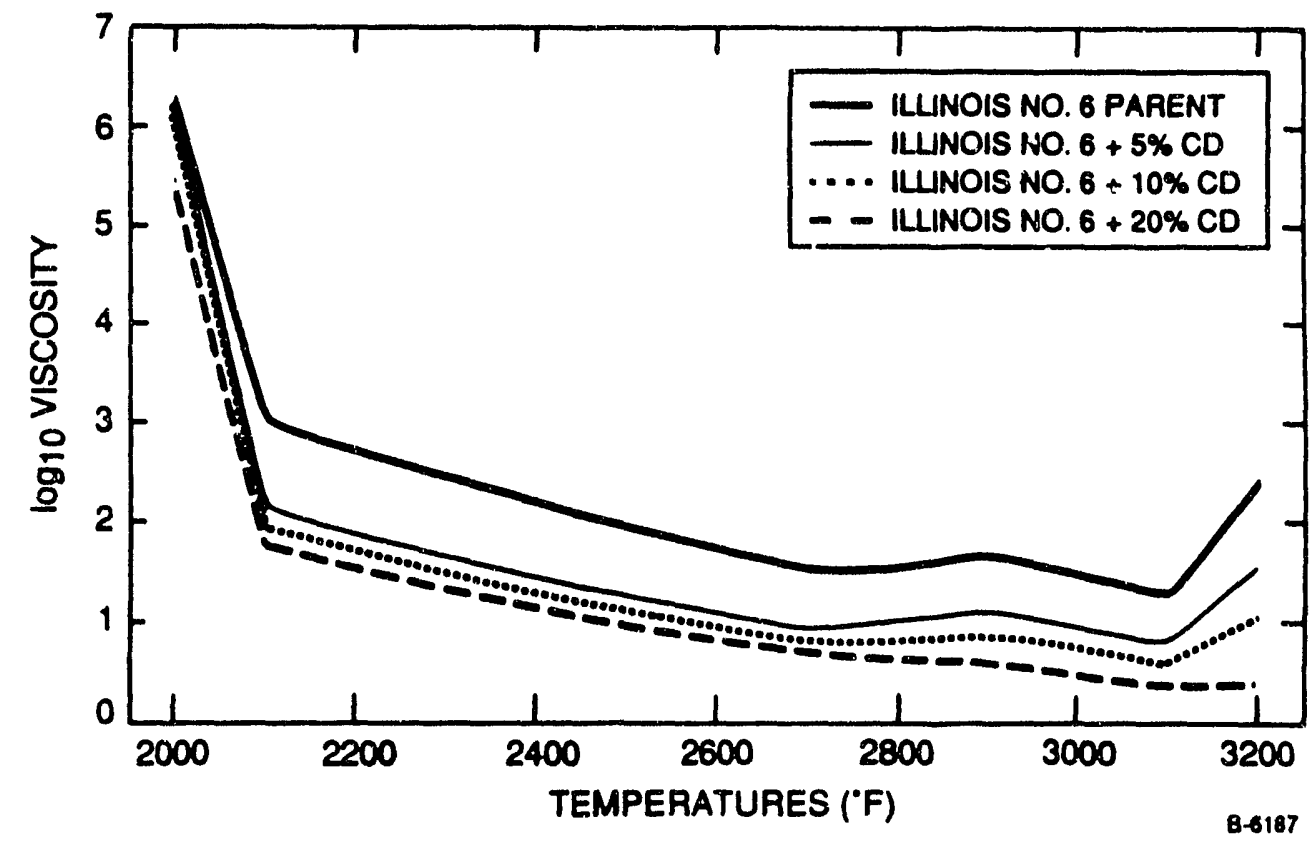

Figure 43. Variations in liquid phase viscosity with temperature for Illinois No. 6 coal, including calcined dolomite addition 
of slag properties (wetability, viscosity, corrosivity) versus temperature and atmosphere must be further developed so that PHOEBE and other models like it can provide more accurate information about conditions for which they were not originally designed, such as high temperature reducing zones in a HITAF system.

\section{DELIVERABLES}

No experimental research will be performed under this task. Instead, literature review, research being performed concurrently at UNDEERC, and discussions with researchers studying slag modification will be used to prepare a report describing the state of knowledge about slag property modification through the use of additives. It will also include recommendations for an experimental matrix to determine the most beneficial use additives in the HITAF system that will be built in Phase II. The report will be prepared for inclusion in the Phase I report and as part of the Phase II research proposal. 
Task 3.2 .6 Duct Heater

The objective of this task is to develop the concept for an in-duct gas fired heater which will raise the air temperature from $1800^{\circ} \mathrm{F}$ (the discharge of the air heat exchanger) to $2450 \mathrm{~F}$ which is the temperature required at the turbine inlet for the proposed cycle efficiency. This heater is to have very low pressure loss and produce very low levels of NO ${ }^{\cdot}$

\section{Background}

In any combustor, the primary source of $\mathrm{NO}_{x}$ is thermal $\mathrm{NO}_{x}$, principally by the Zeldovich Mechanism. Because of the strong dependence of No production on temperature, it is very important that temperatures at any point in the combustion process be kept at minimum levels conducive to the energy release required. This means that the combustor should operate in a lean stoichiometry at all times and at all locations. The key to this is to provide very rapid mixing of the fuel with the oxidizer, thereby reducing local inhomogeneities in the mixture and limiting residence time at these less-than-optimum conditions. Rapid mixing in conventional combustors has usually required very high swirl levels, numerous fuel injectors, resulting in a high pressure loss device. This impacts overall cycle efficiency. Experiments have been performed at UTRC and P\&W Aircraft in advanced combustors which utilize the density gradients present in swirling reacting flow to enhance mixing. This concept is called "Centrifugally enhanced Mixing". Results have shown that complete mixing of two streams (fuel and oxidizer) can occur in less that two duct diameters, providing that the combustor and fuel injection module are carefully designed. With such rapid mixing, it may be possible to inject fuel (methane or natural gas) into the heated air stream with such efficiency that the stoichiometry of the fuel-air mixture can be kept very. lean. This will result in low peak temperatures, and therefore low No production. The advantage of this type of mixer/injector design is that experiments have shown the devices to have very low pressure drop through the combustor. The key items to be examined are the effectiveness of mixing with the injector, and the overall penetration of the fuel-air mixture into the main air flow path.

\section{Technical Approach}

To develop a low-pressure-loss, rapid mixer for the in-duct boost heater, laboratory tests will be conducted in a reduced scale cold flow apparatus. Efficiency of the mixer will be determined using planar digital imaging and probe sampling with the goal of minimizing pressure losses within the duct heater while maintaining a uniform mixture profile. In Task 3.2 .6 a laboratory scale mixer will be constructed to examine the mixing characteristics of a centrifugally-enhanced swirl mixer. The cycle analysis performed as part of the proposal has indicated that the density ratio of the fuel to the main air flow in the in-duct heater will be 2.56 , with a duct diameter of 6 feet. In this task, we propose to construct a $1 / 10$ scale model of the duct heater shown schematically in Fig. 44, use 


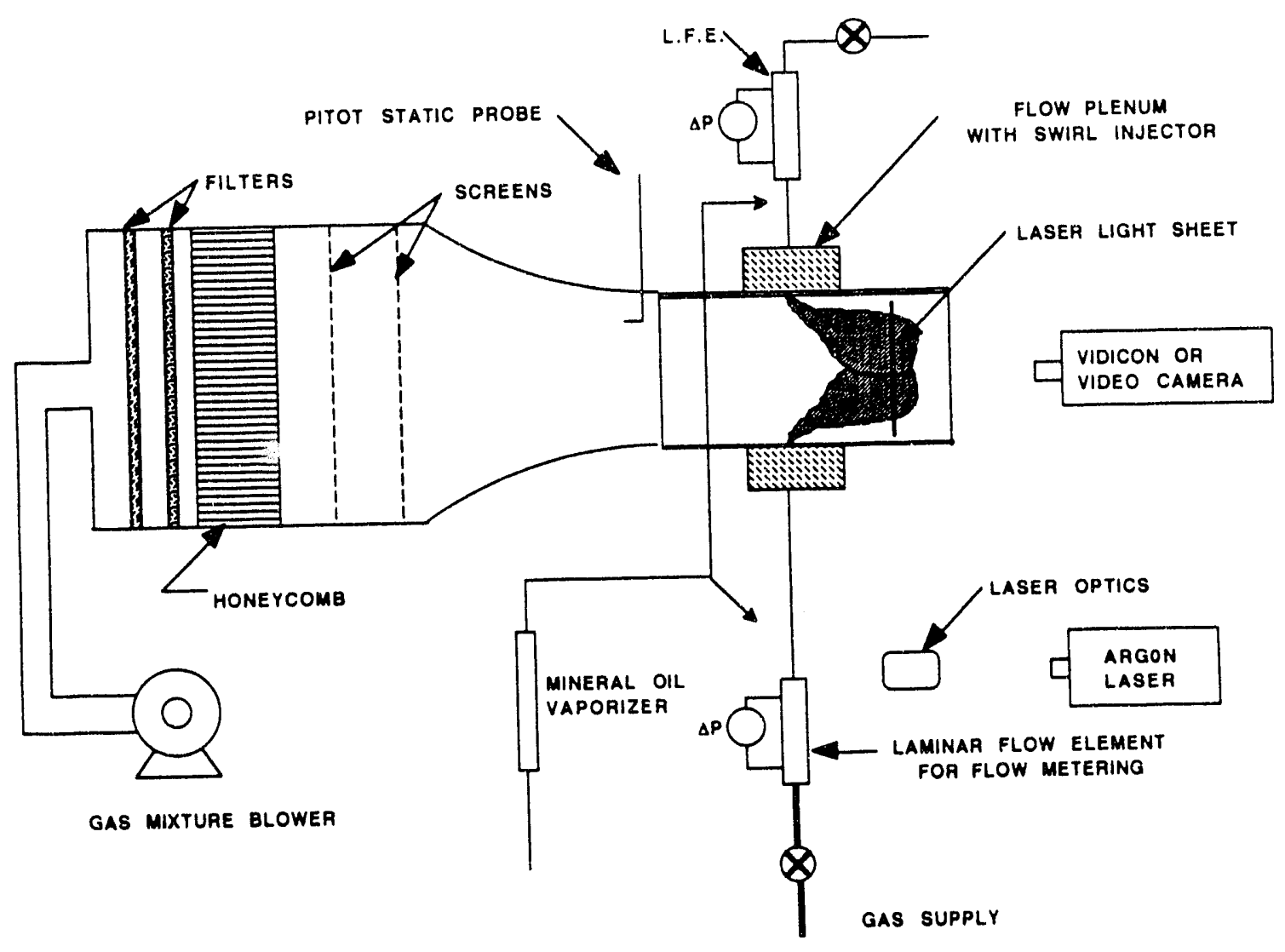

Fig. 44. HITAF Duct Heater Test Apparatus

argon to simulate the fuel, and a mixture of nitrogen and helium to simulate the hot gas stream. These gases will provide the appropriate density ratio between the injected "fuel" and the heated "air". The duct will be 7.25 inches inner diameter, with opposing centrifugally-enhanced mixing injectors of 1 inch diameter. A mixture of helium and nitrogen ( $50 \%$ by volume of each) will be injected in the outer swirl passage, with argon in the central core. The main duct flow will be the mixture of helium and nitrogen. A time of flight (TOF) mass spectrometer will be used to probe the discharge of the swirler-injector and at specific axial and radial locations in the duct to determine the concentration profile. Flow visualization will be performed by seeding the argon with a mineral oil seed, and using Mie-scattered light intensity from an argon-ion laser to determine relative concentration of the seeded gas in the duct. The duct velocity for these tests will be 4 feet/sec, with the injected gas velocity of $24 \mathrm{feet} / \mathrm{sec}$. This will provide a momentum ratio of 36 , which has demonstrated excellent penetration in other experiments.

The sub tasks within Task 3.2 .6 can be listed as below. 
Task 3.2.6.1 Construct flow visualization section with gas flow control

Task 3.2.6.2 Design centrifugally-enhanced swirl module

Task 3.2.6.3 Construct swirl module using stereo lithography

Task 3.2.6.4 Test mixer as a function of momentum ratio using TOF mass spectrometer and gas sampling probe

Task 3.2.6.5 Examine mixing using Mie-scattering and flow visualization

Task 3.2.6.6 Optimize swirl injector module

Task 3.2.6.7 Hot gas test for gas composition

The program steps outlined will be used to develop a cold flow mixer which will provide uniform composition profiles at the duct exit, with very rapid mixing to maintain a nearly constant stolchiometry. The optimum mixer will be tested in a laboratory scale heated gas apparatus.

To examine $\mathrm{N} 0$ production at $1800^{\circ} \mathrm{F}$, an apparatus will be designed and constructed using an Astro High Temperature Graphite-Element Furnace to provide a heated gas stream. Shown schematically in Figure 45, the

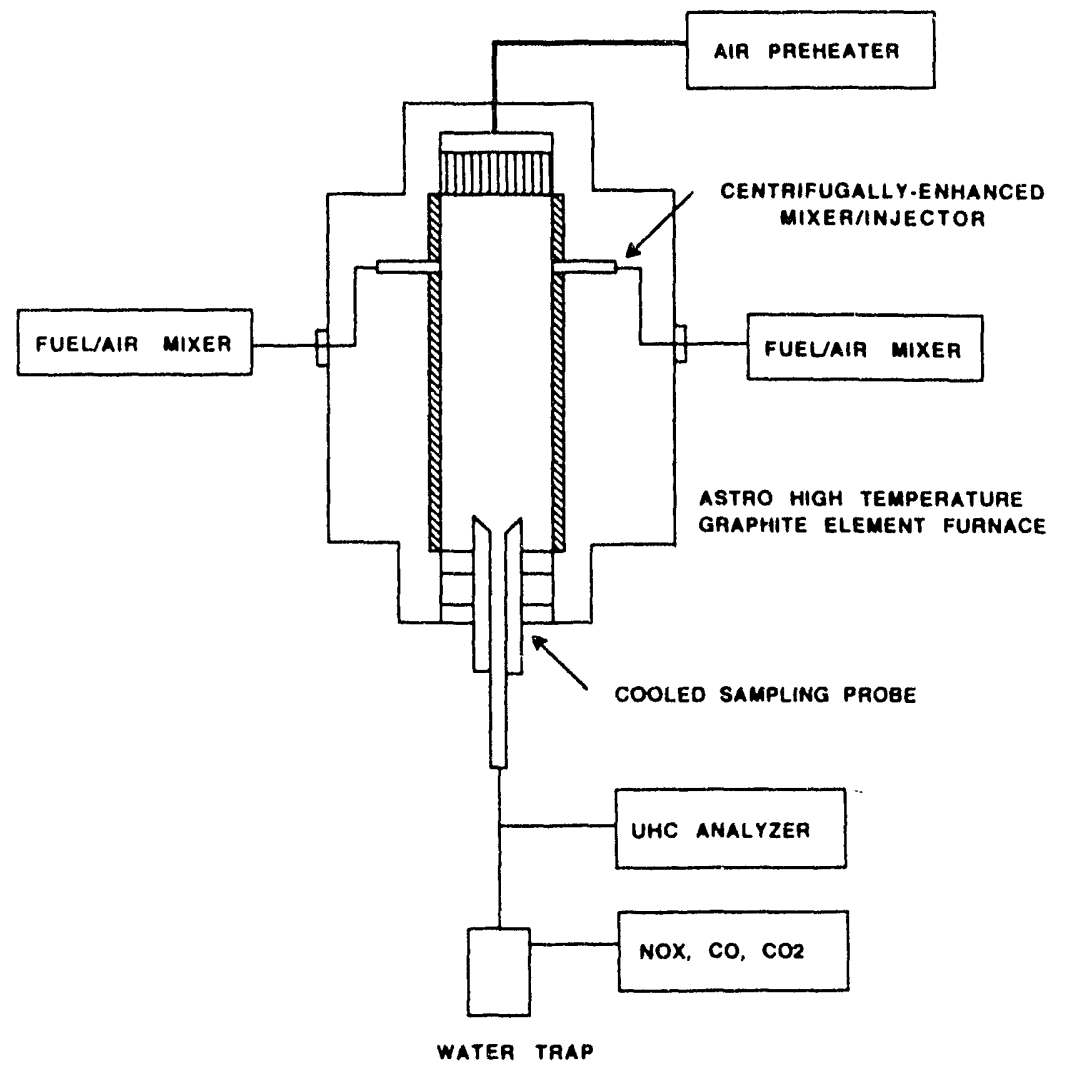

F1g. 45. Heated Gas Test. Apparatus Schematic 
apparatus is composed of the furnace with an integral ceramic muffle tube. Air is preheated prior to entering the furnace to $1000^{\circ} \mathrm{F}$ using electrical resistance heaters. In the upper entrance region, the air is heated to $1800^{\circ} \mathrm{F}$. In the mid-section of the furnace, methane is introduced through a centrifugally-enhanced mixer. Gas samples are withdrawn through the water cooled sampling probe which can be moved vertically along the axis of the furnace to provide data on gas composition as a function of residence time. The alumina muffle tube, useful in oxidizing atmospheres up to $1850^{\circ}$ C $\left(3362^{\circ} \mathrm{F}\right)$, is $7 \mathrm{~cm}$ in diameter and $56 \mathrm{~cm}$ long. Since a $30 \mathrm{msec}$ residence time is needed to oxidize the fuel, based on Chemkin calculations, the velocity of bulk gas in the muffle tube will be $200 \mathrm{~cm} / \mathrm{sec}$. For proper modeling of jet penetration, the jet velocity from the fuel injectors will be $400 \mathrm{~cm} / \mathrm{sec}$. To properly model the centripetal acceleration of the mixer/injector with a $45^{\circ}$ swirl angle, the injector diameter will be 2.54 $\mathrm{cm}$ which will provide a centripetal acceleration of $>10,000 \mathrm{~g}$ s. The gas sampling probe will be used to measure $\mathrm{NO}_{\mathrm{y}}$, unburned hydrocarbons, $\mathrm{C} 0$, and $\mathrm{C} 22$ concentrations at the discharge of the furnace. Gas chromatographic analysis for other species can be performed if desired.

Deliverables

The experiments described above will provide a guide to the efficiency of mixing and combustion in the in-duct heater. Based on the measurements in the sub scale experiment, analytical predictions of emissions and temperature profiles for a full-scale in-duct heater will be made. The sub scale experiments will provide a data base as to relative momentum ratios needed between the gas flows, injector design, combustor length needed, and pressure drop which will be expected for the full scale device. Data will be obtained from the experiments, and used to develop a concept for the full scale device. Emissions as a function of gas flow splits, momentum ratios, combustor geometry (diameter and length) will be recorded and presented graphically. A final design concept will be proposed based on these results. 
Task 3.2.7 0xygen Enriched Combustion Via Membranes

Objective

To establish membrane module design parameters necessary to support overall flame properties required for efficient energy exchange - radiative, convective - between flame zone and primary heat exchanger and/or control of ash properties in the boundary layer region of the primary heat exchanger.

Background

Oxygen enrichment of primary combustion air in the near burner region is anticipated in one burner design - well mixed rich system - requiring a short intense flame. Oxygen enrichment for burnout in the far field region is anticipated necessary for the long lazy, delayed controlled mixing, flame in order to achieve carbon burnout. High temperature oxygen rich zones near the primary heat exchanger may be necessary to prevent ash slagging on the heat exchanger surface. Flexibility in oxygen enriched flow rates will be necessary as the coal type, and consequently, heating value and mineral matter content, is varied. Membrane modules provide the flexibility in delivery rate and oxygen enrichment or depletion not available via pressure swing adsorption systems.

Technical Approach

Using the overall, desired flame properties established by the combustor design process, and UTRC's unique membrane property data base, membrane module sizing and input stream flow rates necessary to establish required permeate (oxygen rich) residual (nitrogen $\mathrm{rich}$ ) streams are determined. Once the mass flow rates of the two streams are determined, mixing strategies will be examined for the alternative flame types.

Compression penalties to achieve oxygen enrichment/depletion in the primary flame zone will be unacceptable if only part of the membrane treated air stream is utilized. Both components will be introduced to the combustion process at critical stages. The manner of introduction, the mixing processes established, will be critical in determining Nox levels and degree of carbon burnout. Benchscale and pilot scale mixing configurations will be planned with membrane separated streams to determine optimal approaches.

Deliverables

Preliminary design specifications for oxygen enrichment/depletion mass flow rates for the specified flame types. Preliminary mixing strategies and est plans to develop mixing techniques. 
Task 3.3 Modeling

Task 3.3.1 HITAF Combustion Modeling

Task 3.3.1.1 Submodel Improvement

Objective

Identify the submodels in the comprehensive combustion code that require improvement before using the code for combustor simulation. Develop and test new submodels.

\section{Background}

Since the comprehensive combustion code was developed, a considerable amount of effort has been carried out, funded by DOE and others, on the fundamentals of coal combustion. This information should be assessed and the appropriate submodels modified if necessary in order to provide the maximum confidence in the computer simulations.

\section{Technical Approach}

This task will concentrate on four critical submodels:

- carbon oxidation kinetics

- nitrogen oxide formation and control,

- deposit/wall heat transfer, and

- wall deposition.

Information relevant to these areas will be surveyed, improved submodels developed, coded and tested. The carbon burnout model should be improved by considering the final stages of carbon burnout. The NO $x$ model requires modification to allow for $\mathrm{NO}-\mathrm{CH}$ type reactions and to more accurately simulate the evolution of fuel nitrogen from particles. The performance of the radiant heater is dependent on heat transfer through wall deposits; a wall heat transfer model must be coupled to the particle deposition model to allow an accurate prediction of HITAF performance.

\section{Deliverables}

Improved submodels for carbon burnout, No formation, deposit/wall heat transfer and wall deposition. 
Task 3.3.1.2 Combustor Simulation

Objective

To provide simulation of the full-scale HITAF in order to give confidence in the technical feasibility of the concept.

\section{Background}

There is no experience that can be used co demonstrate that the HITAF will meet the program goals. At the conclusion of this program, small pilot scale data will be available on conceptual performance, but at approximately $1 / 500$ th scale. The comprehensive computer code must be used as the scaling tool.

\section{Technical Approach}

In this task, three dimensional simulations will be made for both combustor concepts. The earlier engineering analysis tasks will use the two dimensional code for screening because a quick turn around is required. In this task the three dimensional model, with improved submodels, will be used. The simulations will include examples for both combustor types and will provide information on:

- NO Formation;

- Carbon burnout;

- radiant air heater outlet temperature;

- wall deposition rate, and combustor outlet temperature;

Design variations will include:

- number and location of burners for the controlled delayed mixing case;

- segmented air addition for the controlled delayed mixing case;

- coal type,

- staged air injection location for the well mixed rich case;

- slag removal system for the well mixed rich case.

Deliverables

Performance predictions for the full scale HITAF. 
Task 3.3.1.3 Concept Verification

objective

The objectives of the small pilot scale tests are: 1) to verify the concept of integrating the low $\mathrm{N}_{\mathrm{x}}$ combustor designs with the high temperature air heating system in the combustor walls; 2 ) to evaluate the two different primary zone configurations and evaluate the trade-offs between the controlled delayed mixing concept (which may require primary zone cooling) and the well mixed rich system concept in terms of impact on overall cycle efficiency, level of ${ }^{\mathrm{NO}}{ }_{x}$ emissions achievable and ash handling issues.

\section{Background}

There are no data to verify the HITAF concept technical feasibility. This task will provide information on the radiant heater concept for two combustor types.

\section{Technical Approach}

This testing will be conducted in the new 1 million Btu/hr multifuel furnace currently being constructed in the Combustion Laboratory at the University of Utah. This downfired unit has been designed to include interchangeable, tubular ceramic wall panels so that heat transfer and operability issues can be experimentally defined under low $\mathrm{NO}_{\mathrm{x}}$ operating conditions. The furnace also includes multiple injection ports and sufficient residence time to permit the use of both reburning and augmented SNCR in conjunction with long axial flames as defined in the previous testing.

Test Parameters will include:

1) Primary cone - two mixine, concepts, downstream air addition

2) Radiant Wall Panels - construction materials, panel design

3) Secondary NO Control Zone - natural gas injection pattern

4) Tertiary No Control Zone - injection temperature, residence time.

\section{Deliverables}

Confirmation of HITAF concept performance and the minimum No achievable using all levels of control. 
Task 3.3.2 Air Heater Structural Modeling

OBJECTIVE

The objective of this task is provide the structural designs for key ceramic components of of the radiant and convective air heaters of the HITAF system.

\section{BACKGROUND}

The HITAF concept, which is based on transferring high quality heat from coal combustion products to air for powering a gas turbine, is crucially dependent on the use of structural ceramic materials in high temperature heat exchangers because super alloys cannot withstand temperatures above $1500 \mathrm{deg} F$ ( $800 \mathrm{deg} C$ ) for extended periods in oxidizing atmospheres. However, the use of structural ceramic materials in high temperature heat exchangers will require special design considerations because of the brittle fracture properties of these materials.

The term fatigue as applied to the fracture strength of structural ceramics has a much different meaning than for metals. For metals, the term fatigue usually applies to changes in strength and/or ductility in the metal as a function of stress cycling. The process of fatigue in metals typically involves the generation of dislocations in the metal due to the stress field, movement of these dislocations, concentration of the dislocations at major features of the microstructure, and subsequent loss of the ability of the metal to accommodate local stress by changing shape on a local level of the microstructure. Structural ceramics do not generate any significant numbers of dislocations as a result of applied stress. Their crystal structure and electron bonding do not allow for easy generation or movement of dislocations, even at temperatures as high as $90 \%$ of their melting point. Structural ceramics behave in an essentially elastic manner up to temperatures of at least 60 to $80 \%$ of their melting or dissociation temperatures. Thus the term fatigue as applied to ceramic materials is a process whereby the tensile strength of the ceramic decreases with time as a function of the application of stress and exposure to temperature and other environmental variables. Therefore, structural engineering of ceramic materials requires statistical data on fatigue characteristics of the particular ceramic materials under actual high temperature and other environmental conditions. Such data will be generated under Task 3.1.3, Air Heater Materials, for use in probabilistic and deterministic failure analysis of key ceramic components for the HITAF system.

\section{TECHNICAL APPROACH}

Detailed analyses of the coupled effects of structural and thermal loads will be performed on key ceramic components of the radiant and convective air heater designs using state-of-the-art computer models for fluid dynamics, with simultaneous heat transfer, and thermal and mechanical stresses. These model calculations will be extended to include deterministic and probabilistic failure analyses of key ceramic components of the air heaters for both steady and time-dependent operation of the 
HITAF. Data on fatigue characteristics of candidate ceramic materials, specifically Weibull parameters, measured in Task 3.1 .3 will be used for structural engineering studies of key ceramic components of the HITAF system.

\section{DELIVERABLES}

A report will be prepared documenting the results of structural engineering studies of the key ceramic components of the radiant and convective air heaters. This report will include estimates of expected maximum stresses and fatigue characteristics of ceramic materials which would be used as air passage walls, air seals, and headers. 
Task 3.3.3 - Ash Equilibrium Calculations

\section{OBJECTIVE}

The objective of this task is to estimate the extent of reaction between alkali species and the air heater materials as well as the extent of reaction between ash deposits and the air heater materials.

\section{BACKGROUND}

The effect of coal ash constituents on silicon carbide and other heat exchanger materials must be understood in order to design the heat exchanger elements and to choose coals and/or combustion conditions in the HITAF. The behavior of silicate liquids and vapor phase alkall at equilibrium provides a useful framework in which to develop the needed understanding. The interaction between vapor phase sodium and silicon carbide has been modeled for a limited range of compositions. The interaction between slag and silicon carbide has not been modeled to date.

Sodium reacts readily with silica to form sodium silicate glasses and this compound is thermodynamically favored at temperatures between approximately $1000^{\circ}$ and $1600^{\circ} \mathrm{C}$ (Wibberly and Wali, 1982). Above $1600^{\circ} \mathrm{C}$, the gaseous species $\mathrm{NaOH}$ and $\mathrm{Na}$ are thermodynamically favored, while below $1000^{\circ} \mathrm{C}$, the condensed species $\mathrm{Na}_{2} \mathrm{SO}_{4}$ and $\mathrm{NaCl}$ are favored.

Fox and coworkers (1990) have studied the reaction between silicon carbide and sodium salts (sulfate and carbonate) at $4 \mathrm{~atm}$ and $1000^{\circ} \mathrm{C}\left(1800^{\circ} \mathrm{F}\right.$ ). They identified a temperature rarge in which corrosion took place. The bounds of this range are $884^{\circ} \mathrm{C}$ to approximately $: 000^{\circ} \mathrm{C}$. The lower $11 \mathrm{mlt}$ is defined by the melting point of sodium sulfate which forms on the substrate from $\mathrm{SO}_{3}$ and sodium compounds in the gas phase. Below the melting point of sodium sulfate, little reaction takes place between the condensed salt and the $\mathrm{SiO}_{2}$ layer on the carbide surface. The upper temperature limit is set by the dewpoint of sodium sulfate. The latter quantity is affected by the total pressure and the gas composition. Price and van Roode (1990) observed experimentally that corrosion of silicon carbide by sodium halide vapors is maximum near $800 \mathrm{C}$ and drops of rapidly as the temperature is increased to $1000^{\circ} \mathrm{C}$.

The reaction of sodium with silica can result in corrosion of silicon carbide. However, when coal is the fuel, high silica ash particles are present in the gas and this reactivity can prove beneficial. Coal ash in bulk contains 30 to $50 \mathrm{wt} \% \mathrm{SiO}_{2}$, primarily distributed as quartz or clay. Reaction between sodium and silica in the char particle can stabilize the sodium and prevent it from vaporizing. As discussed below, the retention of sodium in char particles has been modeled by Peterson and coworkers. It will be important to understand the fate of sodium during and after the combustion process in order to assess the potential for corrosion of silicon carbide by sodium vapor. 
Ash deposits can also react with silicon carbide. In specific, ash reacts with the protective $\mathrm{SiO}_{2}$ layer found on silicon carbide in oxidizing environments. To prevent corrosion of $\mathrm{SiC}$ by ash, the equilibrium state must be such that the ash is in equilibrium with pure $\mathrm{SiO}_{2}$. If this condition does not hold, the protective $\mathrm{SiO}_{2}$ layer will not be stable with respect to the ash and will dissolve. A simple example will serve to illustrate this point. Figure 46 shows the phase diagram for the system anorthite $\left(\mathrm{CaAl}_{2} \mathrm{Si}_{2}{ }_{6}\right)$ and silica (Schairer and Bowen, 1947). Consider the region above $1368 \mathrm{C}$ in which a liquid phase is always present. This corresponds to a molten ash deposit on a silicon carbide substrate. On the right hand side of the figure and below the liquidus line, the liquid is always in equilibrium with a pure silica phase (cristoballite or tridymite). On the left hand side of the figure, however, the liquid is in equilibrium with anorthite and not $\mathrm{SiO}_{2}$. Therefore pure silica is not stable in this composition range. This latter condition is analogous to "basic" coal slags and the former, to "acidic" slags. The ability to predict the equilibrium between $\mathrm{SiO}_{2}$ and coal ash deposits holds the key to predicting corrosion in the HITAF.

\section{Modeling Capabilities (UND)}

PHOEBE, a numerical package designed and developed at the Energy and Environmental Research Center as part of a long-term study of coal ash deposition phenomena, is useful for understanding the equilibrium behavior of large multicomponent thermochemical systems. The theory behind this distribution calculation is the concept of Gibbs free energy minimization. According to Gibbs free energy theory, the composition with the minimum free energy is the composition at chemical equilibrium for a given temperature. This type of calculation is not applicable to all facets of ash behavior in combustion conditions. However, it is very appropriate to use this type of model when 


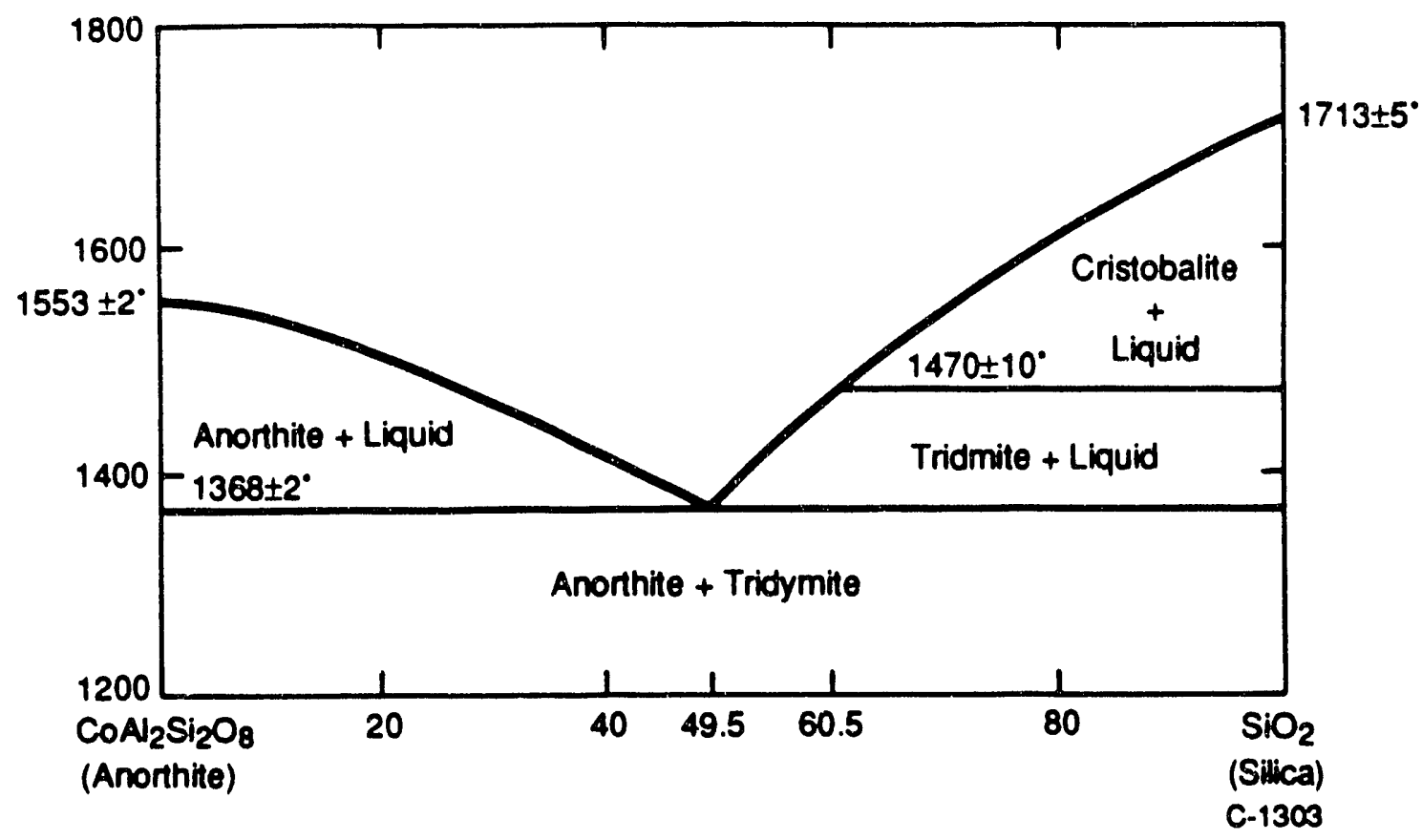

Figure 46. Phase diagram for the system $\mathrm{CaAl}_{2} \mathrm{Si}_{2} \mathrm{O}_{6}-\mathrm{SiO}_{2}$.

studying slag deposits on a ceramic heat exchanger in a HITAF system because the particles deposit at very high temperature and sinter sufficiently so that the deposit will come to chemical thermodynamic equilibrium quickly.

In PHOEBE, the determination of the equilibrium phases is accomplished by adopting the Castillo-Grossman suggestion: i.e., the free energy minimization is performed over all possible phase distributions. In addition, since the Gibbs free energy of the system is approximated by the so-called 'ideal' Gibbs free energy, there exist systematic dependencies that reduce the possible number of phases (Kalmanovitch et al., 1989). The equilibrium phase determination calculation is thus carried out very efficiently in PHOEBE.

One piece of information that is required in choosing a coal or coal blend is how the viscosity of the slag varies with temperature. PHOEBE can be used to determine the composition and quantity of liquid phase as a function of temperature and gas composition. From the composition, the liquid phase viscosity can be calculated based on an equation developed by Urbain et al. for metallurgical slags and modified by Kalmanovitch and Frank (1988) for application to coal ash melts. 
Modeling Capabilities (PSIT)

The PSIT team has developed a number of unique models over the years that will be used in Task 3.3 as described below. The team can also acquire a number of other models that are used routinely on-going research projects. These models are all operational and avallable for immediate use in this project. This will provide for timely response to the contract needs. Furthermore, many of these computer codes and models are non-proprietary and PSI will make whatever provisions that are required to make these available to DoE for its in-house use during and subsequent to this contract.

SOL-GAS-MIX - This code represents the state-of-the-art for computational equilibrium thermochemistry. It was developed originally at the 0ak Ridge National Laboratory and has been used extensively at PSIT, UTRC, and Sandia Labs, among others. This code is particularly suited to the study of the thermochemistry of complex systems involving condensed phase species and non- ideal solutions such as found in coal mineral matter and slag layers. It has been shown to find solutions in many condensed phase problems where the NASA CEC code fails to converge. PSIT has modified this code (SGM 2) to predict non-ideal solution compositions and to describe transformations (vaporization, condensation, coalescence) of major coal minerals during combustion.

Advanced Equilibrium Models for Ash PSI Technology Company has developed under a separate DOE contracts two non-ideal, equilibrium thermochemistry models (SGM2 and SGMCIS). The basis of the working thermochemistry models is the SOLGASMIX equilibrium computer program, developed by Eriksson (1975). This code, based on free energy minimization, can predict the amounts of the different phases present in equilibrium (gases, liquids mixtures, and pure condensed compounds) and the composition of these phases. The input to the code is the temperature, pressure, and the amounts of the different elements in the system.

In calculations reported using SOLGASMIX, ideal gas phase and condensed phase solutions have been assumed with unit activity coefficients for the condensed phase species. A literature review of the experimental data for alkali-ceramic oxide systems and for other refractory oxides present in the ash and the slag, however, shows wide deviations of component activities from unity and strongly non-ideal behavior. Therefore, an ionic lattice model for non-ideal molten oxide melts (particularly silicates) was

integrated with SOLGASMIX to generate a more universal model (SGM2) for equilibrium thermochemistry, to account for deviations from ideality. This model is being used to predicting ash thermochemistry in ongoing DOE-mineral matter transformation projects. Details of the ionic lattice model have been discussed by Gaye and Welfringer (1984) and is discussed very briefly below.

The ionic lattice model represents the mineral oxide melt in the following manner: 
An anionic sublattice, with vacancies, filled with oxygen anions

- A cationic sublattice, filed with cations in the decreasing order of their charge $\left(e . g ., \mathrm{Si}^{4}+, \mathrm{Al}^{3}+, \mathrm{Ca}^{2}+\ldots\right)$.

The lattice structure is described in terms of asymmetric (e.g., Si-0-Al) and symmetric (e.g., Si-0-Si) cells, with numbers $2 R_{i} j, R_{i} i$, respectively, and energy parameters for asymmetric cell formation, $W_{j} j$ and for energy interactions, $E_{j} j$. Values for the cell formations $\left(W_{j} j\right)$ and cell interaction $\left(E_{i} j\right)$ parameters have been deduced for various oxide systems. The ionic lattice model calculates the activities of the individual component oxides, given the guessed mole fractions and temperature from the main module in SOLGASMIX. The calculated activities are returned to the main program to check for the criterion of free energy minimum and updated if they have not. Activities of various oxides calculated for quaternary component systems with the above model are in good agreement with those determined experimentally.

Model for Volatile Species Release from Burning Char Particles

Liberation of volatile species during pulverized coal combustion may be complicated by chemical interactions of the volatile species with other species within a char particle. It has been noticed that the fraction of sodium that reaches the bulk flue gas as a vapor showed a correlation with the total amount of organically bound sodium in the coal divided by the total amount of silicates present. It was also noticed that the fraction of potassium that reaches the flue gas as a vapor did not follow the same behavior, but did appear to correlate with the fraction of sodium that reached the bulk flue gas as vapor. Bachovchin et al. (1986) reported a loss of potassium from emathalite during a reaction with sodium chloride vapor at $1123 \mathrm{~K}\left(1561^{\circ} \mathrm{F}\right)$.

In an effort to understand the behavior of the alkali species a model for the escape of sodium from a char particle was developed by Peterson and co-workers in an on-going DOE-mineral matter transformation project. The model assumes that the organically bound sodium can vaporize, migrate to the char surface, and escape. Sodium which originally exists as part of the mineral matter and sodium which reacts with silicate inclusions is assumed not to escape from the char particle.

This model assumes spherical mono-disperse silicate particles embedded in larger spherical mono-disperse char particles. An easily vaporizable volatile species (e.g., organically bound sodium) is initially present in the char particle at a concentration of $C_{0}$. The volatile species is envisioned to vaporize very quickly and migrate to the char particle surface where it escapes to the bulk flue gas. Enroute to the char particle surface the volatile species can undergo mass transfer from the bulk char phase to silicate particle inclusion surface. At the silicate particle surface the volatile species can chemically react, and thus are lost from the bulk char phase. This loss can be modeled as a source term 
in the diffusion equation. This model has been used to calculate the fraction of sodium that escapes the char particle during combustion and hence is available for reaction in the gas phase.

TECHNICAL APPROACH

Existing models at PSI $\int$ and UNDEERC will be used to predict the impact of alkali vapor on ceratilc surfaces and to explore the interactions between slag and ceramic materials in the HITAF.

\section{DELIVERABLES}

The result of this task will be an evaluation of the impact of alkali species in coal on ceramic materials, including the temperature range that is most critical for corrosion and the levels of alkali that are acceptable in the parent coal. A similar evaluation of the interaction of molten slag with ceramic materials will be completed. The results of this task will be used in coal selection and coal cleaning. Evaluation of coating materials for ceramics can also be conducted using these methods. 
Task 3.3.4 Mineral Matter Transformations

\section{OBJECTIVE}

The objective of this task is to use existing PSIT models to predict mineral transformations under HITAF combustion conditions.

\section{BACKGROUND}

Given the time and financial constraints of this program, it is not possible to measure the size and composition of ash particles formed from all coals under all possible combustion conditions. To extrapolate the results of laboratory testing (see Task 3.2.2), PSIT plans to utilize a fundamentally-based mineral transformations model developed previously under DoE AR\&TD support. Prior to using the model, any significant differences between mineral evolution under standard pc combustion conditions and HITAF combustion conditions shall be incorporated. Note, however, that modifications are not expected to be necessary. The expected differences in ash formation between HITAF and standard combustion conditions should be attributable to the size of the pulverized coal grind and the resulting size and distribution of minerals, both of which are accounted for in the mineral transformations model.

In brief, the PSIT mineral transformations model operates as follows: CCSEM measurement of coal mineralogy is used as the starting point of the model. CCSEM provides a statistical description of the type, size, and chemical composition of the major minerals contained in a pulverized coal sample. The coal particle size distribution is also used as an input, enabling the mineral transformations model to accommodate the finer grind anticipated for the HITAF. While CCSEM does not identify the size of coal particles and define a relationship between coal particle size and mineralogy, it is done computationally as part of the model.

The operating premise of the model is that the minerals in coal are randomly distributed according to the relative volumes of coal and mineral particles. In other words, the model assumes that there is no preferential grinding of coal along coal-mineral planes to produce preferential mineral-rich classes of coal particles. This means that the variation in mineral content from coal particle to coal particle is a random process, and can therefore be modeled using statistical techniques. The model therefore redistributes the minerals among the various size classes of coal particles using a combination of Poisson statistics and Monte Carlo techniques. Extraneous or excluded minerals are also identified. At the conclusion of this step, a "reconstituted" coal with minerals of different sizes and compositions distributed among the various size classes of coal particles is obtained.

Once the inorganic species are redistributed, the model begins the ash formation computation. Coalescence is allowed to proceed fully within each individual coal (char) particle, barring char fragmentation. No kinetic barriers to mineral coalescence within a burning char particle are assumed. 
Results calculated with this assumption incorporated into the model are in good agreement with laboratory scale combustion test data, as discussed in previous DoE supported work at PSIT.

\section{TECHNICAL APPROACH}

For this task, PSIT plans to use the mineral transformations model in conjunction with the experimental study of Task 3.2 .2 to predict the size and composition of ash particles resulting from combustion of the four program coals under HITAF conditions. As part of this effort, the effects of changes in coal particle size distribution on ash particle size and chemical composition may be explored. If needed, additional coals beyond the four selected for testing in Phase I can be examined with the model if CCSEM data for the coals is available.

\section{DELIVERABLE}

The deliverable for this task is an analysis of the effects of coal particle size, combustion conditions, and coal type on the ash particle size and composition produced in the HITAF combustor. The results will explore changes which result from changing the grind of the coal, and may permit us to explore ash formation in additional coals beyond the four selected in Phase I of this program. 
Task 3.3.5 - Slag Deposition Modeling

\section{OBJECTIVES}

The objective of this task is to use models being developed at PSIT and UNDEERC to predict the deposition rates and composition of ash that may deposit on a ceramic air heater in a HITAF system firing a variety of coals. No model development will be undertaken in this task. Instead, the data will be used to design laboratory experiments that should be used to test HITAF materials, and in preparing the work plan for Phase II, the operation of a pilot scale HITAF.

\section{BACKGROUND}

In addition to causing corrosion of ceramic materials, the slag depositing on heat exchange surfaces in the HITAF system will reduce the rate of heat transfer and may even block the flow of gas. In a typical modern boiler, high pressure jets of air, steam, or water are directed against the deposits to blow them off of the boiler surfaces. However, this type of cleaning may not be possible in a ceramic air heater because the ceramic material is susceptible to thermal shock possibly leading to catastrophic failure of the air heater. Therefore, deposition rates must be kept acceptably low through proper slag screen and air heater design, or coals or additives must be chosen so that the slag is very friable and sloughs off of the air heater periodically under its own weight, or is completely molten and runs off of the air heater. In order to make the process of air heater design, coal selection, and additive selection more efficient, computer models of slag behavior should be employed. In order to be effective, the models should be able to predict the composition of the ash formed during combustion of a coal based on data from coal analyses, the size range and composition of the ash that deposits, and the physical properties of the slag deposit.

The first step in predicting the properties of slag that will form in a HITAF is to determine the properties of the ash formed during combustion of a coal from data about the coal itself. Existing models that address this question were described in section 3.3 .4 of this report. Second, the model must predict the composition of the ash that will deposit in different places in the boiler. To do this, the fundamentals of deposit formation must be understood.

The first step in the deposition of ash to form a slag deposit is the separation of ash from the flow of the gas, followed by transport to a furnace surface. There are three main types of separation and transport mechanisms. They are inertial impaction, eddy transport, and small particle transport (thermophoresis and Brownian diffusion). Inertial impaction occurs when the gas flow through the HITAF is diverted by an object such as a slag screen, and the inertia of the particle causes it to separate from the flow of the gas and continue on a relatively straight course to impact the object. Figure 47 illustrates the process. A slag screen is designed to exploit this type of deposition, but such deposition 
will also occur on the leading edge of an air heater tube. The size of the ash particles that deposit by inertial impaction must be large enough that their inertia overcomes the friction of the gas on the particles.

Figure 48 shows the interface between such a deposit and a deposition probe coupon which was inserted into a utility boiler during field work performed by UNDEERC. In hot areas of a furnace this type of deposit forms very rapidly. The micrograph indicates that only larger particles make up these deposits. However, the field of view of the SEM is very limited, and determining the size distributions of sintered particles is difficult. Therefore, a better indicator of the size range of particles that make up these deposits is a comparison of

\section{Gas Stream Lines}

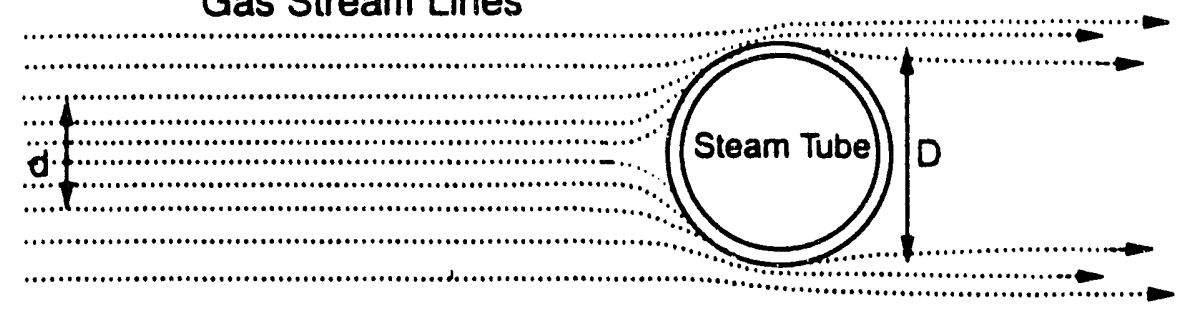

$$
\begin{aligned}
& d / D=\text { Impaction efficiency of system }=f\left(A D_{p}, V\right) \\
& \text { sticking }=f\left(K E_{p}, \mu_{p}, \mu_{s}\right)
\end{aligned}
$$

Figure 47. The inertial impaction process that leads to the formation of large slag deposits.

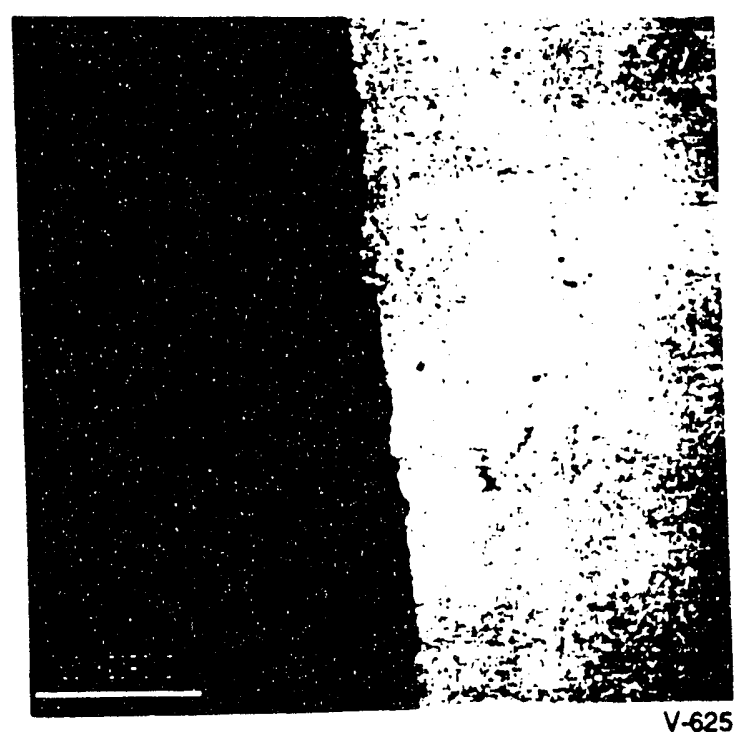

Figure 48. Backscattered electron micrograph of the interface between ash deposited via inertial impaction and a deposition probe coupon. 
the bulk composition of the deposits with the aerodynamically sized ash particles collected during online sampling at the same boiler locations as where the deposits were collected.

Figure 49 shows the concentrations of the major elements in each aerodynamic size range as compared to the composition of the bulk deposit. The figure illustrates a point that is typical of ash particles formed during combustion of high calcium western U.S. subbituminous coals. That is, larger particles tend to have higher concentrations of silicon and lower concentrations of calcium than smaller particles. The higher concentrations of silicon in the larger particles are due to the fact that quartz occurs in the coal as larger mineral particles. The higher concentration of calcium in the smaller particles occurs because most of the calcium in the coals (especially the PRB coals) is organically associated. During combustion, this calcium is vaporized, but immediately condenses as small oxide particles. The variation with size in average composition of the particles has profound effects on the composition of deposits that form from a particular size range of ash. Deposits formed from smaller particles will have high calcium to silicon ratios, whereas deposits formed from larger particles will have much higher silicon to calcium ratios. The different ratios will dramatically effect the viscosity and corrosiveness of the slag. This effect can not be anticipated by standard ASTM analyses of the coal. Therefore, models used to predict the composition and deposition rate of slag in a HITAF boller must predict the size and composition distribution of the entrained ash as an

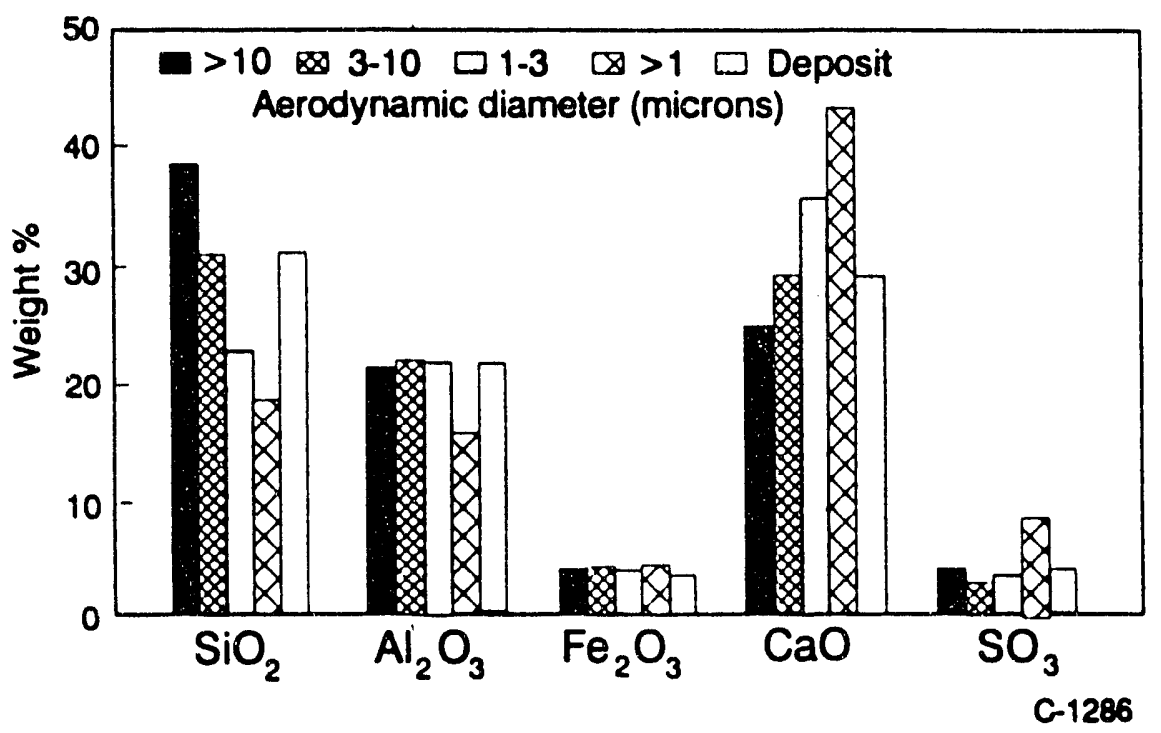

Figure 49. Comparison of the compositions $\left(\mathrm{SO}_{3}\right.$-free) of the aerodynamically sized entrained ash particles and ash deposited on a deposition probe via inertial impaction. 
initial step, then be able to predict the general size range of ash that will deposit in different areas of the boiler. Ash deposition models developed at PSIT and UNDEERC both perform these vital steps.

In addition to inertial impaction, ash can be transported to furnace surfaces by eddies of gas. These eddies form where the flow of gas around an object becomes turbulent. Likely places in a HITAF system would be on the downstream side of suspended objects, or at abrupt transitions in the size or shape of an object suspended in the gas stream. Figure 50 illustrates the process. If the turbulence is of a high intensity, the deposits will form essentially through inertial impaction as the larger particles separate from the flow of the eddy. In more low intensity regions such as at shape transitions in a HITAF air heater, larger particles are not trapped in the eddies so deposits will form from smaller particles. Figure 24 is an SEM micrograph showing the interface between a deposition probe coupon and a low intensity eddy deposit collected by UNDEERC in a utility boiler. The types of particles that become caught in these eddies are typically less than 10 microns in diameter. As Figure 22 indicates, this type of deposit can have a very different composition from those formed by inertial impaction if there are variations in composition with ash particle size such as those common in Western U.S. low-rank coals. Therefore, models used to simulate the formation of slag deposits from this type of deposition must take into account the size and composition distributions of the ash. Both PSIT and UNDEERC models of ash deposition use these distributions in the algorithms.

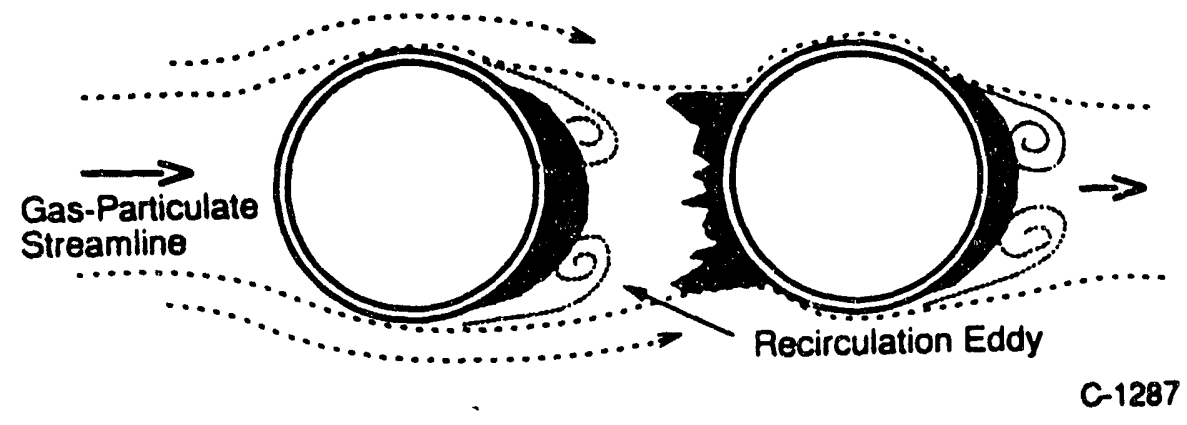

Figure 50. The eddy deposition process that leads to the formation of slag deposits in regions of lowintensity turbulence. 


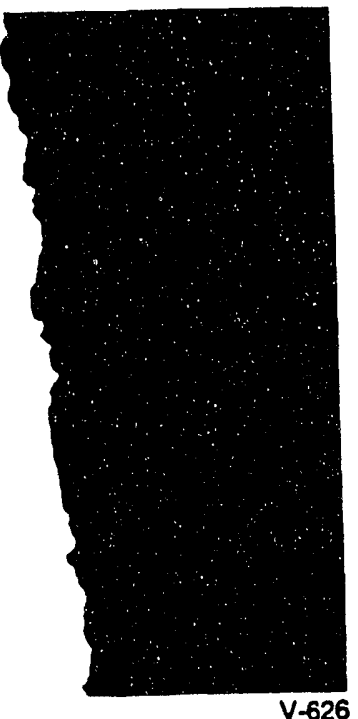

Figure 51. Backscattered electron micrograph of the interface between a eddy deposition deposit and a deposition probe coupon.

The last mechanism of ash transport in coal-fired furnaces applies only to the smallest ash particles. It occurs equally in turbulent and laminar flow regions, although it is masked in accelerating or turbulent flow regions by the more rapid inertial impaction and eddy deposition mechanisms. Therefore, it is only evident in areas where no turbulence or rapid changes in gas speed or direction occur. Such regions in a HITAF include the gas adjoining a suspended air heater. Collectively called small particle transport mechanisms, they include thermophoresis, electrophoresis, and Brownian diffusion. The processes only occur in the boundary layer of relatively still gas next to a furnace surface. Figure 52 shows a deposit formed from this type of transport on a deposition probe coupon. The ash particles are typically less than about 3 microns in diameter. As Figure 44 shows, this type of deposit can have a radically different composition and base to acid ratio from deposits formed from other deposition mechanisms. Therefore, the computer models used to simulate this type of deposition must take into account the distribution of size and composition of ash particles. Both the PSIT and UNDEERC models take these factors into account.

Once the composition of the deposits is predicted, the corrosiveness and viscosity of the slag must be evaluated. The corrosiveness of the slag will likely be temperature, composition, and surface material dependent. No models yet exist to determine slag corrosiveness, therefore, this issue will be addressed in laboratory studies. The viscosity of the slag can be evaluated with existing models. The method is described in Subsection 3.2.5. 


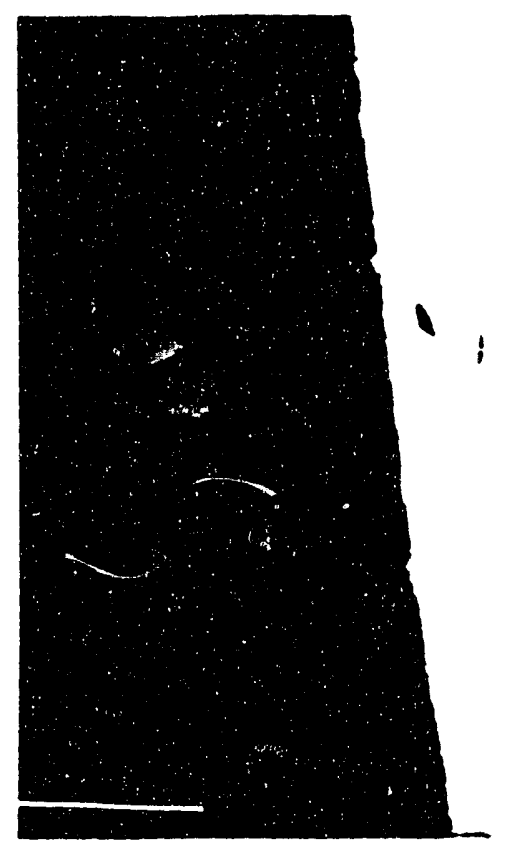

\section{V-627}

Figure 52.

Backscattered electron micrograph of the interface
between a deposit formed from small particle
transport mechanisms and a deposition probe
coupon.

TECHNICAL APPROACH

Both PSIT and UNDEERC will use existing models of ash formation, depositing in a HITAF system to be proposed the properties of slag 2000.

\section{DELIVERABLE}

The deliverable for slag property modeling will be input to the design of the the location of thation HITAF. Specific problems to be addressed will could be expected to convert fure range where the slag from various coals slag layer, and devise additives wet to dry, determine the thickness of a viscosity. 


\section{REFERENCES}

Bonar, J.A.; Kennedy, C.R.; Swaroop, R.B. "Coal-Ash Slag Attack and Corrosion of Refractories," Ceram.Bull. 1980, 59, (4), 473-478.

Boni, A.A. et al. (1990), "Transformations of Inorganic Coal Constituents in Combustion Systems," Phase I Final Report, Contract DE-AC22-86PC 90751.

Brendel, G.F.; Balsamo, N.J., and Glngowski, P.E., 1987, An overview of the use of fly ash in slurried placement applications: Eighth International Ash Utilization Symposium, Washington, D.C., October 29-31, 1987, Proceedings, v. 1 .

Buss, W.E., 1987, Flowable mortar in Iowa: Eighth International Ash Utilization Symposium, Washington, D.C., October 29-31, 1987, Proceedings, v. 1 .

Butt, D.P., Mecholsky, J.J., and Goldfarb, V. (1989) "Effects of Sodium Silicate Exposure at High Temperature on Sintered a- Silicon Carbide and Siliconized Silicon Carbide" J.Amer.Ceram.Soc., 72, 1628-1635.

Caivert, S., Yung, S., and Leung, J. (1985) "Entrainment Separators for Scrubbers", EPA Report EPA-650/2-74-119-b, Ch.7.

Easler. T.E., Tan, C., and Putz, L.M. (1985) "Influence of Oxidizing and Reducing Environments on Coal-Slag-Induced Corrosion of Silicon Carbide Ceramics" ANL/FE-85-11.

Eriksson, G. (1975), Chemica Scripta, 8, 100.

Faber, J., and Slonaker, J., 1989, An overview of the fly ash brick process using bituminous and lignite coal ashes: Utilization of Ash Workshops, St. Paul, MN, May 22, 1989.

Faber, J.H., and Babcock, A.W., 1987, 50 years of ash marketing and utilization in the U.S.A.: 1936-1986: 'ihe Production and General Utilization of Ash, Pretoria, Republic of Jouth Africa, February 1987, Proceedings, Vol. 1.

Federer, J.I. (1990) "High-Temperature Corrosion of Heat Exchanger Materials" in CeramicTransactions, vol 10 , R.E.Tressler and M.McNallan, eds. (The American Ceramic Society, Westerville, Ohio), pp. 425-443.

Ferber, M.K.; Tennery, V.J. "Evaluation of Tubular Ceramic Heat-Exchanger Materials in Basic Coal Ash from Coal-0il-Mixture Combustion," In Technical Paper; Oak Ridge, TN, ORNL/TM-8385, 0ct., 1982; pp 1-90.

Ferber, M.K. and Tennery, V.J. (1982) "Evaluation of Tubular Ceramic Heat Exchanger Materials in Basic Coal Ash from Coal-0il Mixture Combustion" ORNL/TN-8385 
Ferber, M.K. and Tennery, V.J. (1981) "Evaluation of Tubular Ceramic Heat Exchanger Materials in Acidic Coal Ash from Coal-0il Mixture Combustion" ORNL/TN-7958

Ferber, M.K.; Tennery, V.J. "Evaluation of Tubular Ceramic Heat Exchanger Materials in Acidic Coal Ash from Coal-0il-Mixture Combustion," In Technical Report; Oak Ridge, TN, ORNL/TM-7958, Dec., 1981; pp 1-133.

Fergus, J.W. and Worrell, W.L. (1990) "The Oxidation of Chemically Vapor Deposited Silicon Carbide" in CeramicTransactions, .vol 10 , R.E.Tressler and M.McNallan, eds. (The American Ceramic Society, Westerville, Ohio), pp. 43-51.

Fox, D.S., Jacobson, N.S., and Smialek, J.L. (1990) " Hot Corrosion of Silicon Carbide and Silicon Nitride at $1000 \mathrm{C}$ " in CeramicTransactions, .vol 10 , R.E.Tressler and M.McNallan, eds. (The American Ceramic Society, Westerville, Ohio), pp. 227-249.

Gaye, H. and Welfringer, J. (1984), Second International Symposium on Metallurgical Slags and Fluxes, H.A. Fine and D.R. Gaskell, eds., pp. 357-375.

Hasset t, D.J., Pflughoeft-Hasset t, D.F., Kumarathasan, P., and McCarthy, G.J., 1989, Ettringite as an agent for the fixation of hazardous oxyanions: Twelfth Annual Madison Waste Conference, Department of Engineering Professional Development, University of Wisconsin-Madison, September 20-21, 1989.

Hay, P., and Rademaker, P.D., 1987, Aardelite - an economical lightweight aggregate from fly ash: Eighth International Ash Utilization Symposium, Washington, D.C., October 29-31, 1987, Proceedings, v. 1.

Israel, R. and Rosner, D.E. (1983) "Use of a Generalized Stokes Number to Determine the Aerodynamic Capture Efficiency of Non- Stokesian Particles from a Compressible Gas Flow", Aeros.Sci.Tech., 2, 45-51.

Jablonski, G.J, 1987, Fly ash utilization as an extender in plastics and paints: Eighth International Ash Utilization Symposium, Washington, D.C., October 29-31, 1987, Proceedings, v. 1.

Jacober, D.E. and Matteson, M.J. (1985) "The Collection of Aerosols from Gas Streams by Impaction on Multiple Spherical Targets", Aeros.Sci.Tech., $4,433-443$.

Kalmanovitch, D.P.; Frank, M. An Effective Model of Viscosity for Ash Deposition Phenomena Proceedings of the Engineering Foundation Conference, Santa Barbara, 1988.

Kern, W.A., Tressler, R.E., and McNallan, M.J. (1992) "Durabilty of $\mathrm{SiC} / \mathrm{Al}_{2} \mathrm{O}_{3}$ Ccmposites in Contact with Sodium Silicate" Center for Advanced Materials Newletter, 6, 1-6. 
Kim, H.-E. and Moorhead, A.J. (1990) "Effects of Gaseous Corrosion on the Strength of SiC and Si3N4" in CeramicTransactions, vol 10 , R.E.Tressler and M.McNallan, eds. (The American Ceramic Society, Westerville, Ohio), pp. 81-96.

Lahrs, M., 1990, Waste solidification with coal ash, Opportunities in the synfuels industry: Opportunities in the Synfuels Industry Symposium, Bismarck, ND, August 27-29, 1990.

Manz, 0.E., 1989, Worldwide production, utilization and properties of lignite and brown coal ash: Year 4 accomplishments Western Fly Ash Research, Development and Data Center at Grand Forks, North Dakota, p. 1.

Manz, 0.E.; Faber, J.H., and Takagi, H., 1989 Worldwide production of fly ash and utilization in concrete, Utilization of Ash Workshop, St. Paul, MN, May 22, 1989, Proceedings.

Manz, 0.E., and Manz, B.A., 1989, Utilization of fly ash in road bed stabilization: Some examples of western U.S. experience: Utilization of Ash Workshops, St. Paul, MN, May 22, 1989.

Manz, 0., 1989, Utilization of by-products from western coal combustion in the manufacture of mineral wool and other ceramic materials: Utilization of Ash Workshops, St. Paul, MN, May 22, 1989.

Pietsch, A. (1978) "Coal Fired Prototype High Temperature Heat Continuous Flow Exchanger", EPRI Report AF-684 (Electric Power Research Institute, Palo Alto, CA).

Pintcke, T.P., 1987, Applications for the coal ash in construction: Eighth International Ash Utilization Symposium, Washington, D.C., October 29-31, 1987, Proceedings, v. 1.

Price, J.R. and van Roode, M. (1990) "Corrosion Resistant Coatings for Silicon Carbide" in Ceramictransactions, .vol 10 , R.E.Tressler and M. McNallan, eds. (The American Ceramic Society, Westerville, Ohio), pp. 469-493.

Rosner, D.E. and Tassopoulos, M. (1989) "Deposition Rates from Polydispersed Particle Populations of Arbitrary Spread", AIChE J., 35, 1497-1508.

Schairer, J.F. and Bowen, N.L. (1947) Bull.Soc.Geol.deFinlande, 20, 71.

Schuh, M.J., Schuler, C.A., and Humphrey, J.A.C. (1989) "numerical

Calculation of Particle-Laden Gas Flows Past Tubes", AIChE J., 35, 466-480.

Shaffer, F.D. (1989) "Fluid Mechanics of Ash Deposition" in 1989 DoE AR\&TD Contractors Meeting Proceedings, DOE/METC-89/6108, p. 242. 
Smith, R., 1990, Coal ash use in waste stabilization/solidification procedures: Opportunities in the synfuels industry: Opportunities in the Synfuels Industry Symposium, Bismarck, ND, August 27-29, 1990.

Styron, R.W., 1987, Fly ash lightweight aggregate: The agglite process: Eighth International Ash Utilization Symposium, Washington, D.C., October 29-31, 1987, Proceedings, v. 1.

Tennery, V.J. "Economic Application, Design Analysis, and Material Availability for Ceramic Heat Exchanges," In Technical Paper; ORNL/TM-7580, $1981 ;$ pp 1-65.

Torrey, S., Ed., 1978, Coal ash utilization: fly ash, bottom ash, and slag, Park Ridge, New Jersey, Noyes Data Corporation, p. 28-62.

Tressler, R.E. (1990) "Environmental Effects on Long Term Reliability of $\mathrm{SiC}$ and Si3N4 Ceramics" in Ceramictransactions, vol 10 , R.E.Tressler and M.McNallan, eds. (The American Ceramic Society, Westerville, Ohio), pp. 99-124.

Urbain, G.; Cabier, F.; Deletter, M.; and Anscau, M.R. Trans. J. Br. Ceramic Society 80, 139, 1981.

Ward, M.E. and Kubasco, A.J. (1983) "Ceramic Heat Exchanger Technolngy", EPRI Report AP-2883 Electric Power Research Institute, Palo Alto, CA).

Weber, L., 1987, Controlled density low strength material backfill in Illinois: Eighth International Ash Utilization Symposium, Washington, D.C., 0ctober 29-31, 1987, Proceedings, v. 1.

Weishahn, L., 1990, Safeguarding a regional market - use of coal ash as filler in asphalt: Opportunities in the Synfuels Industry Symposium, Bismarck, ND, August 27-29, 1990.

Wibberly, L.J. and Vall, T.F. (1982), Fuel, 61, 87.

Zygarkicke, C.J., Benson, S.A., Toman, D.L., Steadman, E.N., Brekke, D., Erikson, T.A., and Hurley, J.P. (1990), "Combustion Inorganic Transformations," Final Report for the period July 1989 to June 30, 1990, work performed under Contract DE-FC21- 86NC10637.

keep just in case 
APPENDIX A

State-of-the-Art Performance Program

All of the performance studies for the proposed program will be carried out using a sophisticated power plant performance analysis computer system called "State-of-the-Art Performance Program" (SOAPP). This system utilizes modularized representations for each type of power plant component or subsystem permitting virtually complete freedom in selecting the desired configuration. It is capable of analyzing gas turbine engines, steam cycles, and combined cycles plus a complete power station including a gasifier and cleanup system, conventional or fluid bed coal combustor, heat storage, and other types of advanced technology. It is easy to use, versatile, and fast. It incorporates the most up-to-date calculation techniques available. The full system is currently in use on the IBM 3090 computer, in both batch and interactive modes of operation.

The development of SOAPP was done at Corporate expense. The basic system structure, communication techniques and mathematical routines were developed by Pratt \& Whitney Aircraft (PWA) in 1970, as were the first component calculation modules and component map routines. Other maps and modules for aircraft gas turbines have been added continually by PWA. In the intervening years, PWA assisted the United Technologies Research Center and the TurboPower Marine Division with the extension of the SOAPP library to include modules necessary for advanced industrial power plants. These additions included boilers, heat exchangers, fuel cells, coal and oil gasifiers, fuel gas cleanup systems, coal-fired conventional and fluid bed combustors. SOAPP has been used in a large number of Corporate- and Government-funded projects involving aircraft gas turbines, industrial gas turbines, combined cycle power systems, integrated gasification and fluid bed-combined cycle power systems, fossil-and nuclear-fueled closed cycle systems using fluids such as helium and argon, and nuclear aircraft power plants.

\section{Functional Construction of SOAPP}

SOAPP is a computer system comprised of a preprocessor coupled to a library of modules and maps. The following general description is provided as background information concerning the functional construction of SOAPP from an overall viewpoint. It is this overall functional construction which provides the program's extreme versatility.

Streams and Modules: Just as a power plant system can be considered to be made up of major component elements connected by pipes and ducts, the basic SOAPP structure simply involves streams and modules. The streams represent identifiable, homogeneous mass flows comprised, in general, of a mixture of several constituents and passing through connecting pipes and ducts. The modules are engineering representations of individual component elements programmed into computing code. The physical properties of each stream (i.e., pressure, temperature, enthalpy, etc.) are fixed except as 
modified by the module calculation. In other words, the modules are connected by the streams. A module would then be a representation of any power plant element which acts to change physical properties, or constituency, of the flow passing through. Examples would include: compressors, turbines, combustors, heat exchangers, pumps, boilers, etc. The streams act to maintain material and energy balances between component modules.

Map/Module Pairs: In order to define a specific piece of hardware, its performance characteristics and physical geometry must be established along with the general physical operating behavior. For example, a compressor is represented by an ideal isentropic compression process, modified by an efficiency, and delivers flow according to some rotor speed and pressure ratio schedule. The compressor module would consist of the necessary equations and calculation steps to represent these functions for any general compressor. However, a given compressor of a specified number of stages and aerodynamics design would perform its function with flow, rotor speed, pressure ratio, and efficiency all related by a particular relationship, usually determined empirically by a rig, model, or full-scale test. These empirical relationships are called compressor maps in conventional gas turbine terminology. In SOAPP language, the term maps extends to any empirical relationship connecting any variables of any real component. Thus, if a gasifier is represented in module form by chemical equilibrium calculations, its map might be an empirically derived graph which relates the percentage of unconsumed carbon content in the product gases to the oxygen/carbon ratio. Therefore, a complete component element representing specific physical hardware must be described by a map/module pair, where the module computes the operation of a general component type, and the corresponding map furnishes actual data for the particular component desired.

Preprocessor: The preprocessor is the heart of SOAPP. This is a self-contained computer program which automatically translates a description of any given stream and component configuration arrangement into a working computer model. The preprocessor sets up all internal computing logic and iteration procedures necessary for a complete performance calculation, as well as the output format. To accomplish this, the preprocessor draws upon the SOAPP library according to coded instructions.

Library: The SOAPP library keeps in central storage a complete array of maps and modules. Their location in the library is designated by a descriptive code name. In addition, the library is used to store preselected configuration input. This enables an engineer to set up a desired configuration just one time and keep it available for future running for an indefinite period of time. Further, if it is subsequently desired to change a given power plant configuration after it is initially set up, it may be called in from the library, modified as desired, then returned to the library as modified for future reference. 
Operating Modes: The SOAPP system has four basic operating modes: (1) configuration; (2) design; (3) run; (4) print.

In the configuration mode, the complete power plant system is set up according to components and streams in a given order.

In the design mode, the engineer must give the computer system the numerical constants required to define the starting point for a given operating condition. These constants represent the minimum number of independent variables required to define the equilibrium operation of the simulated power plant. This is the starting point of a performance calculation and for an open cycle configuration it requires at a minimum a specification of ambient conditions. It would also include specification of a component, physical variables if its size or geometry are unspecified, or, vice versa. For example, a heat exchanger might have effectiveness specified, with tube surface area left as a dependent variable to be calculated, or tube geometry must be specified with effectiveness to be calculated.

In the run mode, a series of design point calculations or off-design conditions can be found. After the initial design case has been established by the design mode, a series of cases may be run from run mode input instructions.

Print mode controls the calculation output. The engineer has at his disposal a series of options. He can elect the standard output print, he can selectively display calculated data on a graphic scope, or he can instruct the computer to automatically plot output variables either for graphics scope display or on hard copy on an automatic plotting machine.

Inter-Active Operation: By means of the remote terminal (which is usually a PC or work station equipped with a graphics monitor) the engineer can use SOAPP on a inter-active basis. The program is stored on a central IBM 3090 computer which is coded for operation on a time-sharing system.

Calculations from the remote terminals are queued in and out of the computer in a matter of seconds, for essentially instantaneous access. As a consequence, the engineers can run data, inspect and evaluate the results, make further modifications, and run new data at their own pace.

Summary: The engineers can use the SOAPP system to complete an entire simulation problem from start to finish without any special computer programming, providing all necessary elements reside in the library. They can set up their system in the configuration mode, describe physical hardware and external conditions in the design mode, and run performance calculations in the run mode, with results automatically provided.

Available SOAPP Modules

SOAPP modules all contain design, off-design, and dynamics representation capability. The SOAPP library also stores gas and physical property data 
for all potentially important working fluid constituents that might occur in the system. The program automatically handles thermodynamic properties for mixtures of substances in homogeneous flow streams.

A partial list of modules currently available in the SOAPP library includes:

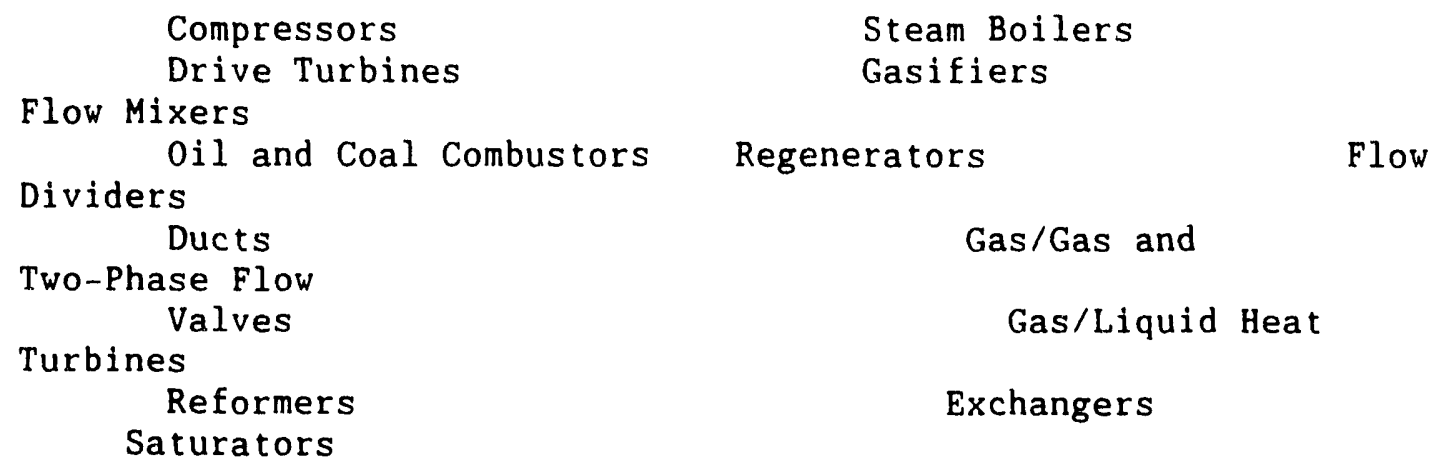

Brief descriptions of some of the standard system component modules are provided in the following paragraphs.

Gasifier: Three different representations for gasifier modules can be used in SOAPP. The are input/output, equilibrium, and set yield models. The input/output model is a very simple, but extremely useful model. For this model the gasifier inlet and exit composition and temperature are specified (to correspond to known gasifier performance), but the reactant and product flows are scaled to meet the requirements of the power plant being simulated.

The equilibrium gasifier model employs a computational procedure developed at UTRC for the solution of specific combustion problems involving airbreathing and rocket propulsion devices. With this method, the equilibrium composition and thermodynamic properties of a reacting mixture are obtained by applying a successive approximation procedure to find simultaneous solution of the standard equations of chemical equilibria and conservation of (atomic) mass for specific values of pressure and either temperature or enthalpy. This model is capable of estimating gas composition for a number of gasifier types (e.g., Texaco, Shell, Koppers-Totzek) which operate at high temperature.

Corrections to equilibrium estimates can be made to better simulate real gasification processes by using the set yield model. This model uses empirical data to specify a fixed or preset yield of one or more species such as carbon or methane. These yields are essentially set aside at the start of the calculation and the remaining constituents brought to equilibrium. The set yield species are taken to be at the equilibrium temperature and an overall heat balance is achieved. Use of the set yield option for carbon enables an accounting to be made of soot. 
DATE FILMED $2 / 2 / 93$ 
